\title{
Adopting Agile Project Management Methods in Software Projects Involving Outsourcing
}

By

\section{Nivarthana Warnakulasooriya}

A thesis submitted to the Victoria University of Wellington

In partial fulfilment of the requirements for the degree of Master of Commerce

Victoria University of Wellington 


\begin{abstract}
With the evolvement of how software was built, how quickly the initial requirements change, how fast new technologies were appearing in tech world and evolving innovation needs of dynamic businesses, the software industry was feeling the need for a better way of managing projects. In 2002 a group of well-known software professionals got together to develop a set of industry guidelines now known as 'The Agile Manifesto' to help standardize this new way of managing projects which helped lay foundations to now widely used 'The Agile Project Management methodology'.
\end{abstract}

While Agile was gaining momentum, the software development world saw the rise of another way of developing software which is known as outsourcing. Outsourcing in commonly referred form involves two or more geographically dispersed teams collaborating to develop the same software. However the fusion of agile methodology with outsourcing opens up new challenges which includes cultural, geographical and time barriers. This study tries to understand how well agile works with outsourced projects using a quantitative approach. The study will also look at how factors physical distance, time and culture impact success of agile in outsourced projects using a quantitative approach. Identifying factor/factors which has the biggest impact on success of agile in outsourced project will also help identify and prioritize which principles and practices need to be fixed first.

Data collected through a questionnaire was quantitatively analysed using correlation, simple and multiple regression analysis. Data was sourced from industry professionals and practitioners who had enough experience with outsourced agile projects to be able to provide insights through a questionnaire. Correlation tests, simple regression and multiple regression analysis tests between time difference, culture difference, physical distance and success of agile methodology in outsourced projects were then carried out in a bid to understand the relationship of three independent variables and the dependent variable.

The study contribute towards quantitatively understanding how well agile methodology works in outsourced projects. Identifying dominant factor/factors that hinder success of agile methodology in outsourced projects also help users of agile project management to prioritize 
the principles that should be fixed first to better fit agile methodology in outsourced projects. Using agile methods that are based on modified principles are expected to contribute to overall success of the outsourced projects. Last but not least this study identifies further research avenues towards improved work in the related area. 


\section{Acknowledgements}

I would like to acknowledge all the people who provided me with support, confidence and assistance in undertaking and completing this Master's thesis.

Firstly I would like to thank my supervisor A/Prof Bob Cavana, without whom this work would not have been possible. He provided me with valuable insights and helped me structure this research. His generosity with time, effort and feedback was invaluable.

I would also like to thank all my family and friends who's always been patient and understanding throughout.

I was also lucky to have two stellar proof-readers in Lalanee "the Boma" Ginige and Chamesh "Chabba" Warnakulasooriya on my side.

Last but not least I would like to make this an opportunity to thank all of the participants in my study for taking time to return the questionnaire and staff at Victoria University including Megan Key, Lisa Wood and Tracey Wharakura. 


\section{Important Disclaimer}

Victoria University of Wellington and its Council, its members, staff, employees, students and agents undertake no duty or care in contract, tort, or otherwise, to users (whether direct or indirect) of the material in this thesis and make no warranties or representations of any kind in relation to any of its contents.

Users of this work, whether direct or indirect, must take appropriate legal or other expert advice in relation to their own judgement and such legal or other expert advice.

Under no circumstances will Victoria University of Wellington and its Council, its members, staff, employees, students or agents be liable in any way whatsoever, whether in contract, tort (including negligence), for breach of any statutory or regulatory duty (to the fullest extent punishable by law), or otherwise to any user (whether direct or indirect) of this work for any loss or damage whatsoever arising directly or indirectly as a result of the use of contents of this thesis.

Each exclusion in the clauses of this disclaimer and each protection given by it are to be construed as a separate exclusion applying even if for any reason the exclusions or protections are held inapplicable in any circumstance. 


\section{Contents}

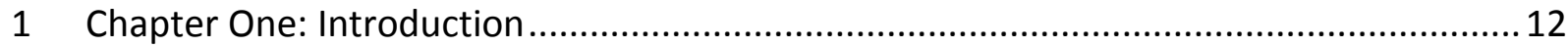

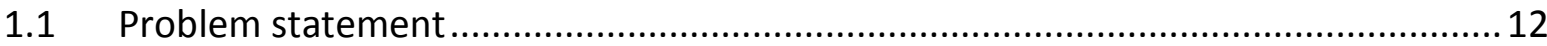

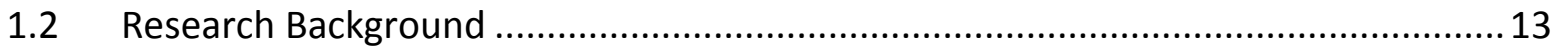

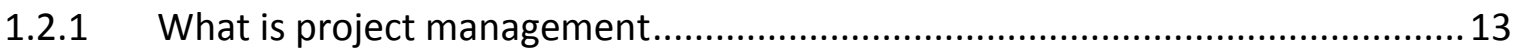

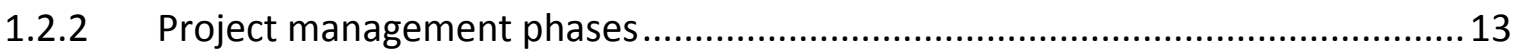

1.2.3 What is Project management methodology ..................................................... 14

1.2.4 What is Software project management ......................................................... 15

1.2.5 What is Software development life cycle.................................................. 15

1.2.6 Software project management methodology .............................................. 17

1.2.7 When traditional development methods don't work ...................................... 17

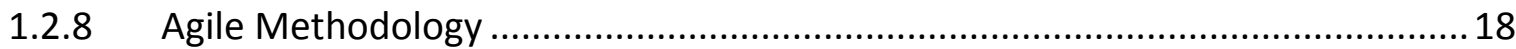

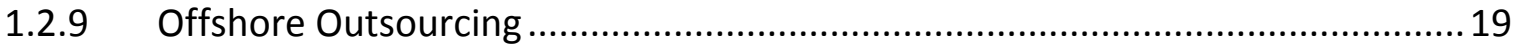

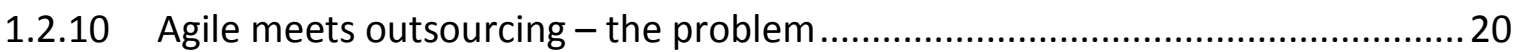

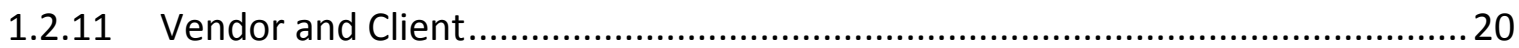

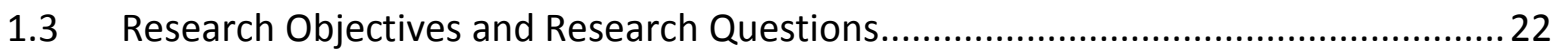

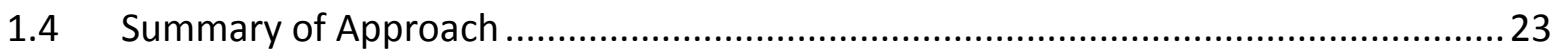

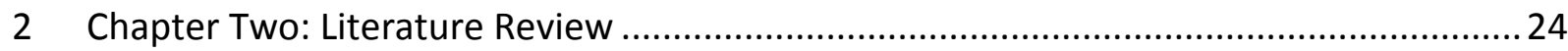

2.1 Agile Method of Software Project Management ................................................ 24

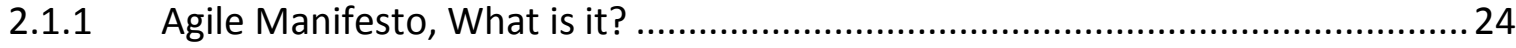

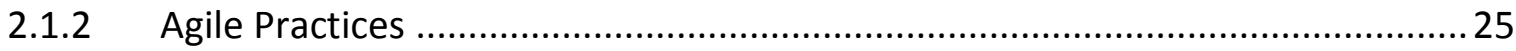

2.2 Square peg in a round hole - problems with fusion of agile and outsourcing ..........26

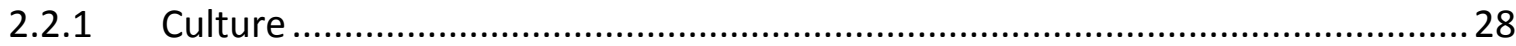

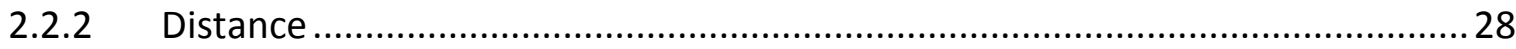

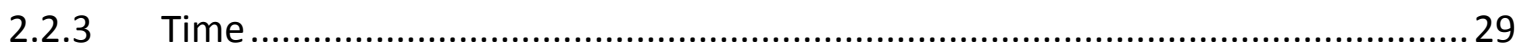


2.3 How to measure "how well"? Project success vs. success of the project management

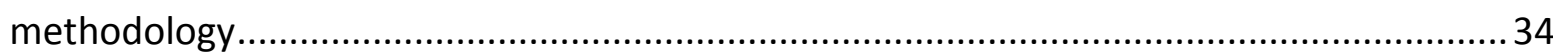

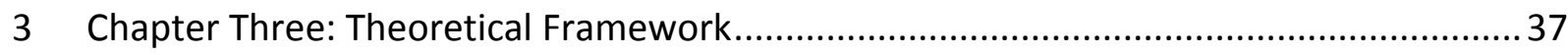

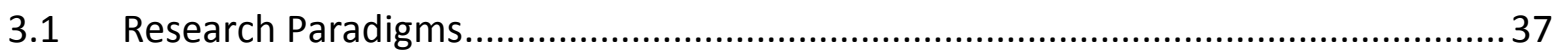

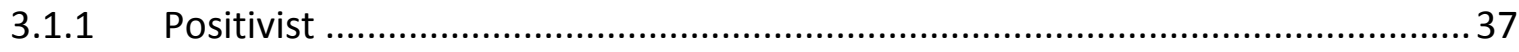

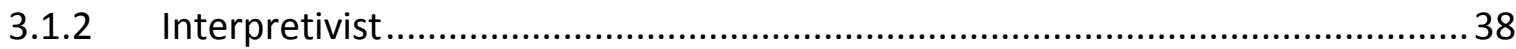

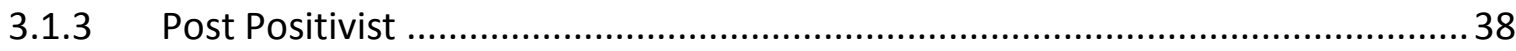

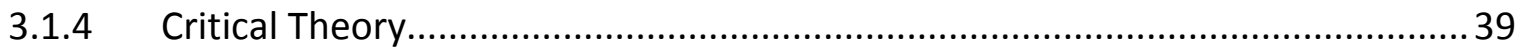

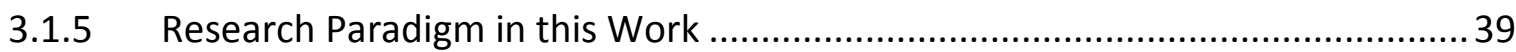

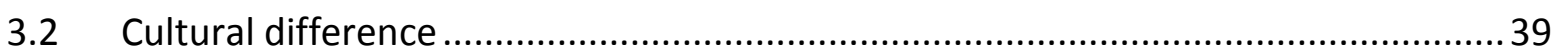

3.2.1 Hofstede Cultural Difference Model .............................................................. 40

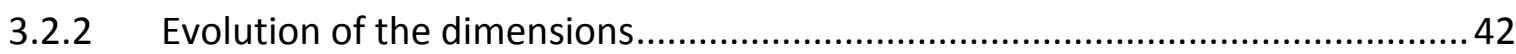

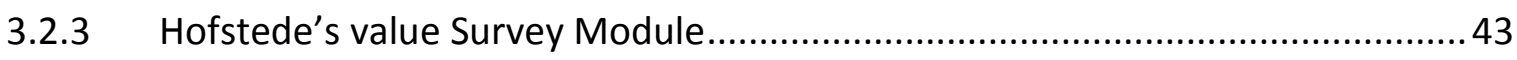

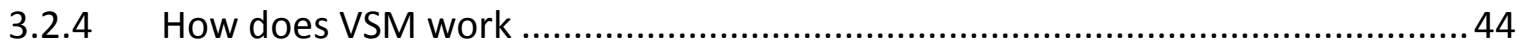

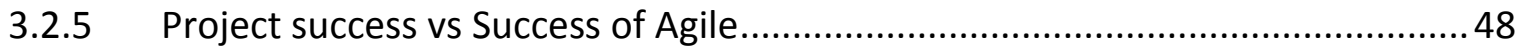

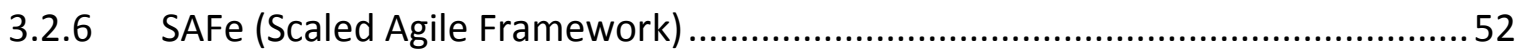

4 Chapter Four: Conceptual Model for the Research ......................................................55

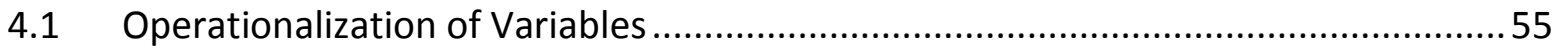

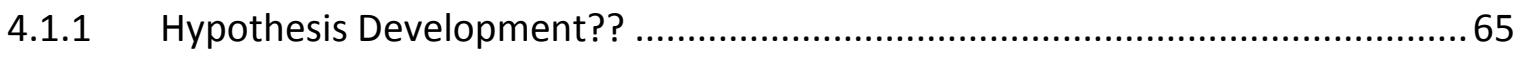

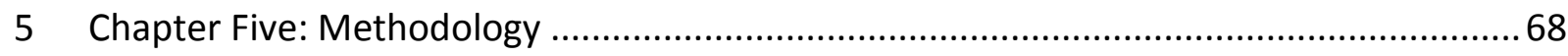

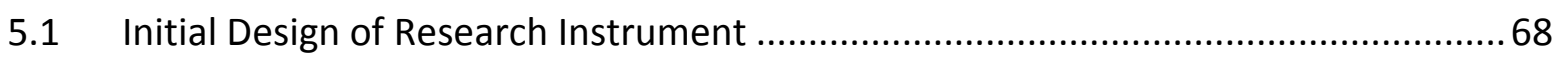

5.2 Correlation of questions to variables measured .............................................. 70

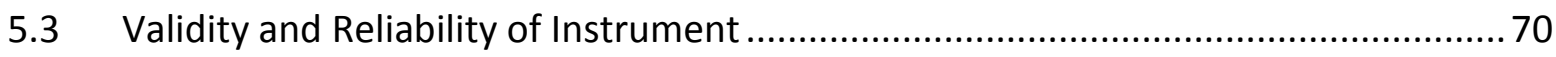

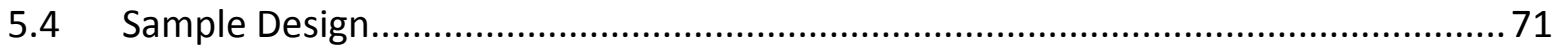

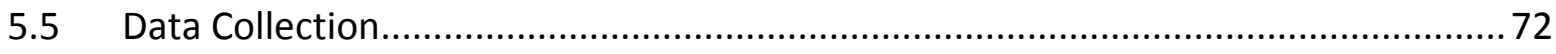

6 Chapter Six: Data Analysis, Results and Research Findings ........................................ 73 


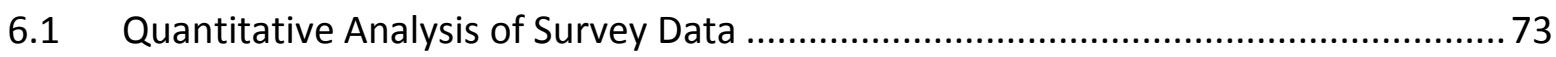

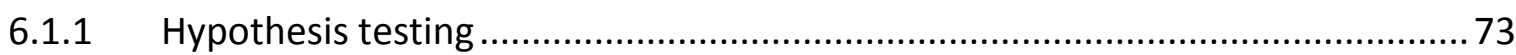

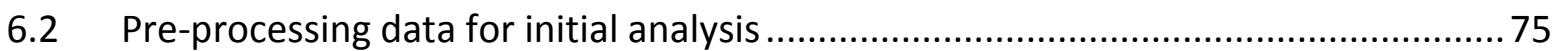

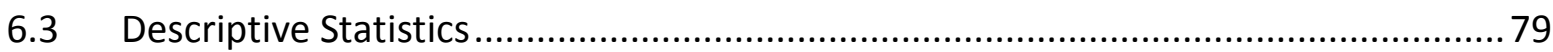

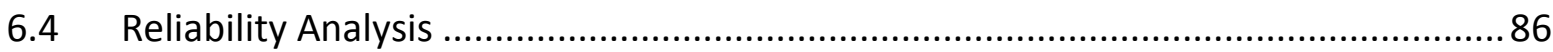

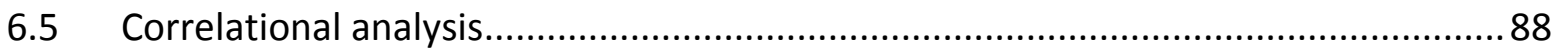

6.5.1 Culture difference vs Success of agile in Outsourced Projects .......................... 88

6.5.2 Time difference vs Success of agile in Outsourced Projects .............................89

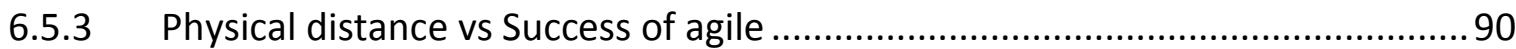

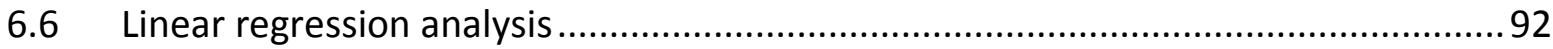

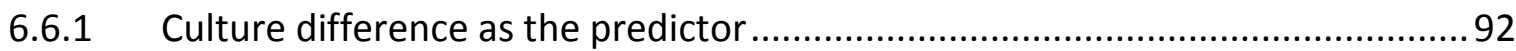

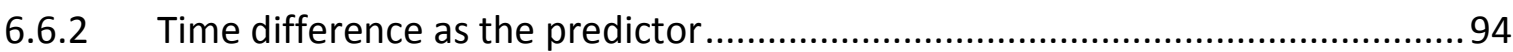

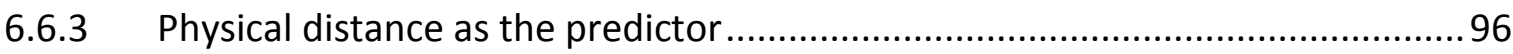

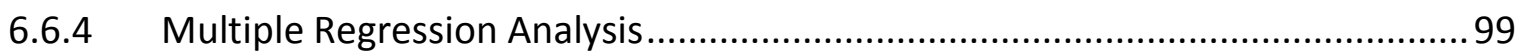

6.7 So how well has agile done so far with outsourced software projects? .................102

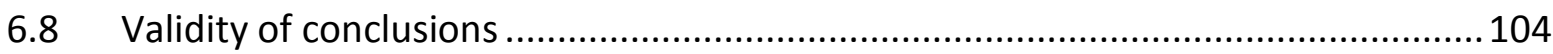

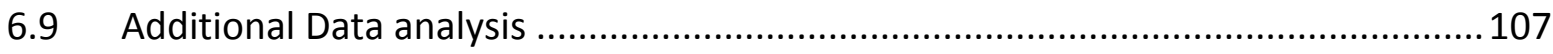

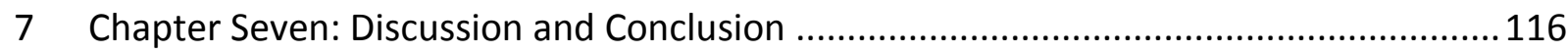

7.1 Agile principles vs Dominant Independent Variables........................................117

7.2 Discussion of Each Principle Against Affecting Independent Variables ..................118

7.3 Summary of findings through Data Analysis ..................................................... 125

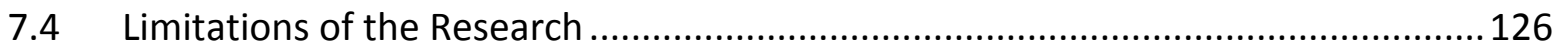

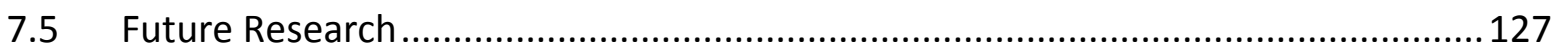

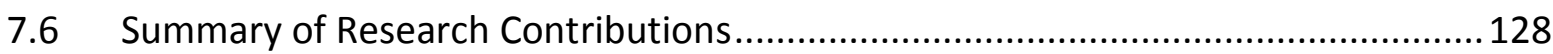

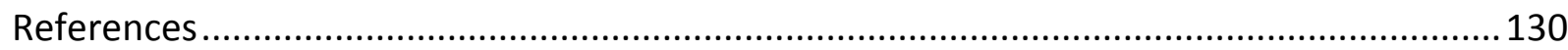

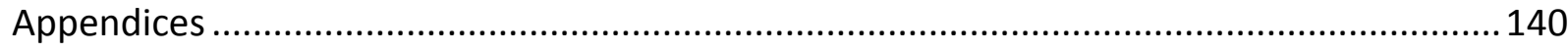




\section{List of Figures}

Figure 1-1 Software Development Life Cycle Source - Software Development Life Cycle (2007)

Figure 2-1 Project Management Success and Project Success

Figure 2-2 Differences in scopes between projects success and project management success

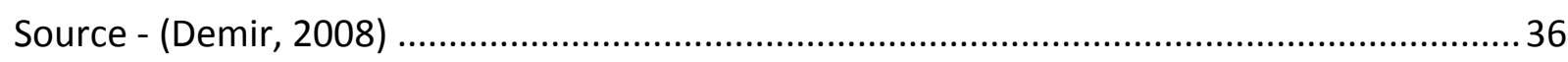

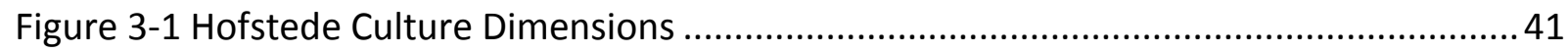

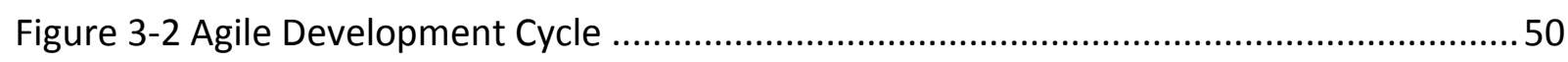

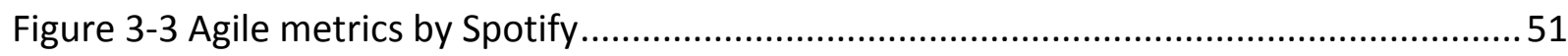

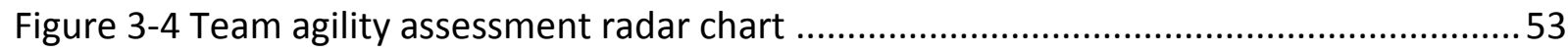

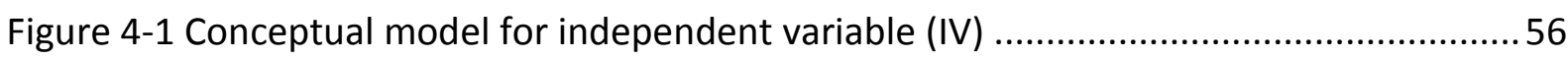

Figure 4-2 Conceptual model including both independent (IV) and dependent (DV) variables

Figure 4-3 Conceptual model expanded to show composition of dependent variable ..........62

Figure 6-1 Country culture comparison example Source - (Geert-hofstede.com, 2013) ........76

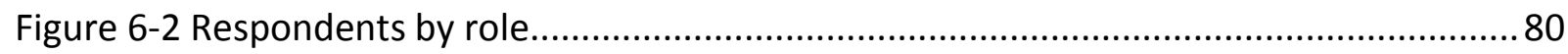

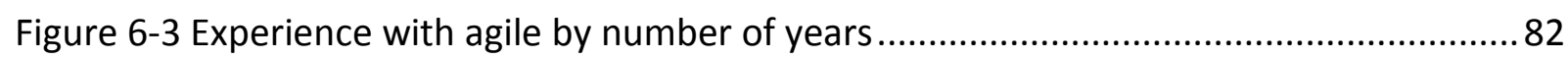

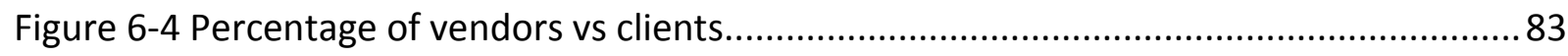

Figure 6-5 Error Residuals of Regression Analysis with Physical Distance as the Predictor ..... 98

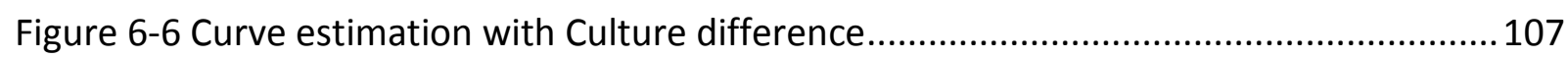

Figure 6-7 Curve estimation for physical distance ......................................................... 108

Figure 6-8 Curve estimation with time difference ..........................................................109

Figure 6-9 Regression curves between physical distance and agile success score................111

Figure 7-1 Respondent Data on Digital Task Board.......................................................121 


\section{List of Tables}

Table 4-1 Tool to aid analyse principles against variables ....................................................63

Table 5-1 Purpose served by questions in the instrument ................................................ 70

Table 6-1 Culture difference (descriptive statistics) ............................................................ 77

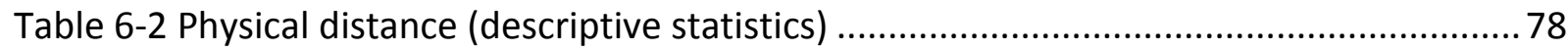

Table 6-3 Time zone difference (descriptive statistics)..................................................... 78

Table 6-4 Respondent by role (descriptive statistics) ......................................................... 81

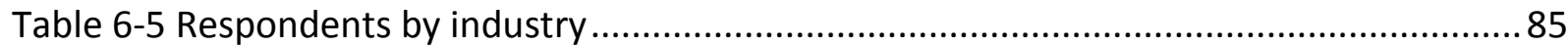

Table 6-6 Descriptive statistics for all three independent variables.......................................86

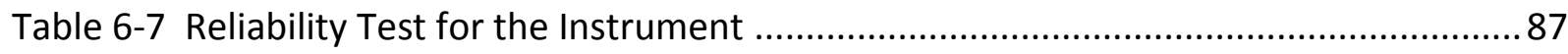

Table 6-8 Pearson Correlation between Culture Difference and Success of Agile in Outsourced Projects

Table 6-9 Pearson Correlation between Time zone Difference and Success of Agile in

Outsourced Projects (2-tailed)

Table 6-10 Pearson Correlation between Time zone Difference and Success of Agile in

Outsourced Projects (1-tailed) 90

Table 6-11 Pearson Correlation between Physical Distance and Success of Agile in Outsourced Projects 91

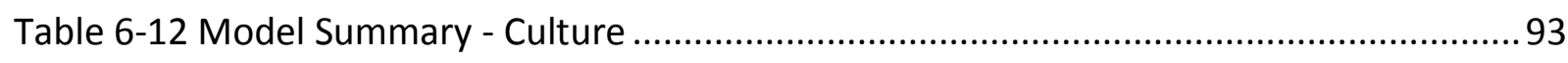

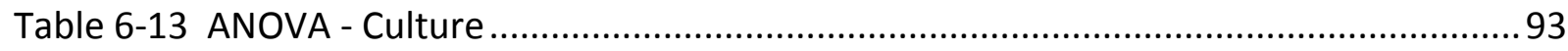

Table 6-14 Culture difference - Regression Results .......................................................... 94

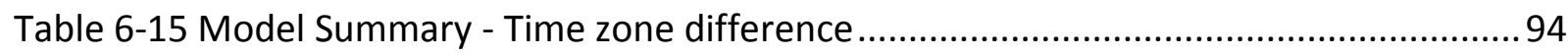

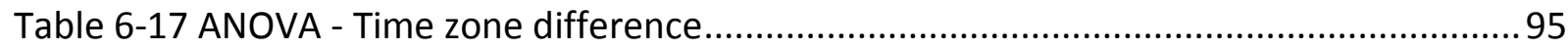

Table 6-18 Time zone Difference - Regression Results ........................................................96

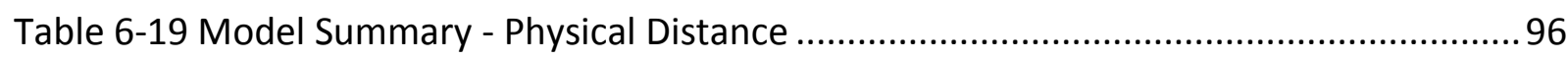

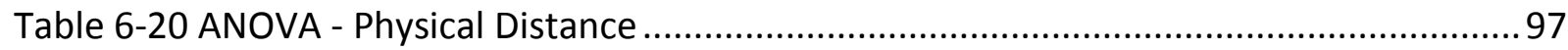

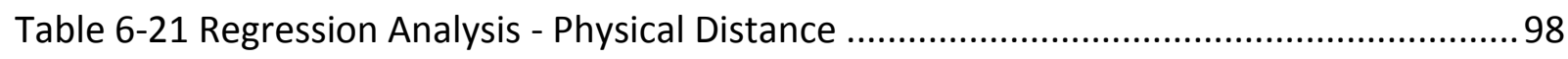

Table 6-22 Model Summary - Multiple Regression ..............................................................99

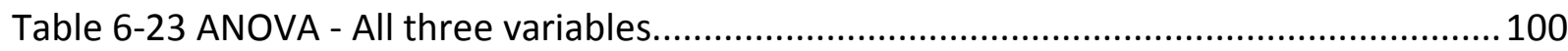


Table 6-24 Multiple Regression - All Three Variables ........................................................100

Table 6-25 Multiple Regression Physical Distance and Time ............................................... 102

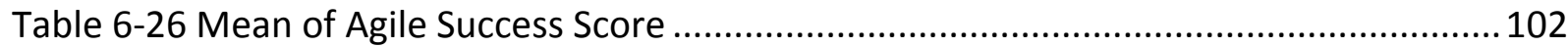

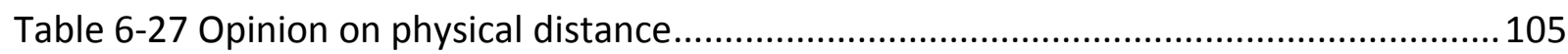

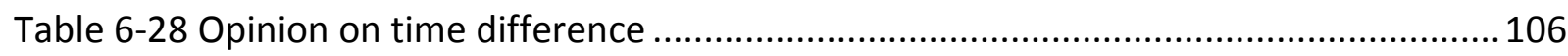

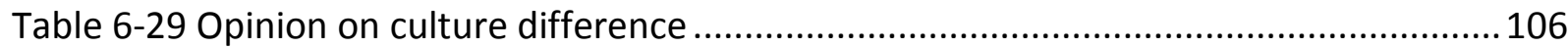

Table 6-30 Correlation matrix between variables................................................................... 110

Table 6-31 Linear model summary for log transformed physical distance and dependent variable

Table 6-32 Inverse model summary for log transformed physical distance and dependent variable

Table 6-33 Linear model summary for log transformed time difference and dependent variable

Table 6-34 Linear model summary for log transformed culture difference and dependent variable

Table 7-1 Agile Principles and Controlling Factors Summary..... 118 


\section{Chapter One: Introduction}

This chapter presents the motivation and scope for this research. It also provides an introductory pitch for concepts like project management, software project management, fall of traditional methodology and the rise of agile methodology and problems around outsourcing and agile methodology. This chapter also presents the research objectives and questions that are explored by this study and presented a brief summary of the approach.

\subsection{Problem statement}

Agile project management is widely used in today's software development industry from Silicon Valley big players to small town software development shops (Kwak, 2005). Successful adaptability of project management methodology or methodology fit is important for success of overall project and is one of the key ingredients of project success (Sheffield \& Lemétayer, 2013). On the other hand, recent years of software industry has seen the rise of a new era with outsourcing becoming a well-recognized industry practice (Robinson, 2011).

Agile however was originally developed for in-house software project management where teams were co-located in most cases inside the same premises (The Agile Alliance, 2001). To be able to successfully adopt/change agile methodologies to work in outsourced software projects it's important to understand how well agile is currently working with outsourced software projects, what factors affect the seamless adoption of agile in outsourced projects. If it's not working very well research has the potential to explore what can be changed to make it work. 


\subsection{Research Background}

\subsubsection{What is project management}

According to both formal (Turner, 2014) and informal (Wikipedia, 2013) definitions project management is "the process of planning, organizing, motivating and controlling resources, procedures and protocols to achieve specific goals in scientific or daily problems". According to the same sources, a project is a temporary attempt to develop a product or a service which is usually constrained by time and budget. It will also have a predefined set of deliverables to be seen at the end or during the project. The systematic application of project management tools and techniques to complex engineering project only started during $1950 \mathrm{~s}$. Before that time projects were usually managed by chief architects, engineers and master builders themselves. Project management also has its own challenges to deal with which is to attain all of the project goals while honouring the pre-defined constraints which are usually scope, time, quality and budget.

\subsubsection{Project management phases}

Initiating - Initiating process determine the scope of the project. This stage is important and has to be performed well to make sure business needs are met. The key here is to understand the business environment and making sure that all necessary controls are looked at, in the project. Outcome of the initiation phase should include a plan which includes analysis of business requirements, objective behind the requirements, a review of current state of the operations, a financial analysis of the costs and benefits including a budget, stakeholder analysis and project charter including costs, tasks, deliverables and schedules Planning - Following initiation phase the project is planned in detail in terms of cost and resources with the objective of estimating the work needed and manage risk during project execution. 
Execution - The implementation phase is where the actual product/ service development happens. This phase make sure that project management deliverable are executed in accordance with the project plan.

Monitoring and controlling - This phase consists of processes in place to observer the project execution so that potential problems can be identified in a timely manner and action taken. Monitoring and controlling includes measuring the on-going project activities, monitoring the deliverable to make sure the project is ticking along its timeline as planned and if there is a lag behind identify and apply corrective measures, manage change control so that only approved changes are implemented. Project maintenance is an on-going process where correction of errors and product updates are regularly applied. In terms of software development which is the subject industry in my work, maintain a product is of utmost importance to deter and prevent security vulnerabilities from being exploited by hackers around the world. Without continuous patching and updates electronic systems will be left behind open door for hackers to get in which runs the risk of tarnishing corporate image to outside world.

Closing - Last stage involves formal acceptance of the project and ending. This phase consists of contract closure and project closure which respectively involves completing and settling of contract and finalizing the activities of all process groups.

\subsubsection{What is Project management methodology}

Often referred to as the methodology there are a number of different approaches of achieving the above mentioned project management goal. They belong to categories such as lean, iterative, incremental and phased. PRINCE2, PMI, critical chain, process based, agile, lean and extreme are a few of those many project management methodologies (Wells, 2012). Traditional approach put more emphasis on planning and design stages while an approach like agile has less emphasis on planning over implementation stages. In other words agile is geared towards developing an output/ tangible product/ service faster, than spending more time in design and planning stages like traditional approaches (Spalek, 2014). 
Traditional project management comprises of a number of elements from initiation, planning and design, execution and construction, monitoring and controlling systems and completion. Many industries are said to have a variation of these stages where some steps are combined, expanded and skipped. In software development industry traditional approach is called 'the waterfall' model. According to the cone of uncertainty some rigorous planning made at the forefront of project start quickly become volatile due to constant change of requirement, something that can be seen in software development industry often (Wikipedia, 2013).

\subsubsection{What is Software project management}

Software project management is essentially the above said way of project management only this time to build software products. With the boom in computing industry in 1980s the software industry grew very quickly when industry realized the advantage of low cost of software production as opposed to complex hardware production. This is evident in that many articles have published by multitude of authors for recognized journals like PMJ (Project Management Journal) (Rivard \& Dupre, 2009).

As software industry grew exponentially, the task of managing a software project became an extremely complex one as a project drew on many personal, team, and organizational resources (Mishra \& Mishra, 2013) to mitigate issues with end user involvement, poor communication between project parties, unrealistic project goals, inaccurate estimates, immature technology, project complexity, stakeholder politics just to name a few of many.

\subsubsection{What is Software development life cycle}

According to Langer (2008) development of software usually involves following generic steps.

- Determine the need for a system to assist a business process

- Define the system goals

- Gather business requirements and convert to system requirements

- Design database and applications 
- Build, test and implement the database and applications

This high level process of making software is defined is moulded into a life cycle which is called SDLC (Software Development Life Cycle) that includes a set of related activities which in turn results in a software product. SDLC includes five core activities or life cycle phases. They are as shown in Figure 1-1 below as requirement analysis, design, implementation, testing, and evolution.

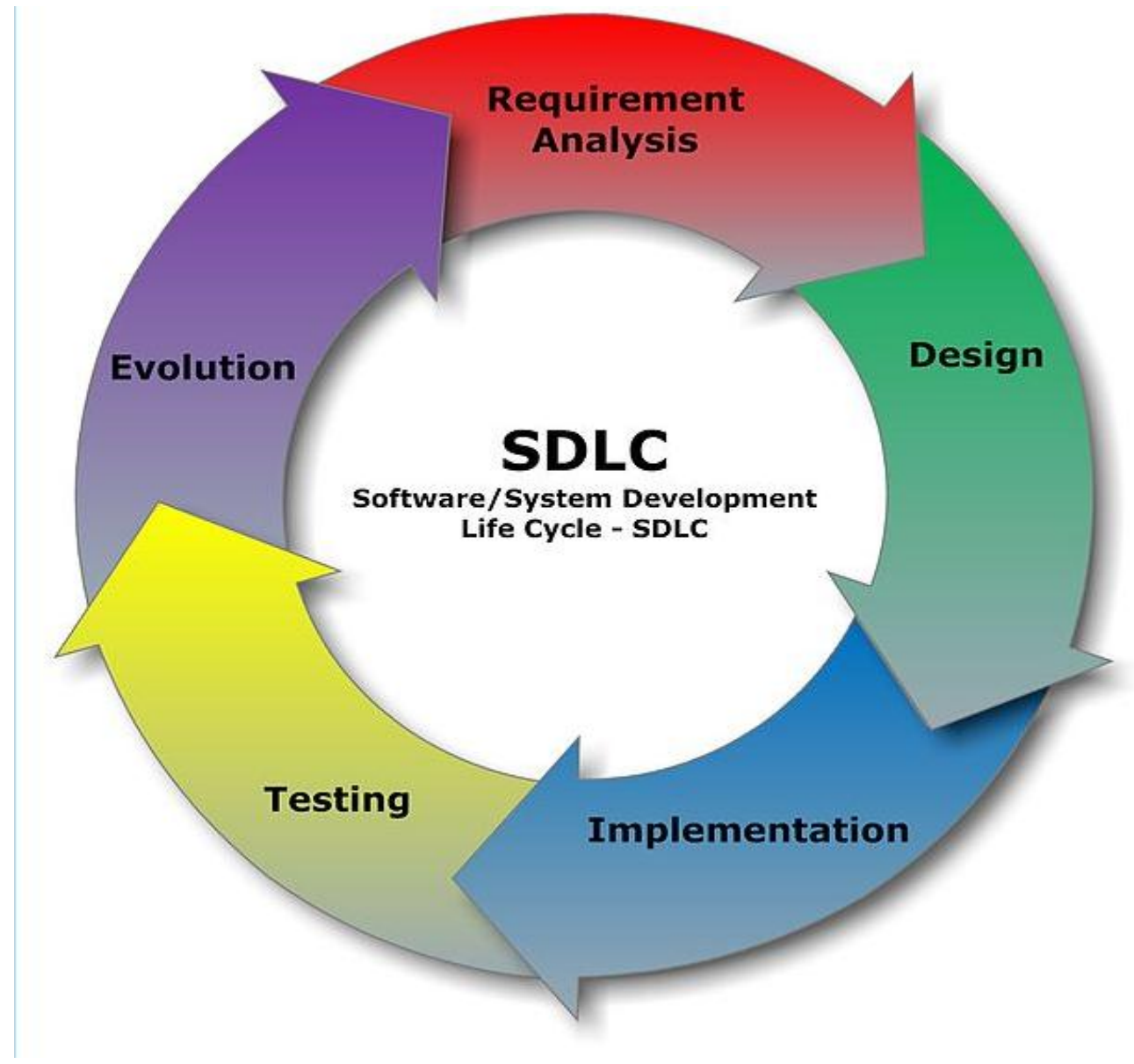

Figure 1-1 Software Development Life Cycle Source - Software Development Life Cycle (2007) 


\subsubsection{Software project management methodology}

Software project management is the management of above mentioned SDLC. To manage this daunting process software development firms use different project management methodologies such as agile, waterfall and lean among many to name a few (Stoica, Mircea, \& Ghilic-Micu, 2013). SDLC breaks Software development processes to more manageable phases (ALECU, 2011) which ease the ability to monitor them.

There are many software development life cycle methods. Gupta \& Pal (2012) highlights the major software development life cycle methods, among which are the waterfall method, waterfall method with iterative feedback, B-Model, incremental model, V-model, Spiral model, wheel and spoke model, unified process model, rapid application development and agile.

A life cycle model or a software project management methodology usually covers the whole spectrum from its inception, requirement definition through to fielding and maintenance as shown above. Most software project management methodologies fit into three main categories. They are iterative, structured and hybrid (Stafford, 2011).

\subsubsection{When traditional development methods don't work}

Progressing linearly from conception is the common method in waterfall style as conceptualisation, requirements gathering, design, implementation and testing is considered to be a linear process. This was the dominant model when computer systems were monolithic machines with minimal front end interfaces compared to slick user interfaces seen today. This was partially due to high programmer bias in specifying the requirements back in the day where little input was sought from stakeholders (Laplante \& Neil, 2004). It's quite easy to see why waterfall would work in such an environment as requirements seldom change since conceptualization and users can't provide feedback about incorrect assumptions/missing features in the developed system. However the coin has flipped in modern day electronic system as users and stakeholders considered to be of high priority 
since they can reject and accept systems based on ever changing needs, which means now they can add/modify/remove new/existing requirements even as late as implementation phase.

However constant change of requirements imposes much force on the waterfall model up to a point it cannot tolerate. For a methodology that assumed stable and mature requirements since inception of the project, this becomes quickly intolerable. As a result of the friction between changing requirements and rigidity of tradition waterfall based methodologies, alternative models sprung to life. Among those new memberships were Crystal methods, dynamic systems development methodology, extreme programming, feature driven, joint application development, lean development, rapid application development spiral methodology and agile methodology.

Agile is one such methodology which tries to address issues in waterfall methodology around changing requirements and the subject of this thesis. The next section looks at Agile in detail.

\subsubsection{Agile Methodology}

Agile methodology is one of many software project management methodologies which enjoy widespread use in software industry. In February 2001, 17 software professionals met at Snowbird resort in Utah to discuss lightweight development method as opposed to heavily regimented, regulated methods at the time. The conference resulted in the publication of the Agile Manifesto (The Agile Alliance, 2001) which specified high level concepts that govern agile methodologies. The Agile Manifesto states that,

1. Individuals and interactions should be prioritized over processes and tools

- Emphasizes the importance of self-organization, motivation and interactions like colocation and pair programming.

2. Working software over comprehensive documentation

- Working software is more useful and welcome than just presenting to clients in meetings 
3. Customer collaboration over contract negotiation

- Requirements are hard to finalize initially. So customer collaboration and stakeholder involvement is more important

4. Responding to change over following a plan

- Agile methods are focused on quick responses to change and continuous development

The Agile way of managing projects encourages an iterative approach which focuses heavily in managing human interactions rather than processes and tools. In fact this idea is one of the 4 main founding pillars of agile philosophy as pointed out above. Methodologies that share agile philosophy are widely used in software, technology, creative and marketing industries. The idea is to break down the problem into small manageable blocks of work which are then iteratively transformed into a final product through sprints. Sprints are basically short bursts of team activity used to transform the requirements to final product. Sprints are usually 1-4 weeks of duration (Wikipedia 2013) each.

\subsubsection{Offshore Outsourcing}

Offshore outsourcing involves relegating an external organization to perform some/all tasks of product/service design/development/testing to a country other than the one where the process originally started. Simply put outsourcing can also be viewed as sub-contracting which involves getting external expertise and resources to develop the end product/service.

Outsourcing is an attractive option for many firms who intend to reduce certain costs such as labour and material costs, high taxes, and excessive government regulations. But they are not the only reason for outsourcing to become an attractive option (Sharma, Sengupta \& Gupta, 2011). Firms which need expertise in specialized areas of product and service development and often find it hard to find the local talent and expertise. This makes specializing external provider a perfect choice. 
Lack of local resources and talent pushes more firms towards retrieving the services from an external provider often come from an offshore low cost location such as Asia or South America. This is quite evident in the software industry where talent supply and demand suffers a massive gap in some countries. Importance of IT outsourcing is also evident in the rigour of current studies that have covered the subject (Lacity, Khan, Yan and Willcocks, 2010).

\subsubsection{Agile meets outsourcing - the problem}

Agile was not developed with outsourcing in mind. This is evident as a number of agile principles seem to have assumed co-location of team members and ability of face to face communication (The Agile Alliance, 2001). Taking a closer look at the agile manifesto (The Agile Alliance, 2001) which the 12 principles agile methodology is based on, one can clearly see that it doesn't fit the interest of outsourced projects and other research has confirmed this (Largent, 2010). Agile methodology was developed to let teams closely collaborate with each other and face to face communication is one of the main pillars that hold the philosophy behind agile (Largent, 2010). But outsourcing, whether onshore or offshore has a distance barrier (Ambler, 2005). Things get even more complex with offshore outsourcing where additional barriers have to be overcome. Main research question is therefore built around these issues as below,

\subsubsection{Vendor and Client}

Ahimbisibwe, Cavana, \& Daellenbach (2015) has looked into critical success factors of outsourcing software project from a vendor's perspective. Authors highlight two different perspectives in outsourcing software project in their study as vendor \& client and points out how it can be different. Ahimbisibwe (2015) and Ahimbisibwe, Cavana \& Daellenbach (2015) looked at 37 candidates critical success factors for outsourced software development projects identified from 148 publications and arrives at three main candidates critical success 
factors which are vendor's perception of organizational factors, vendor's perception of team factors and vendor's perception of customer factors and their influence on project success which is regulated by vendor's perception of project factors and project management methodology.

Authors also pitch an interesting point of view by stating that when traditional plan based methods are employed as the project management methodology some critical success factors contribute differently towards project success than when agile methodology was applied and vice versa. He also states, some of the insights provided explains why software development project's success and failure can be explained by their context and emphasizes the importance of selecting a suitable management methodology for the project to be successful.

While Ahimbisibwe (2015) and Ahimbisibwe, Cavana, Daellenbach (2015) have done some outstanding work comparing and contrasting traditional plan based methodology to agile methodology in an exploration of what critical success factor contribute towards project success, their work lack the point of view from a client perspective. It is obvious that Client perspective is as important as vendor's perspective in an outsourced project, especially as the client controls the acceptance or rejection of milestones as the project progresses and have a strong say in the final verdict as to whether project was a success or not. Client controls the funding of the project and it's inevitable that vendor actions are catered and modified to suit client's liking as the project progresses. Hence, any outsourcing project can be thought of as a link between a vendor and a client.

We will distinguish between client and vendor responses in my research through a questionnaire. The data collected for this study will contain both client and vendor's views on the outsourcing projects so it will yield a better understanding and better generalizability of research findings as the final data points will be contributed by both client and vendor parties.

It's inevitable in this work that the reliability and generalizability of the data is quite dependent upon subjective perception of the success of certain project tasks from both client and vendor perspective but including both can strengthen the findings and neutralize any bias induced by the two different roles. 


\subsection{Research Objectives and Research Questions}

As mentioned before Agile was not developed with outsourcing in mind. Agile methodology is relatively new and isn't designed to be applied in outsourcing situations. This has led to new research alleys and spring of new terms like distributed agile (Hamid, 2013) and it's evident that using agile in outsourced software projects are widespread (Shrivastava \& Date, 2010). Taking a closer look at the agile manifesto (The Agile Alliance, 2001) which is the 12 principles agile methodology is based on, one can clearly see that it doesn't fit the purpose as other research has confirmed this (Largent, 2010). Agile is based on a few assumptions that are contradictory to what real world outsourcing projects has to deal with. Co-location, faceto-face communication has been assumed (Largent, 2010). Clearly, outsourcing whether onshore or offshore has a distance barrier (Ambler, 2005). Things get even more complex with offshore outsourcing where additional barriers have to be overcome.

A Key objective of this study is to uncover how well agile works with outsourced software projects. The finding will then be helpful at further investigating and provide directions at changes that are likely needed to be able to better use agile project management methodology in outsourced software projects. Industry professionals will be consulted to discover the ways their organizations are using agile and tweak they've made to fit the round peg in a square hole.

The main research question or any of its sub questions doesn't seem have been answered by current studies in the area from a quantitative perspective. One objective of the research is to quantitatively identify a rating for agile as to how well it has worked so far in outsourced projects. Identifying the extent to which each factor time, culture, and physical distance impact on success of agile methodology which later provides a foundation to identify whether any one factor dominantly impacts on the variations observed on success of agile methodology in outsourced projects are also among the objectives of this research. Finally a discussion around which founding of founding 12 principals are likely to be modified or aided with modified practices is carried out The main research question and sub questions are 
therefore built around these issues and formed as below,

1. How well do current agile principles and practices work with outsourced software projects?

2. To what extent does each variable distance, time, culture impact on success of agile methodology in outsourced projects?

3. Does one variable dominantly impact the dependent variable over others?

4. Which principles are least likely to work in an outsourced software project?

\subsection{Summary of Approach}

A literature survey is conducted to identify the main factors that are likely to be having an impact on success of agile methodology in outsourced projects. Data about success of agile methodology in outsourced projects are collected from around the globe through a questionnaire. Professionals/ practitioners of agile project management are the chosen participants of the questionnaire and data related to factors that affect the dependent variable are also collected there by enabling data analysis between independent and dependent variables.

Therefore the road to finding answers to research question follows a quantitative approach. My industry experience over 5 years in software development will also be put in the mix of final conclusions of the research. 


\section{Chapter Two: Literature Review}

This chapter provides a detailed view of current literature in the related subject area. It also introduces The Agile Manifesto (The Agile Alliance, 2001), related practices and most importantly a detailed discussion around challenges faced by the adopters of agile project management methods in outsourced projects.

\subsection{Agile Method of Software Project Management}

\subsubsection{Agile Manifesto, What is it?}

As the online manifesto put together by the original authors 'Principles behind the Agile Manifesto' (The Agile Alliance, 2001) emphasizes, the people factors and others play a very important role in forming the agile framework principles. Some of those principles are italicized below with questions that can be asked against their fit with outsourcing, "Close daily co-operation between team members" - one can question the following with regard to outsourcing. There will be two or more teams to start with. Close daily co-operation is not practical in offshore outsourcing and prone to communication breakdowns (Jaanu, Paasivaara \& Lassenius, 2012). What practices should be followed with onshore outsourcing (if teams are located with relatively close proximity)? (e.g.: still can be an issue with multi city onshore outsourcing)

"Projects are built around motivated individuals, who should be trusted "- Multiple teams from different companies involved here - with offshore outsourcing it's even different companies in different countries with possibly a very different organizational culture and HR recruitment policies. What are the practices and guidelines to get individuals from multiple teams to build trust and working relationships between them when studies (Richardson, Casey, McCaffrey, Burton, \& Beecham, 2012) have demonstrated that there are different factors acting as barriers to build trust among the team members in outsourcing situations? 
"Face to face communication is the best form of communication (co-location)" - Same questions raised in point 1 above can be asked here. What workarounds are available to overcome difficulties posed by different language proficiencies (Khan \& Azeem, 2014)?

"Self-organizing teams" - What practices should companies follow to get their spatially, temporally and culturally dispersed teams to work together to deliver technical excellence when there is apparent differences (Gorton \& Motwani, 1996) in the way two cultures would communicate, their attitude towards work ethic and sense of time?

"Continuous attention to technical excellence" - In case of two teams that work towards a single project who comes up with the initial technical architecture design which is a very important task to set the project in the correct direction? Mistakes here can be costly to repair. Inherent differences of willingness to raising the voices (Nicholson \& Sahay, 2001) in public in some Asian cultures countries doesn't help the situation and what measures does agile framework provide to mitigate these risks?

"Sustainable development, ability to maintain constant pace" - With developers, business analysts dispersed by multiple dimensions as shown above, what practices and guidelines are available for seamless adoption of agile into outsourced projects? Especially in a distributed environment where developers are expected to be aware of cross cultural issues of project stakeholders (Griffith \& Harmancioglu, 2009).

\subsubsection{Agile Practices}

Agile practices are what implement the agile method for projects. Practices of Scrum method is one of the broadly used agile method and the chosen implementation of agile in this thesis. As outlined by Agile Alliance and Institute Agile (2013), a subset of below agile practices that closely relate to implementation of scrum are listed below.

Incremental development,3C's, User stories, Story splitting, Backlog grooming, Backlog, Planning poker, Relative estimation, Definition of ready, Task board, Burndown chart, Daily meeting, Iterations, Time box, Continuous integration and automated build ( $\mathrm{Cl})$, Version control, Test driven development, Usability testing, CRC cards, Quick design session, Domaindriven design (DDD), Refactoring 


\subsection{Square peg in a round hole - problems with fusion of agile and outsourcing}

Ambler (2005) argues that primary challenge for out sourcing lies in the distance, time and cultural differences that erect barriers of communication which then leads to misunderstood software requirements that goes undiscovered until late into the project. According to him, as part of the workaround for risk involved without sourced projects clients insist for a fix bid process which will be based on a detailed requirements document upfront which opens gateways to failures mentioned below,

1. Clients including requirements they don't really won't or not sure if they want.

2. Original requirements become obsolete as project progress

3. Being not being adept at defining what they want but point to what they don't need when they see it

4. Scope creep to mitigate any financial responsibility 
Practices like scaling down the documents for developers in India as opposed to get them to read a 100 page requirements document is something he suggests based on just one evidence. These ideas seems to be his personal opinion so can be seen as a gap which can be filled with additional research work by suggesting better practices that work with agile outsourcing which are also confirmed and supported by a significant number of IT practitioners.

Another study by Dorairaj and Noble (2013) looks closely at knowledge management among agile teams. Authors mention the barriers to well managed knowledge during distributed global agile teams which are spatial, temporal and socio cultural barriers. He also stresses the importance of team co-location in agile methodology where teams gather, store, share and use invaluable knowledge through close face to face communication which is imperative to success of software development projects. Their study included 55 participants from a range of different countries across the globe authors to derive findings regarding six techniques to manage knowledge in globally distributed agile development. This study doesn't look at how well agile methodology worked in outsourcing rather have a specific focus on how globally distributed agile teams to knowledge management. Nevertheless authors Dorairaj and Noble further confirms that dimension time, culture and distance affect agile outsourcing which provides further evidence to form the base of our study.

More studies (Boden, Avram, Bannon \& Wulf, 2009) have investigated the effect from distance, time and cultural barriers to effectively managing knowledge in software development projects. The authors of the above mentioned study have also iterated the lack of research and literature around agile and outsourcing.

One thing you should notice by now is that multiple studies are pointing at the same direction highlighting common problems dimensions time difference, physical distance and cultural difference. The next sections will discuss each of these dimensions. Distance and time are easy to understand but has a non-trivial role to play in our study. Culture on the other hand is vague and confusing is expected to have an impact on success of agile methodology in outsourced projects. 


\subsubsection{Culture}

There is no single across the board standard definition for culture. However most definitions of culture are convergent towards a similar idea. Below we will look at a few definitions that were given to explain culture.

Kroeber and Kluckhohn (1952) states that Culture consists of patterns, explicit and implicit behaviour acquired and transmitted by symbols, constitute the distinctive achievement of human groups, include their embodiments in artefacts; the essential core of culture consists of traditional (i.e. historically derived and selected) ideas and especially their attached values. Culture systems may, on the one hand, be considered as products of action, on the other as conditioning elements of further action.

Another definition (Hong, Morris, Chiu, \& Benet-Martínez, 2000) that looks at culture in a dynamic constructivist approach defines culture as "networks of knowledge consisting of learned routines of thinking, feeling, and interacting with other people, as well as a corpus of substantive assertions and ideas about aspects of the world it shares among a collection of interconnected individuals who are often demarcated by race, ethnicity, or nationality; externalised by rich symbols, artefacts, social constructions, and social institutions (e.g. cultural icons, advertisements and news media); used to form the common ground for communication among members; transmitted from one generation to the next... ; undergoing continuous modifications".

\subsubsection{Distance}

Often teams come from different countries as the major leverage point for companies those who outsource their work is to access relatively cheap labour market, specialization and expertise in their partner countries. Hence it's inevitable that outsourcing project involve teams come from countries miles apart from each other. Distance dimension takes this into account as a variable and obviously will be defined as the physical distance between the two countries. 


\subsubsection{Time}

Time may look like it's proportionally increasing with distance but it's not the case always. Think of two countries that have the same latitude but a different longitude or relatively smaller latitudinal gap but a greater longitudinal gap. Countries like Sri Lanka, China, and India all fall under similar time zones but lie quite far away from each other. New Zealand and Japan have thousands of kilometres between them but not much of a time difference compared to New Zealand and US or New Zealand and UK/Europe. It's important to treat time as a separate dimension to distance to understand/explore if working under similar time zones even with a considerable distance would make inter team project flow any smoother.

Research done in related areas directly support the arguments for agile and outsourcing status quo established so far. One such study by Pauleen \& Young (2001) tried to understand the problems faced by virtual team facilitators in organizing and facilitating virtual teams. Deriving from methods in AL (Action Learning), authors developed a training program which was aimed at achieving three goals: to generate interest and incentive for would be participants, to let them acquire necessary skills required to spin off and lead their own virtual teams and generate data for analysis. After 10 weeks of running the training program participants implemented a virtual team setting in their organizations and feedback was collected thoroughout the duration.

After analysis, researchers found that it's essential to build a level of personal relationship with virtual team members before commencing a virtual working relationship. These findings form a basis for some ground explored in my work. Data will be collected from industry professionals to see how much they favour the concept of close working relationship in an outsourced agile link. Pauleen \& Young's (2001) work also assist in arguing for the idea that agile has to undergo some modifications to be considered a successful project management methodology for outsourcing projects as agile, already reiterated many times is designed to work with co-located teams. In outsourcing projects agile now has to deal with virtual teams. So has not building a close relationship damaging the prevalence of agile in an outsourced setting and giving it a bad reputation? Do agile practitioners think building a close 
relationship is a key pillar for a strong agile house? Research work on this thesis will help form a base for discussions related to above questions.

Problems related to spatially, temporally and culturally separate teams have been looked from a perspective of social categorization theory and social identity theory as well. Related ideas by Tajfel and Turner (2004) establishes that subgroups develop separate identities and display in group behaviours where members cohere and interact more with other members in their subgroup and less with those in outer group. In a nutshell this kind of in-group behaviour has found to contribute to reduced corporation and increased conflicts between subgroups which threaten the smooth running of the overall group. This is a well relevant scenario for outsourcing as the groups are separated into subgroup not by one dimension but three.

Bos, Shami, Olson, Chesin \& Nan (2004) carried out work on sub group dynamics using a simulated game to analyse distributed teams and collocated teams. They established that collocated members formed one group and all other isolates formed their own sub group. Overall there haven't been many studies done on distributed teams that can provide good insights into agile and outsourcing. Nevertheless work mentioned above form a good base for further studies like this.

Importance should also be given to leadership as it can influence team process and outcomes. While the leader role uses his/her problem solving skills and social control skills to provide direction to subordinates towards completing a task they are also providers of social and emotional support to group members to resolve conflicts and ensure smooth operation of the whole team. Breakdowns within teams can adversely affect overall team performance. Studies such as Armstrong and Cole (1995) has looked at how the position of the team leader had unprecedented effects in conflict management and established that location of the leader further exaggerated negative team dynamics. This seems quite relevant to an outsourced project management setting regardless of the project management method. Among the question that can be asked in regards to this are, how do leadership roles established with in client and vendor teams? Do they have separate leaders at both locations or do they have one leader is responsible and overlooks the entire projects? 
In another study, Ocker, Huang, Benbunan-Fich, \& Hiltz (2011) look at the leadership dynamics in distributed teams. Researchers found that feeling of inequality among team members enforced pre-existing feelings of being second class citizens, also that the leader adamantly trying to enforce his/her power leads to team members opposing his/her position and creating a friction between leader and members. With possible involvement of multiple leaders stemming from both client and vendor these dynamics are likely to impact smooth running of a project using agile project management method.

Maznevski \& Chudoba (2000) describe international teams as internationally dispersed groups of people who are usually assigned that are strategically important and complex who rarely meet in person conducting almost all their interaction and decision making using available telecommunication technologies. Authors also state that internationally distributed teams play an important role in today's organizations but little is known about their dynamics. Managers from around the world are required to build close networks with intense interaction towards achieving organization's global strategy.

Authors Maznevski \& Chudoba(2000) collected data over a period of 21 months between 3 global teams using multiple methods which included interviews, observations, communication logs, questionnaires and company documentation in a fortune 100 context which had three distributed teams working towards a common goal. Researchers saw global teams as a series of interaction incidents which in turn incorporates a set of decision processes via a particular medium. Researchers also noticed that interaction incidents themselves were sequenced in repeated temporal patterns which in fact happen to have the pattern of bursts of communication with high involvement followed by a period of a few weeks with interactions less intense. This is quite relevant to projects, managed using agile the methodology as communication is of utmost importance for success. With additional challenges posed by geographically dispersed teams these observations could be used to leverage its potential and minimize the negative effect posed by communication challenges. For example identifying a pattern of intense bursts followed by less intense period signals that there is a chance to confirm communication between remote teams should be well facilitated, mediated and supported during communication intense period more than the period that follows. Doing so might improve the process behind agile and remote teams. 
Face to face communication is the ultimate winner in all communication methods with no direct replacements. Work in this area has provided evidence for this. Hightower and Sayeed (1996) is one such study where researchers established that face-to-face communication outperforms other mediums of communication when it comes to efficiency and effectiveness.

However this doesn't mean that geographically dispersed teams are out of luck when it comes to using agile which heavily relies on using face to face communication. Although faceto-face communication has no superior replacement for it, using modern telecommunications methods such as video conferencing and digital aids can help narrow the gap opened by lack of face to face communication (Maznevski \& Chudoba, 2000). Hence it's clear that questions can be raised around how lack of up close communication affects seamless working of agile in outsourced projects. If telecommunication can aid in filling the gap posed by lack of close communication how successful will they be, do industry professionals use these methods and agree that theory actually works in practice are some of the questions that can be asked. Studies also exist which showed a mix of face-to-face and telecom media outperforms instances without face-to-face communication which is quite obvious in a sense.

The idea of interaction incidents presented in Maznevski \& Chudoba (2000)'s work is highly relevant in outsourced teams using agile. Interaction incidents are a series of social interactions, or continuous communication among two or more members using one medium. Decision process, message complexity, decision process and form come in varying levels. These interactions come in the form of information gathering, problem solving, idea generating and decision making. This can be readily seen in any agile team hence communication is key. One of the four main agile philosophies is "individuals and interactions over process and tools". Team members are expected to communicate face to face to quickly resolve road blocks which pop up during the sprint (The concept of sprint is later explained, different agile implementations use different terms but they all converge on the same concept - a sprint is usually the short time frame a predefined set tasks that are expected to be finished). Concepts around interaction incidents directly correlate to form of communication found in agile as programmers, analysts and testers work together to gather information, solve problems, generate ideas and make decisions. 
Researchers observed that successful teams matched and used the correct form of communication based on the complexity of the interaction whether it was decision making or problem solving, whereas not so successful teams were all over the place discussing complex strategic matters over mediums which didn't suit the type of interaction. Researchers hence establish that to be an effective global virtual team longer and complex interactions should be matched by an appropriate medium given the trend of increase in global virtual teams. 


\subsection{How to measure "how well"? Project success vs. success of the project management methodology}

Demir (2008) points out that project success is not the same as project management success. Most practitioners emphasize that software project success is closely related to project management quality or success which highlights that project management solutions/methodology like agile/lean/waterfall/PMI isn't the only factor that impacts heavily on overall project success. Demir (2008) also highlights the lack of established scientific evidence for such relation in the software management literature moreover he also reasons as to why such relationship between project success and project management success has not been established by referring to Pinto and Slevin (1998), the work which points out that success and failure are quite subjective.

Demir (2008) also highlights the difficulty to do empirical research in areas like software engineering where he attributes it to the lack of fundamental research that is required for empirical studies. This is due to the relatively young age of disciplines like software engineering and project management.

Nevertheless he uses the illustration of various stages that comprise project success and project management success as depicted in Figure 2-1 Project Management Success and Project below. 


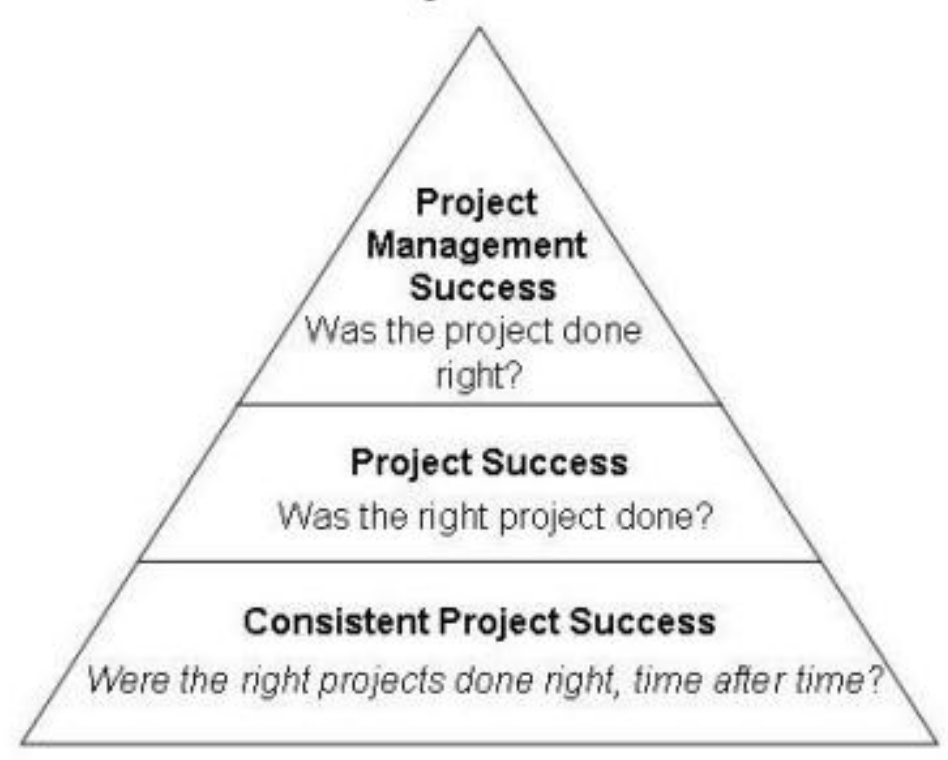

Figure 2-1 Project Management Success and Project Success

Source - (Demir, 2008)

Expanding on above as illustrated in Figure 2.2 below, the scope of project management success which is of interest to this study is more related to the implementation phase (was the project done right?) whereas scope of project success is more about doing the right project (was the right project done?). Hence the project management success is what is of much more relevance concern to us in our work as we look at agile which fits right into project implementation phase as it is a project management methodology/tool used by project managers "to do the project right".

Therefore in the theoretical framework we will discuss in detail how to measure how well agile methodology performs in a project. 


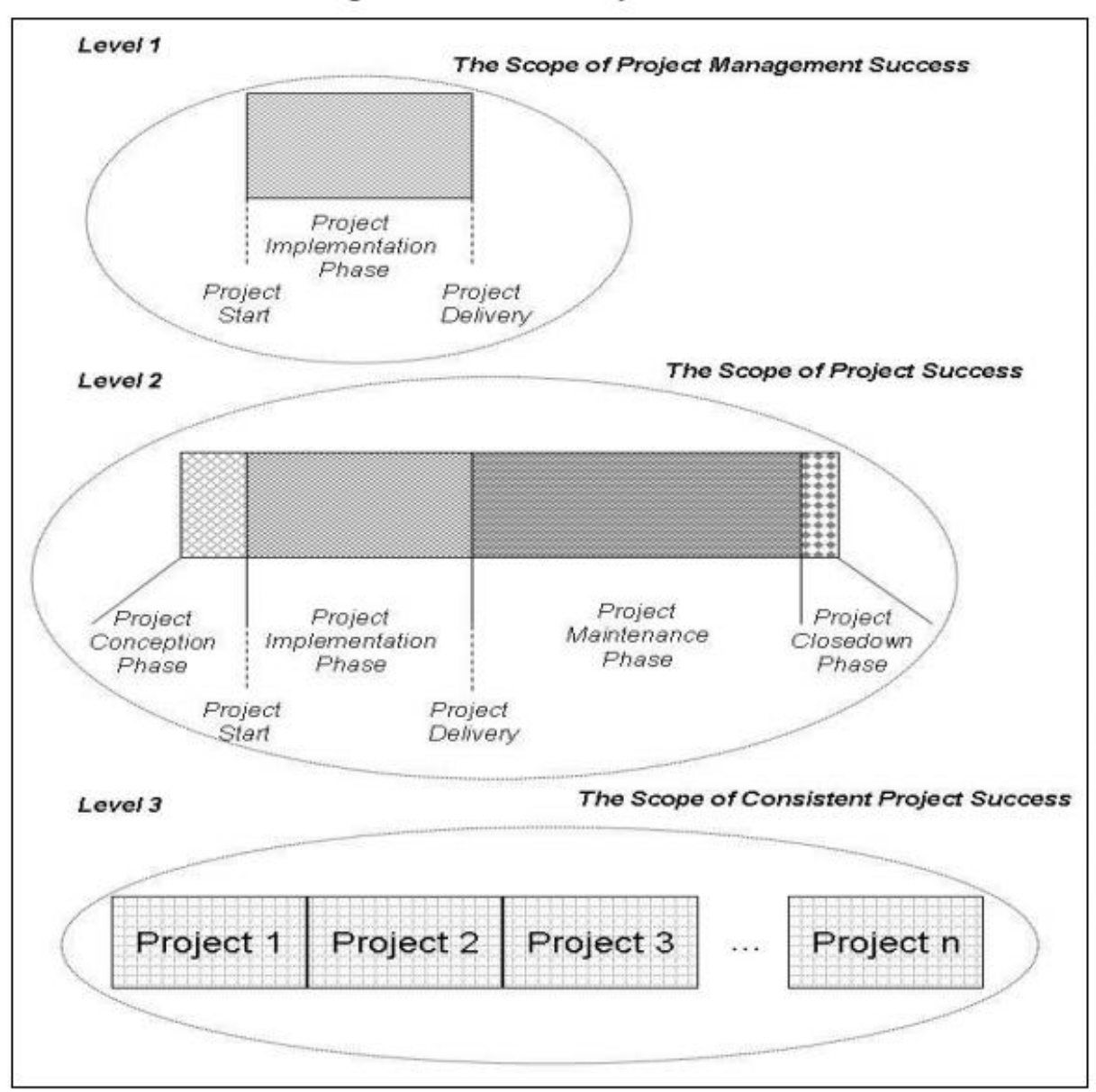

Figure 2-2 Differences in scopes between projects success and project management success Source - (Demir, 2008) 


\section{Chapter Three: Theoretical Framework}

This chapter establishes the related research paradigms this study is based on. It also introduces Hofstede's culture difference model (Hofstede, 1988) and SAFe (ScaledAgileFramework.com, 2015) which acts as tools to operationalize some of the variables.

\subsection{Research Paradigms}

Kuhn (1962/2012) introduced the notion of paradigms to explain the collective beliefs, values, techniques, laws and instrumentation shared by the members of the scientific community. Kuhn opinionated that all research regardless of discipline begins at a philosophical level which lays foundation for a scientific paradigm towards generating knowledge. Furthermore Guba and Lincoln (1994) defined paradigms as the "basic belief systems based on ontological, epistemological and methodological assumptions". Here the ontology refers to the social reality, epistemology to how researchers gain knowledge of reality and methodology as to how researchers come to find out the reality.

Paradigm boundaries can be realized by using ontological, epistemological and methodological differences of each paradigm. Computing related disciplines have been using all of these paradigms to build their body of knowledge up to current status quo (Greg, Kulkarni \& Vinze, 2001). The sections below briefly summarize each paradigm to complement the theoretical framework for this research.

\subsubsection{Positivist}

Closely related to the concepts of logical positivism and logical empiricism which is found on rigid rules of logic and measurement, truth, absolute principles and prediction, positivism assumes existence of objective truth. Positivists tend to rely typically on deductive logic. According to the work by Orlikowski and Baroudi (1991), Positivist studies are premised on 
the existence of a priori fixed relationships within phenomena which are typically investigated with structured instrumentation. Such studies serve to test theory, in an attempt to increase predictive understanding of phenomena.

Researchers are only independent observers of the research phenomena and findings are based only on independent observations and methods that other researchers can repeat (Fossey, Harvey, McDermott \& Davidson, 2002). Experimentation and hypothesis testing are primary attributes of positivist methodologies and researcher doesn't intervene in the phenomena under study. Knowledge is presented in form of cause-effect laws.

\subsubsection{Interpretivist}

The interpretivist paradigm as opposed to the positivist paradigm assumes the existence of social contexts that create realities and establishes that those realities don't exist independently of humans, hence explores how and why individuals act the way they do. Interpretivist research relies on inductive logic, emphasizes participant perspective and rejects priori assumption about research phenomena.

Among the main characteristics of interpretivist style research is dependency on social interaction between the researchers and individuals to generate knowledge. Interpretive researchers believe that social reality can only be interpreted, and hence cannot be apprehended, characterised, and measured in an objective manner (Orlikowski \& Baroudi, 1991).

\subsubsection{Post Positivist}

Post positivist paradigm assumes the existence of multiple constructed realities instead of a single objective reality. These realities can be apprehended, characterised, and measured only "reasonably closely" rather than in absolute sense as a result of human fallibility (Guba \& Lincoln, 1994). 
Post positivist research acknowledges the existence of human factor in findings, researchers try to be as neutral as possible and focus is primarily on experimentation and hypothesis testing.

\subsubsection{Critical Theory}

Critical Theory research assumes the existence of social contexts that create realities that are historically constituted and can be iteratively reproduced by people despite the changes in their social and economic status (Orlikowski \& Baroudi, 1991).

According to Orlikowski and Baroudi (1991) Critical studies aim to critique status quo, through the exposure of what are believed to be deep-seated, structural contradictions within social systems, and thereby to transform these alienating and restrictive social conditions.

\subsubsection{Research Paradigm in this Work}

The research paradigm followed in this work seems to sit closely with Positivist paradigm. But one can also argue the existence of people factors in the phenomena under study. It is also acknowledged that what's measured here is also loosely objective and follows a quantitative approach. One could consider this is also in line with a post positivist paradigm referring to the presence of a subjective bias around perception of a soft concept as success of a project management methodology. However measures were taken to make sure that the reliability and validity of data collection instrument was at good levels to help minimize the people factor. Hence the researcher thinks it's fair to consider the work follows a positivist paradigm.

\subsection{Cultural difference}

Cultural difference between regions/countries plays an important role in my research work. One of the main intentions of the research design is to answer the research question "how well does agile work in outsourcing projects' (section 1.3 question 1). Now this in turn were expanded into dimensions that can have an impact on flawless operation of multicultural teams who have to overcome barriers imposed by physical distance and time difference 
along with cultural difference. While distance and time differences are straightforward and intuitive to measure culture is not. Following sections expands, elaborates on cultural difference while introducing tools that is used to operationalize cultural difference.

\subsubsection{Hofstede Cultural Difference Model}

Professor Geert Hofstede (Hofstede, 1980) conducted one of the most comprehensive studies of how values in the workplace are influenced by culture. He defines culture as "the collective programming of the mind distinguishing the members of one group or category of people from others".

"He analysed a large database of employee value scores collected within IBM between 1967 and 1973 . The data covered more than 70 countries, from which Hofstede first used the 40 countries with the largest groups of respondents and afterwards extended the analysis to 50 countries and 3 regions. Subsequent studies validating the earlier results include such respondent groups as commercial airline pilots and students in 23 countries, civil service managers in 14 counties, 'up-market' consumers in 15 countries and 'elites' in 19 countries.

The six dimensions of national culture are based on extensive research done by Professor Geert Hofstede,

1. Power Distance Index (PDI)

2. Individualism versus Collectivism (IDV)

3. Masculinity versus Femininity (MAS)

4. Uncertainty Avoidance Index (UAI)

5. Long Term Orientation versus Short Term Normative Orientation (LTO*

6. Indulgence versus Restraint (IND) 


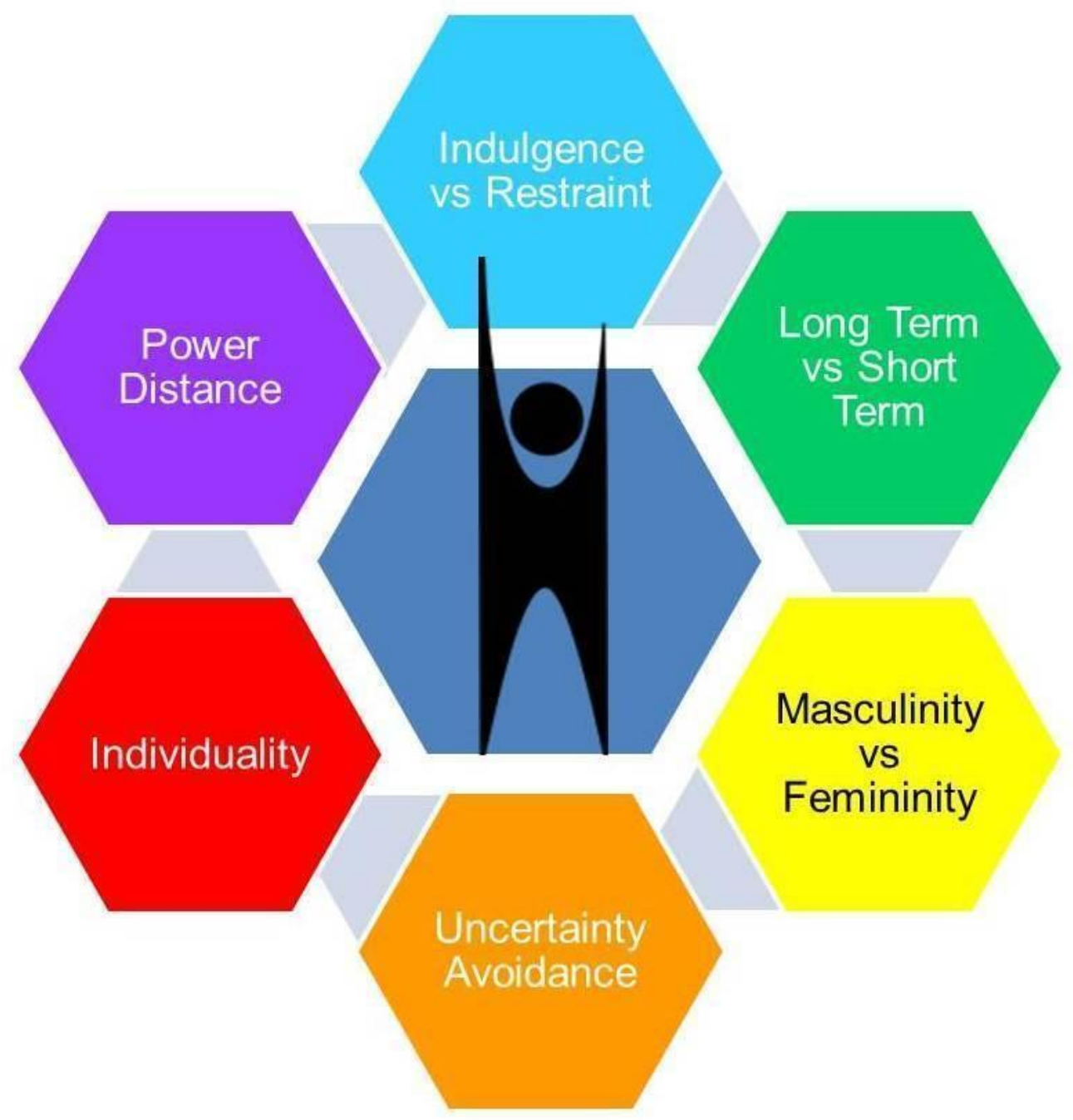

Figure 3-1 Hofstede Culture Dimensions

Source - (Flood, 2014)

The country scores on the dimensions are relative, as we are all human and simultaneously we are all unique. In other words, culture can be only used meaningfully by comparison.

These relative scores have been proven to be quite stable over time. The forces that cause cultures to shift tend to be global or continent-wide. This means that they affect many countries at the same time, so if their cultures shift, they shift together and their relative 
positions remain the same. Exceptions to this rule are failed states and societies in which the levels of wealth and education increase very rapidly, comparatively speaking. Yet, in such cases, the relative positions will also only change very slowly.

The country culture scores on The Hofstede Dimensions correlate with other data regarding the countries concerned. Power distance, for example, is correlated with income inequality, and individualism is correlated with national wealth. In addition, masculinity is related negatively with the percentage of national income spent on social security. Furthermore, uncertainty avoidance is associated with the legal obligation in developed countries for citizens to carry identity cards, and long term orientation (LTO) is connected to school mathematics results in international comparisons.

\subsubsection{Evolution of the dimensions}

The values that distinguished country cultures from each other could be statistically categorised into four groups. These four groups became the dimensions of national culture:

- Power Distance (PDI)

- Individualism versus Collectivism (IDV)

- Masculinity versus Femininity (MAS)

- Uncertainty Avoidance (UAI)

A fifth dimension was added in 1991 based on research by Michael Harris Bond (Bond \& Hofstede, 1988), supported by Hofstede, who conducted an additional international study among students with a survey instrument that was developed together with Chinese professors. That dimension, based on Confucian thinking, was called Long-Term Orientation (LTO) and was applied to 23 countries.

In 2010, research by Hoftede, Hofstede, \& Minkov (2010) generated two dimensions using recent World Values Survey data from representative samples of national populations. One was a new dimension, and the second was more or less a replication of the fifth dimension. 
The number of country scores for the fifth dimension could now be extended to 93 . On one hand, the fifth dimension of Bond (Bond \& Hofstede, 1988) and of Minkov (2010) correlate strongly, yet the constructs are not fully identical. The country scores used on this site are the scores of Minkov's (2010) research. We refer to this fifth dimension as Long Term Orientation versus Short Term Orientation (LTO).

In the 2010 edition of Cultures and Organizations (Hoftede, Hofstede, \& Minkov, 2010), a sixth dimension has been added, based on Michael Minkov's analysis of the World Values Survey data for 93 countries. This new dimension is called Indulgence versus Restraint (IND).

On the 17th of January in 2011, Geert delivered a webinar for SIETAR Europe called 'New Software of the mind' to introduce the 3rd edition of Cultures and Organizations', in which the research results of Minkov have been included (Geert-hofstede.com, 2013).

The following sections discuss more on each dimension and introduces the tool Hofstede (2013) developed to measure cultural difference between regions or countries".

\subsubsection{Hofstede's value Survey Module}

The Values Survey Module 2013 (VSM 2013 - see appendix A) is a 30-item questionnaire developed for comparing culturally determined values of people from two or more countries or regions (Hofstede, 2013). At the core of the module are 24 questions which cover the 6 dimensions mentioned above with rest of the questions being for the purpose of demographic data collection. The six dimensions are said to cover key issues in cross cultural context. The first version of the module was published in 1982 and only covered 4 dimensions, derived as a result of a comparison of subsidiaries of the IBM Corporation in 40 countries. The 1982 version followed by the 1994 version which covered 5 dimensions and another version that covered 6 dimensions.

The VSM is not for comparing individuals but caters comparison between national cultures which is ideal for this research work as one of the intentions is to explore how cultural difference at a country level/ national level affect the success of agile project management. 
Moreover individual correlations produce dimensions of personality whereas country level comparison produces dimensions of culture.

The following section will expand a detailed version of the inner working of VSM module.

\subsubsection{How does VSM work}

The twenty-four content questions allow index scores to be calculated on six dimensions of national value systems as components of national cultures: Power Distance (large vs. small), Individualism vs. Collectivism, Masculinity vs. Femininity, Uncertainty Avoidance (strong vs. weak), Long vs Short Term Orientation, and Indulgence vs Restraint. All content questions are scored on five-point scales (1 to 5). Any standard statistical computer program will calculate mean scores on five point scales, but the calculation can also be done simply by hand. For example, suppose a group of 57 respondents from Country $C$ produces the following scores on question 04 (importance of security of employment):

$10 \times$ answer $1=10$

$24 \times$ answer $2=48$

$14 \times$ answer $3=42$

$5 \times$ answer $4=20$

$1 \times$ answer $5=5$

54 valid answers totalling 125

Three of the 57 respondents gave an invalid answer: either blank (no answer) or multiple (more than one answer). Invalid answers should be excluded from the calculation (treated as missing). 
The mean score in our case is: $125 / 54=2.31$. Mean scores on five-point scales should preferably be presented in two decimals. More accuracy is unrealistic (survey data are imprecise measures).

\section{Power Distance Index (PDI)}

Power Distance is defined as the extent to which the less powerful members of institutions and organizations within a society expect and accept that power is distributed unequally.

The index formula is,

$P D I=35(m 07-m 02)+25(m 20-m 23)+C(p d)$

in which $\mathrm{m02}$ is the mean score for question 02 , etc. The index normally has a range of about 100 points between very small Power Distance and very large Power Distance countries. $C(p d)$ is a constant (positive or negative) that depends on the nature of the samples; it does not affect the comparison between countries. It can be chosen by the user to shift her/his PDI scores to values between 0 and 100.

\section{$\underline{\text { Individualism Index (IDV) }}$}

Individualism is the opposite of Collectivism. Individualism stands for a society in which the ties between individuals are loose: a person is expected to look after himself or herself and his or her immediate family only. Collectivism stands for a society in which people from birth onwards are integrated into strong, cohesive in groups, which continue to protect them throughout their lifetime in exchange for unquestioning loyalty.

The index formula is,

$I D V=35(m 04-m 01)+35(m 09-m 06)+C(i c)$

in which $\mathrm{m} 01$ is the mean score for question 01, etc.

The index normally has a range of about 100 points between strongly collectivist and strongly individualist countries. $C$ (ic) is a constant (positive or negative) that depends on the nature of 
the samples; it does not affect the comparison between countries. It can be chosen by the user to shift his/her IDV scores to values between 0 and 100.

\section{Masculinity Index (MAS)}

Masculinity is the opposite of Femininity. Masculinity stands for a society in which social gender roles are clearly distinct: men are supposed to be assertive, tough, and focused on material success; women are supposed to be more modest, tender, and concerned with the quality of life.

Femininity stands for a society in which social gender roles overlap: both men and women are supposed to be modest, tender, and concerned with the quality of life.

The index formula is,

MAS $=35(m 05-m 03)+35(m 08-m 10)+C(m f)$

in which $\mathrm{m} 05$ is the mean score for question 05 , etc.

The index normally has a range of about 100 points between strongly feminine and strongly masculine countries. $\mathrm{C}(\mathrm{mf})$ is a constant (positive or negative) that depends on the nature of the samples; it does not affect the comparison between countries. It can be chosen by the user to shift her/his MAS scores to values between 0 and 100.

\section{Uncertainty Avoidance Index (UAI)}

Uncertainty Avoidance is defined as the extent to which the members of institutions and organizations within a society feel threatened by uncertain, unknown, ambiguous, or unstructured situations.

The index formula is,

$\mathrm{UAI}=40(\mathrm{~m} 18-\mathrm{m} 15)+25(\mathrm{~m} 21-\mathrm{m} 24)+\mathrm{C}($ ua $)$

in which $\mathrm{m} 18$ is the mean score for question 18 , etc. 
The index normally has a range of about 100 points between weak Uncertainty Avoidance and strong Uncertainty Avoidance countries. $\mathrm{C}(\mathrm{ua})$ is a constant (positive or negative) that depends on the nature of the samples; it does not affect the comparison between countries. It can be chosen by the user to shift his/her UAl scores to values between 0 and 100 .

\section{Long Term Orientation Index (LTO)}

Long Term Orientation is the opposite of Short Term Orientation. Long Term Orientation stands for a society which fosters virtues oriented towards future rewards, in particular adaptation, perseverance and thrift. Short Term orientation stands for a society which fosters virtues related to the past and present, in particular respect for tradition, preservation of "face", and fulfilling social obligations.

The index formula is,

$\mathrm{LTO}=40(\mathrm{~m} 13-\mathrm{m} 14)+25(\mathrm{~m} 19-\mathrm{m} 22)+\mathrm{C}(\mathrm{Is})$

in which $\mathrm{m} 13$ is the mean score for question 13 , etc. The index normally has a range of about 100 points between very short term oriented and very long term oriented countries. $\mathrm{C}(\mathrm{Is})$ is a constant (positive or negative) that depends on the nature of the samples; it does not affect the comparison between countries. It can be chosen by the user to shift her/his LTO scores to values between 0 and 100 . 


\section{$\underline{\text { Indulgence versus Restraint Index (IVR) }}$}

Indulgence stands for a society which allows relatively free gratification of some desires and feelings, especially those that have to do with leisure, merrymaking with friends, spending, consumption and sex.

Its opposite pole, Restraint, stands for a society which controls such gratification, and where people feel less able to enjoy their lives.

The index formula is,

IVR $=35(m 12-m 11)+40(m 17-m 16)+C($ ir $)$

in which $\mathrm{m} 11$ is the mean score for question 11 , etc. The index normally has a range of about 100 points between high indulgence and high restraint. C(ir) is a constant (positive or negative) that depends on the nature of the samples; it does not affect the comparison between countries. It can be chosen by the user to shift her/his IVR scores to values between 0 and 100.

\subsubsection{Project success vs Success of Agile}

One can be misled at a first glance with the thought that project success is what needs to measure to quantify how well Agile worked in a specific project. But we discussed already (section 2-3) that project success and success of project management methodology are significantly different concepts.

But there doesn't exist any one study that outlines a comprehensive set of guidelines or a framework which facilitates measuring success of agile methodology. Luckily this doesn't cause a problem at all. "How well does agile work?" is a question that can be answered regardless of which scenario the methodology is applied to. This can further be explained by illustrating where agile fit in the SDLC (software development lifecycle).

Figure 3-2 below gives a comprehensive visual representation of agile process which clearly shows the significant involvement of agile methodology in the implementation phase of SDLC 
(Thenusan, 2014). This further explains why project success alone will not be a proper representation of "how well agile methodology worked" in a project. Obviously agile only focuses and is designed to focus on a smaller portion of the entire project. Success or failure of one phase of a project clearly doesn't represent the overall ratings of a project and vice versa. Hence this argument can be extended to say that a failure of a project doesn't necessarily represent a failure of agile methodology which only applies to implementation phase. Now since agile focuses on implementation phase of all SDLC phases which comprises of the entire project it's more accurate to relate success of implementation phase of SDLC to success of agile. Evidence can be found in the agile manifesto (The Agile Alliance, 2001) itself. One of the main ideas behind agile is "working software over comprehensive documentation". Agile works by producing working software that customers can play around with. It does this with short iterations (1 or 2 week) of development. Hence agile is highly involved in implementation phase more than other traditional counterparts like waterfall methodology. 


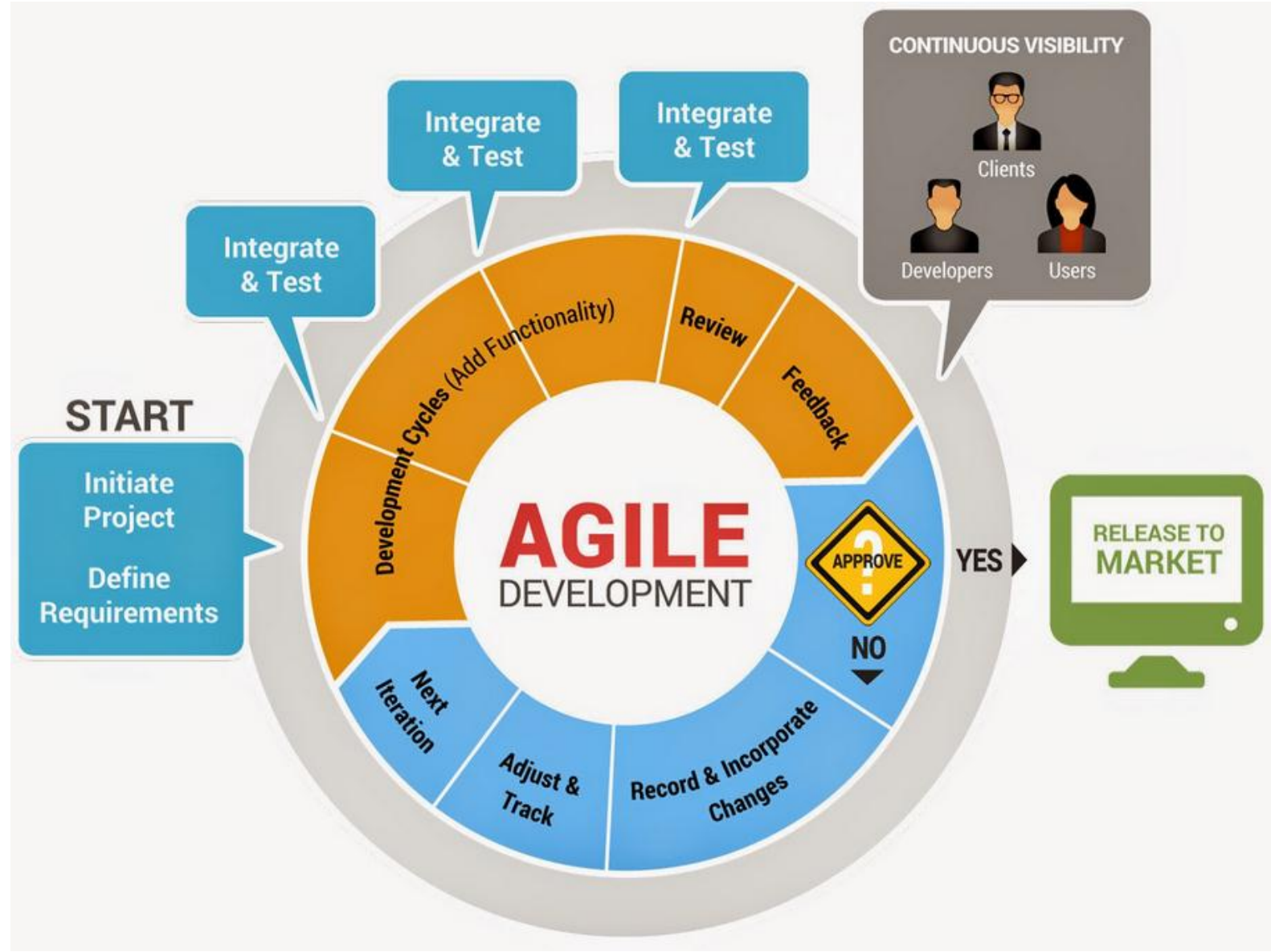

Figure 3-2 Agile Development Cycle

Source - (Rosland \& Cowger, 2015)

So how do we measure how well agile has worked? This questions is answered by agile metrics

A relatively new area of study so not many academic sources which have derived frameworks of metrics but the ideas aren't new. The industry needs to measure the health of their ongoing processes and this is a universally true statement which hasn't proven otherwise reason why we see the existence of quality control systems like TQM (Wikipedia, 2015) (Total Quality Management). Similar it's not arguable that agile as a process needs health monitoring. A question which organizations seem to have done individual researched into hence many blog posts, online resources and articles can be found on the topic. Some of the 
ideas as to how to measure the success/ health of agile in a project are explored in the following section.

One example can be drawn from Spotify which is a recent success story who has taken over music industry by storm with their revolutionary concept of music/media sharing platform according to Medium.com (2015). Based on web and mobile technologies, their team of developers seem to have tried an agile health check model as below where main metrics were monitored continuously which indicated over fall and rise of indicators.

\begin{tabular}{|c|c|c|c|c|}
\hline Metric & & & & Direction \\
\hline Teamwork & $\checkmark \checkmark \checkmark$ & $\checkmark$ & $\checkmark$ & 수 \\
\hline Pawns or Players & $\checkmark$ & $\checkmark \vee \checkmark$ & $\checkmark$ & 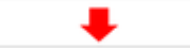 \\
\hline Mission & $\checkmark \checkmark$ & $\checkmark \checkmark$ & & 숨 \\
\hline Codebase Health & $\checkmark \checkmark$ & & $\checkmark \checkmark \checkmark$ & 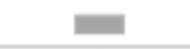 \\
\hline Speed & $\checkmark \checkmark \checkmark$ & $\checkmark \checkmark$ & & 숨 \\
\hline Ease of Release & & $\checkmark$ & $\checkmark \checkmark \checkmark \checkmark$ & 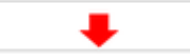 \\
\hline Learning & $\checkmark \vee \vee \vee \vee$ & & & 순 \\
\hline Delivering Value & $\checkmark$ & $\checkmark \checkmark \checkmark$ & $\checkmark$ & 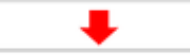 \\
\hline Suitable Process & $\checkmark \checkmark \checkmark \checkmark$ & $\checkmark$ & & 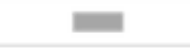 \\
\hline Fun & $\checkmark \checkmark \checkmark$ & $\checkmark$ & $\checkmark$ & 순 \\
\hline
\end{tabular}

Figure 3-3 Agile metrics by Spotify

Source - (Joentakanen, 2014)

Metrics are presented in a short form but it's not hard to understand what they have tried to do. Spotify has measured teamwork, turnover/pawns/players, mission, code base health, speed, value delivered, suitable process to keep their agile process health check on.

It's evident in all these sources that they all have given overall project success less attention/ importance but have paid more attention to other factors too. 


\subsubsection{SAFe (Scaled Agile Framework)}

According to another web resource that is completely dedicated to agile methodology scaledagileframework.com (2015), SAFe assessment can be used to measure how well agile teams do and this seems a perfect purpose- instrument fit for this study. SAFe is founded by Dean Leffingwell. In his book Agile Software Requirements (Leffingwell, 2010) he expands on how agile can be thought in terms of teams, programs and enterprise. He also discusses why the waterfall model doesn't work on software projects and issues underlying the model. He also discusses scaling issues of agile and how agile practices can be used to overcome the scaling issues among many interesting ideas he present in his book.

From this study's perspective the importance of Scaled Agile Framework (SAFe) commonly known as SAFe becomes clearer as it includes a team assessment that can be used to measure how teams are doing which is a perfect fit for an instrument to assess agile teams. The SAFe team assessment is based on five metrics as shown in the radar graph below (Figure 3-4). The five metrics are team, technical, product ownership, release and sprint health. Boeing and Nordia are among the commercial companies who have implemented SAFe in their production environments successfully according to ScaledAgileFramework (2015) which shows us the practical validity of SAFe.

The SAFe assessment takes view of agile from a product ownership, release, team, sprint and technical health points. Better health in each corner indicates better overall performance/health of agile methodology in a project. 


\section{Team Agility Assessment Radar Chart}

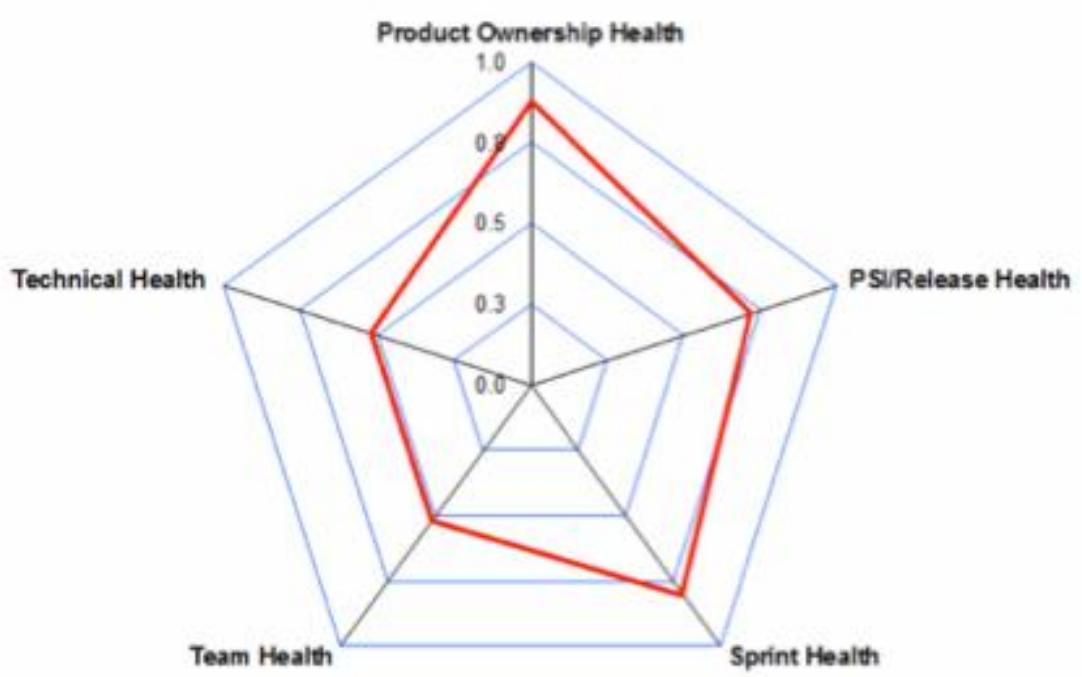

Figure 3-4 Team agility assessment radar chart

Source - (ScaledAgileFramework.com, 2015)

Below we will discuss the metrics in detail.

It is easy to get an understanding of each metrics by focusing on the assessment questionnaire and critically thinking about the metrics with reference to agile method. Below is a comprehensive summary of agile methods from my experience which provides a good foundation to understanding the metrics.

\subsubsection{Agile process}

- Stakeholders, senior management decide to initiate the agile process to build a product and allocate organizational resources for the project and give the go ahead.

- Agile Team members led by the scrum master work with each other closely to quickly implement a prototype of the product. The idea is to quickly build and present a minimum viable product to the customers/stakeholders so they can get a feel for it and give feedback on what needs changing. Proposed changes are prioritized for the 
next iteration/sprint and teams go back to working together aiming to release the next version of the product two weeks' time usually (the iteration time varies)

- The changes and new features for each iteration are known as user stories which are usually written in small sticky notes and displayed/tracked on a physical whiteboard. User stories can also be thought as product features to be implemented. The queue of unfinished user stories for the current sprint is called the backlog and stories in the sprint backlog are prioritized to aid team work on reducing backlog quickly. Unfinished stories at the end of the sprint are called technical debt and will either carry over to the next sprint or will be modified after feedback from stakeholders.

- After every sprint a process called releasing the software occurs which simply means engineers/software developers using tools at their disposal to processes and package the final product ready to be viewed by the stakeholders

- Above steps will repeat in cycles until the final product is ready for production release.

\subsubsection{Expanding the above discussion into SAFe metrics}

Product ownership - focus is on how involved is the product owner. Product owner has an active role to play in any agile team by collaborating with other stakeholders to develop user stories and story acceptance criteria. Product owner is also the main point of contact for other stakeholders when they want to query the status of the project.

Release - focus is on how well the each iteration or sprint is progressing. Questions around planning the release of testable product for the current iteration and whether the team delivers their sprint goals regularly.

Team - help measure level of self-organization, mutual trust and respect, collaboration, efficiency and effectiveness of teams which are key ingredients of a success of agile.

Technical - help measure how well teams reduce their technical debt, improve their technical abilities and knowledge of internal architecture of the product. 


\section{Chapter Four: Conceptual Model for the Research}

This chapter presents a complete conceptual framework for the study. It will also provide a detailed discussion on operationalization of each variable in the conceptual framework while establishing the details on hypotheses related to this study.

\subsection{Operationalization of Variables}

Taking a look back at the research question again given below, we set out the platform for the research using the conceptual framework in the section to follow.

\section{"How well does the current agile methodology work with outsourced software projects?"}

The research design will focus on a plan to investigate how well the agile methodology works with outsourced software projects. We build the part of the conceptual model for the research question as below. 
Ability to successfully apply agile project management principles and practices to a project

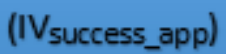

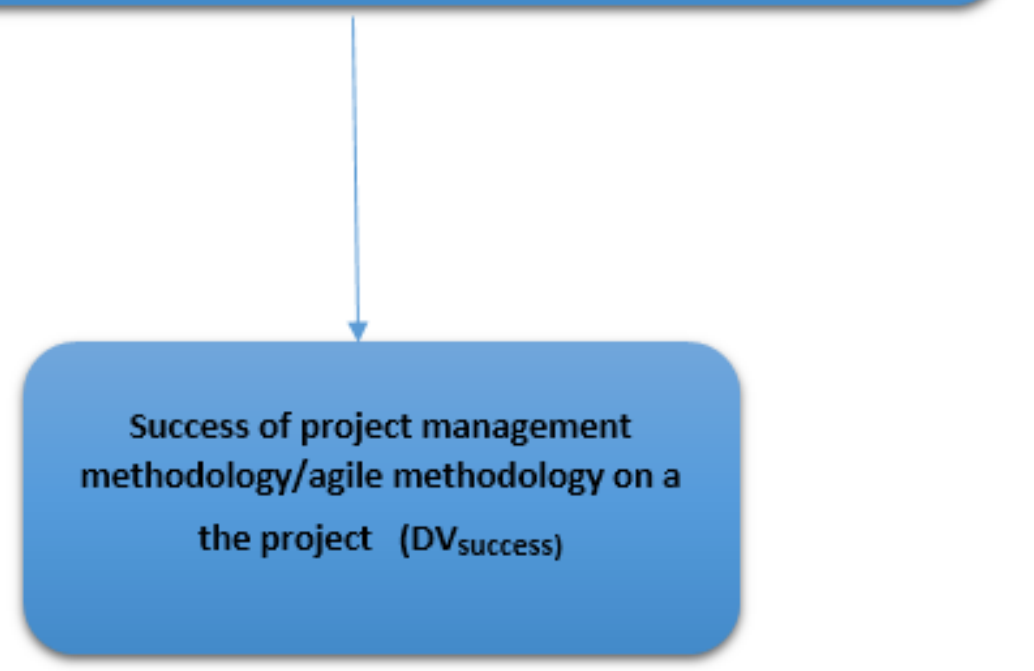

Figure 4-1 Conceptual model for independent variable (IV) 


\section{$\underline{\text { Operationalization of variable IV }} \underline{\text { success app }}$}

As backed by the related literature, we identified three major factors that can affect successful application of any project management method. Those three factors are distance, time and culture.

So variable Ivsuccess_app is modelled to be a collective function of all three variables distance gap, time gap and culture gap as shown in Figure 4-2 below.

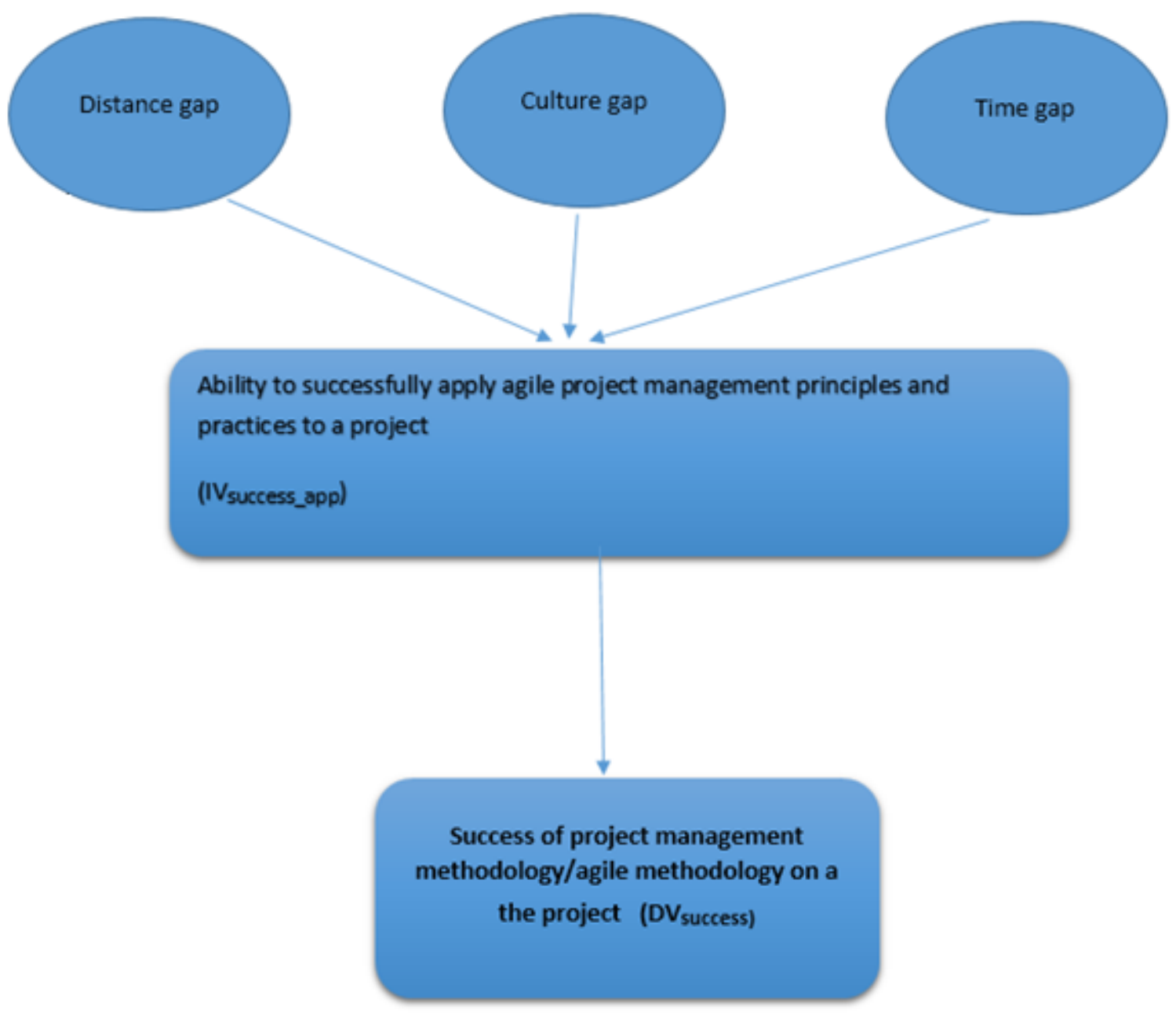

Figure 4-2 Conceptual model including both independent (IV) and dependent (DV) variables 
Hence we will now transform the conceptual model to have Success of Project management methodology to be a function of all three factors distance, time and culture gaps. Next we will discuss the operationalization of these three variables along with dependent variable.

\section{Operationalization of distance gap (physical distance)}

Distance gap $=>\mathrm{Kms}(\mathrm{IV})$

How far apart physically are the two teams in an outsourced project scenario measured in Kilometres or Miles. Questions (7) and (8) (see Appendix B) capture required information for the operationalization of these variables. Questions were carefully laid out not to ask actual distance in Kms from the participants as they would not readily know the answer, rather we would collect information about two countries and pre-process and transform that into actual distance in Kms.

\section{Operationalization of time gap (time zone difference)}

Time gap $=$ Hours $\left(I V_{T}\right)$

Distributed teams can be apart in time dimension by varying levels. We use hour as the unit of measurement. Time Gap is also worked out using the questions (7) and (8) by the country teams are located in. It's easier to think if time and distance are different forms of the same variable and reflects each other. In fact it's not. Consider two teams that come from New Zealand-Japan or Sri Lanka-Delhi. They are located too far apart in thousands of Kilometres but they both belong to the similar time zones. So the time gap really doesn't reflect the physical distance in scenarios like that. 


\section{Operationalization of culture gap (culture difference)}

Culture gap $=$ Read with Hofstede's tables $\left(\mathrm{IV}_{\mathrm{C}}\right)$

We use Hofstede's (1988) model to assign a numerical value to the culture gap. The Hofstede model has already been applied to many countries and readily available through their online tool. Country data we gather in the questionnaire can be applied and transformed into a numerical gap value with aid of Hofstede model. Hofstede used a tool now known as VSM (value survey model - see Appendix A) to collect data through a questionnaire which was then transformed into a numerical value through a set of equations. Hofstede model is widely used and feature in many studies.

\section{Operationalization of Success of Project Management Methodology (agile)}

We use a questionnaire as a tool to collect data for the dependent variable. Research is also designed to have a redundant question in the questionnaire which asks the participants to directly rate their experience or impression on how successful was using agile in an outsourced project scenario. We then use this as a strong verification data point with the data collected by the main set of questions which will include five categories identified as explained below. The questionnaire is solely based on a well-established assessment tool which is widely used by practitioners who follow scaled agile framework online resource (scaledagileframework.com, 2015).

As explained in the literature review this assessment is based on five metrics. They are,
1. Product ownership health
2. Technical health
3. Release health
4. Team health
5. Sprint health

Product ownership, technical, release, team and sprint health decides how successful agile in a project. By measuring these individual dependent variables through our survey tool we will be able to unearth a lot of useful facts with regard to correlations between them and three independent variables distance, time and culture. At the moment through literature we have 
established that there is a connection between independent and dependent variables in the conceptual model, but to what extent is something we don't know and that is a question the analysis of our data could reveal. Is there a factor out of the three independent variables that affect more than other two? It would be interesting to see what the answer is.

\section{Product ownership health (DV}

Measures the health of product ownership. Data will be collected through multiple questions each measured on a scale of 1 to 6,1 being the lowest score and 6 being the highest score. Score will then be averaged to arrive at the final score based on the same scale of 1 through 6.

\section{Release health (DV $r$ )}

Measures how well the releases are done. Same as above and the sibling variables, data will be collected through multiple questions each measured on a scale of 1 to 6,1 being the lowest score and 6 being the highest score. Score will then be averaged to arrive at the final score based on the same scale of 1 through 6 .

\section{$\underline{\text { Team health }(\mathrm{DV}} \underline{\underline{\mathrm{tm}})}$}

Measures how satisfied the team is overall. Data will be collected through multiple questions each measured on a scale of 1 to 6,1 being the lowest score and 6 being the highest score. Score will then be averaged to arrive at the final score based on the same scale of 1 through 6.

\section{Sprint health (DV $\mathrm{sp}$ )}

Sprint is a unit of work an agile team is doing during a short pre specified time period as discussed in literature sections above. Same scale as other sibling variables measure on a 1 6 range. 
Chapter Four: Conceptual Model for the Research

Technical health (DVtec)

Focus on technical aspects of the project and measure factors like technical debt movement. Identical scale as sibling variables measure 1 through 6.

Figure 4-3 below collates the entire conceptual framework so far into one diagram. 
Chapter Four: Conceptual Model for the Research

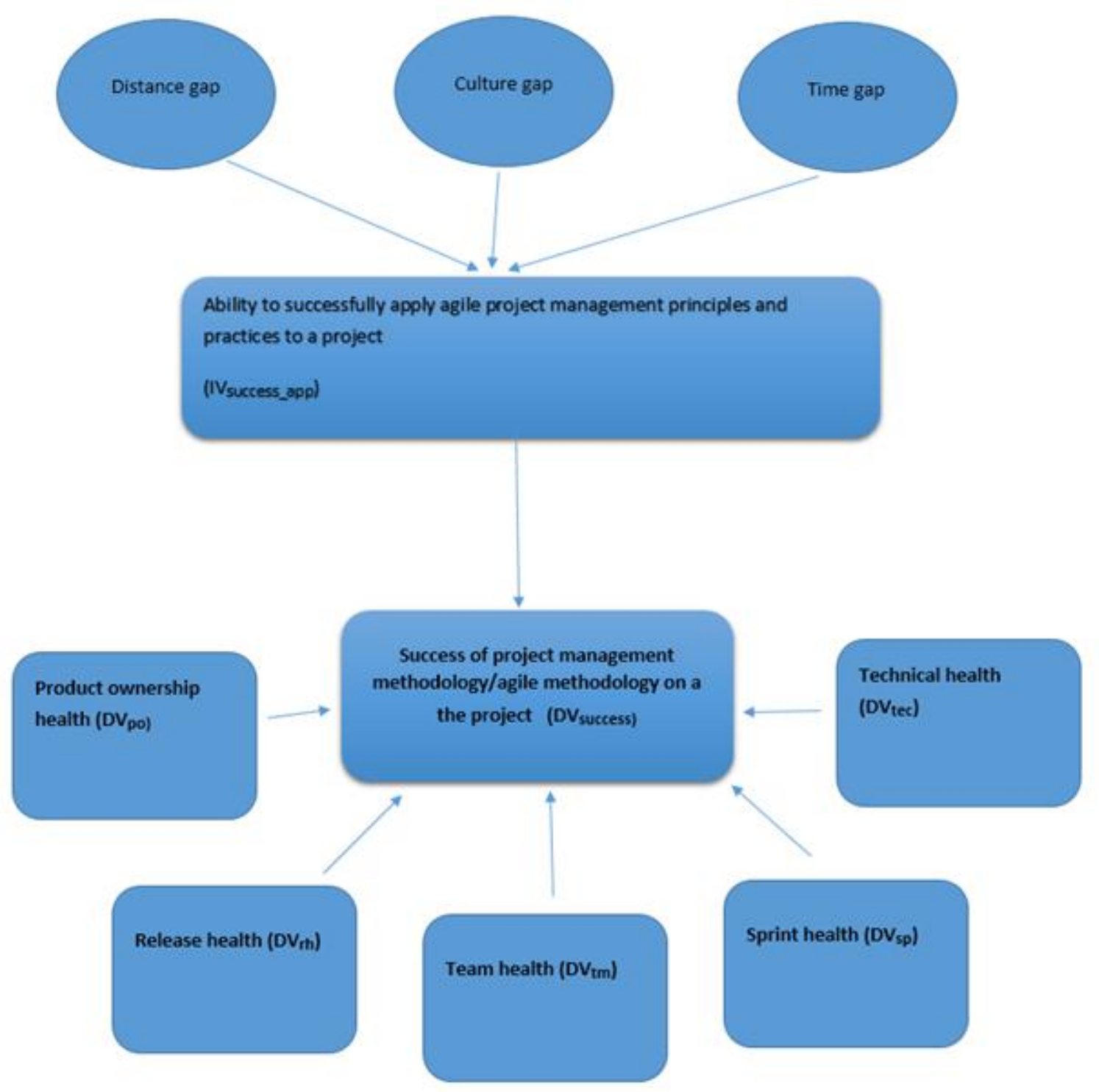

Figure 4-3 Conceptual model expanded to show composition of dependent variable 
To formulate a model to answer the question (section 1.3, question no: 4) "which principles are least likely to work with outsourced software projects?" I need to confirm my point of view of "which agile principles are likely to cause conflicts of interests with outsourced project settings". The following table is built in aid of that task. We will than make direct connection to the three independent variables considered above which are distance, time and culture gaps for each of the principle and mark which principles are likely to be affected by the one or more factors. The words that form these principles, current literature as we already have outlined in agile manifesto and my personal experience is used in identifying which of these principles are likely to be affected by three variables considered. A generic example of the table prepared for analysis is shown below in Table 4-1. A complete analysis is included in the discussion and conclusion chapter (Chapter 7).

\begin{tabular}{|l|l|l|l|}
\hline $\begin{array}{l}\text { Words in the } \\
\text { Principle }\end{array}$ & Distance & Time & \\
\hline $\begin{array}{l}\text { Close daily co- } \\
\text { operation between } \\
\text { team members }\end{array}$ & & & \\
\hline $\begin{array}{l}\text { Projects are built } \\
\text { around motivated } \\
\text { individuals, who } \\
\text { should be trusted }\end{array}$ & $\begin{array}{l}\text { Face to face } \\
\text { communication is the } \\
\text { best form of } \\
\text { communication (co- } \\
\text { location) }\end{array}$ & & \\
\hline $\begin{array}{l}\text { Self-organizing } \\
\text { teams }\end{array}$ & & & \\
\hline $\begin{array}{l}\text { Continuous attention } \\
\text { to technical } \\
\text { excellence }\end{array}$ & & & \\
\hline
\end{tabular}

Table 4-1 Tool to aid analyse principles against variables 
Chapter Four: Conceptual Model for the Research 
Quantitative data analysis techniques such as multiple regression analysis (Cavana, Delahaye, \& Sekaran, 2001) on three independent variables and the dependent variable will also reveal the significant level of each gap variable on success of agile in an outsourced project. We can then relate this directly to principles by using the above table as a tool to see which principles need more attention/ refinement or modification before been adopted for distributed teams in outsourced projects. For example Pearson's correlation analysis will reveal if each of independent variable has a significant effect on success of agile in an outsourced project. But multiple regression analysis will also be able to tell us which variable would have the strongest effect on the dependent variable (Cavana, Delahaye, \& Sekaran, 2001). We can then relate this to the most important principles that need to be thought of before blindly applying them to outsourced software projects.

That concludes the conceptual framework.

\subsubsection{Hypothesis Development}

Based on the research question posted earlier (section 1.3) research objectives are mapped to hypotheses as shown below,

1. To understand quantitatively, how well agile methodology is currently working with outsourced software projects following null $\left(\mathrm{H}_{0}\right)$ and alternative $\left(\mathrm{H}_{1)}\right.$ hypotheses are formed

$\mathrm{H}_{0}=$ Agile methodology only works at a $6 / 10$ rating or less with outsourced software projects

$H_{0}: \mu v_{\text {success }}<=0.6$

$H_{1}: \mu D_{\text {success }}>0.6$

2. To understand how much each variable physical distance, time, culture impact on success of agile methodology in outsourced projects, 
$\mathrm{H}_{0}=$ There is a significant correlation between physical distance and success of agile methodology in outsourced projects

$H_{0}: \rho_{\text {distance/DV }}=0$

$\mathrm{H}_{1}: \rho_{\text {distance/DV }} \neq 0$

Likewise hypotheses are devised for the remaining two independent variables as explained below,

$\mathrm{H}_{0}=$ There is a significant correlation between culture gap and success of agile methodology in outsourced projects

$H_{0}: \rho_{\text {culture/DV }}=0$

$H_{1}: \rho_{\text {culture/DV }} \neq 0$

$\mathrm{H}_{0}=$ There is a significant correlation between time zone difference and success of agile methodology in outsourced projects

$\mathrm{H}_{0}: \rho_{\text {time/DV }}=0$

$\mathrm{H}_{1}: \rho_{\text {culture/DV }} \neq 0$

3. To uncover if one variable is dominantly impacting the dependent variable over another as this might hint in at separating out principles into at least two groups indicating in what priority order detailed principles needs fixing from high priority to low priority.

$\mathrm{H}_{0}=$ any one independent variable doesn't have a dominant impact over others on the dependent variable

$H_{0}: \beta_{\text {distance }}=\beta_{\text {culture }}=\beta_{\text {time }}$ 
$H_{1}: \beta_{\text {distance }} \neq \beta_{\text {culture }} \neq \beta_{\text {time }}$

Once hypotheses are tested and decisions made on alternative and null hypotheses, resulting quantitative findings on three dimensions will then be related to agile principles to explore which principles are least likely to work in an outsourced software project and will therefore need some rethought. 


\section{Chapter Five: Methodology}

This chapter provides details around research methodology used including design of the research instrument, relationship of instrument questions to variables captured, validity and reliability of the instrument while also presenting the details on sample design and data collection.

\subsection{Initial Design of Research Instrument}

This section explains the contents of the instrument that is used in this study. This section will expand on how independent variables and dependent variables are measured. A questionnaire is used as the research instrument to allow measurements of all variables that are explained in detail in the conceptual framework section. Multitude of questions sourced from the Agile Survey (VersionOne, 2015), SAFe team assessment (Scaledagileframework.com, 2015) questionnaire and Ahimbisibwe, Cavana, \& Daellenbach's (2015) work along with a few custom questions comprised questions in the final questionnaire.

\section{Measuring distance}

As detailed in the section (4.1) operationalization of the variables we need to measure how far apart are two countries. To achieve this we include a question that collects input data about countries teams were from. This information is transformed into a distance value in kilometres using a well-known world distance map (Distance Calculator, 1995).

\section{Measuring time}


Data related to countries/cities vendor and client were from can be used to operationalize a value for time difference by referring to known time differences between countries (Time Zone Converter, 1995). This is measured in hours.

\section{Measuring culture gap}

Culture gap will be operationalized according to the Hofstede model (Geerthofstede.com, 2013) as explained in the section 4.1. The Hofstede model (1988) mentioned has been already applied to many countries in the world and really accurate data on culture difference along 5/6 dimensions are readily available through the web tool hosted by the website, Geert-hofstede.com (2013).

The values are available on dimensions of Hofstede model (1988) and two countries can be compared along each dimension. The score difference of each dimension of each variable can then be used to derive a final culture difference value.

\section{Measuring success of agile in outsourced projects.}

The dependent variable is operationalized based on the SAFe team assessment of ScaledAgileFramework (2015). The SAFe team assessment is based on 25 questions collected which are then averaged to derive the final value. The dimensions team health, technical health, sprint health, product ownership health and release health will be measured using 5 questions to reflect a value for each dimension in the SAFe. 


\subsection{Correlation of questions to variables measured}

Table below map each question in the instrument to its objective of being present in the questionnaire in terms of the subject data was collected on.

\begin{tabular}{|c|c|}
\hline Question number & Purpose Served \\
\hline $1,2,10,9,8$ & $\begin{array}{l}\text { For descriptive statistics and background } \\
\text { information (VersionOne, 2015) }\end{array}$ \\
\hline 3 & Reliability of data collected (VersionOne, \\
\hline 4,5 & 2015) \\
\hline 6,7 & $\begin{array}{l}\text { Measure independent variables distance } \\
\text { and time }\end{array}$ \\
\hline 12 & Measure product ownership health (SAFe) \\
\hline 13 & Measure Release health (SAFe) \\
\hline 14 & Measure Sprint health (SAFe) \\
\hline 15 & Measure Team health (SAFe) \\
\hline 16 & Measure technical health (SAFe) \\
\hline 17,18 & Comparison of statistical findings \\
\hline $19-23$ & $\begin{array}{l}\text { Custom made open ended question } \\
\text { collecting personal views }\end{array}$ \\
\hline
\end{tabular}

Table 5-1 Purpose served by questions in the instrument

\subsection{Validity and Reliability of Instrument}

Reliability and validity (Cavana, Delahaye, \& Sekaran, 2001) will be reflected on the overall quality of the chosen instrument for this research. Majority of the questions come from well-known sources like version one agile survey (VeriosnOne, 2015) and SAFe assessment (ScaledAgileFramework, 2015).

Data about the respondent's experience with agile and current usage within their respective firm are gathered to aid in understanding the accuracy of data collected. 
Higher number of respondents coming from good agile backgrounds will indicate higher quality than someone with less agile experience.

Data on required experience with at least one outsourced project to be considered as a valid data point for the purpose of this research, filters out any invalid data points coming from respondents who didn't have any outsourced agile experience. Their viewpoints as IT professionals around how things can be done better is valued and collected through questions 16-21.

\subsection{Sample Design}

This research is based on data gathered through a questionnaire hence a higher quality data set is highly valued. There are no restrictions as to where in the world respondents can come from as long as they have worked in at least one outsourced projects that involved agile methodology. This gives the research a high generalizability and a value as a plus. To accomplish this over 5000 accessible emails were retrieved from agile manifesto (2001) web resource.

It's impossible to figure out which of those addresses are still valid since they contain contacts as old as 15 years. Spelling mistakes in contacts given and invalid email addresses is expected. Hence the actual sample size will be well lower than 5000 and it's hard to say how many exactly beforehand.

The number of respondents naturally would be a small percentage from the intended audience but we aim to receive at least 100 responses to aid in our quantitative analysis. 


\subsection{Data Collection}

\section{Questionnaire Pilot}

A survey instrument evolved from a draft through various refinements was used in the pilot study. The questions that made up the instrument were sourced from multiple sources including Version One Agile Survey, SAFe assessment (ScaledAgielFramework.com, 2015) and Ahimbisibwe (2015). Survey was distributed among a subset of email contacts to have 25 participants return the survey. After data filtering and clean up, 15 responses were put through an initial analysis to confirm validity Cavana, Delahaye, \& Sekaran, 2001) of the instrument. As most questions came from existing well known sources there was a high likelihood of instrument being consistent and valid. Four personnel were contacted to get informal feedback on the survey/questionnaire. Among the received feedback were commonly 'the survey is too long' factor but the survey had to include all questions to allow collection of required data. However 25 questions from SAFe assessment was re-formatted (user interface only, no content, structure or scale changes) to fit in as 5 questions as most of them were asking a similar question under a different context. This helped give users ability to quickly traverse through the questions rather than reading 25 questions and improved the readability according to feedback received after enhancements.

Questionnaire included open ended questions to allow participants to provide feedback and general comments and these were taken into account towards finalizing the production ready version of the questionnaire.

\section{Questionnaire Go Live}

Final version of the questionnaire was distributed among the email addresses extracted as described in section 5.4 - sample design. Questionnaire was open for 3 weeks from $19^{\text {th }}$ October 2015 to $09^{\text {th }}$ November 2015. Stored data was then extracted from Qualtrics into SPSS format. 


\section{Chapter Six: Data Analysis, Results and Research Findings}

This chapter provides details on descriptive statistics and inferential statistics of the data analysed. Details on data analysis including correlation tests, simple and multiple regression tests on both linear and transformed variables, data preparation before analysis, reliability analysis of the instrument, hypothesis testing and conclusions from data analysis are also presented throughout the chapter.

\subsection{Quantitative Analysis of Survey Data}

\subsubsection{Hypothesis testing}

$I V_{D}-$ Because of the nature of data it's more suitable to treat physical distance data as Interval scale data. To be classified as interval we should be able to measure and order (increasing/ decreasing) each data point and clearly represent the interval between them numerically. Distance between two countries can easily be measured if we know the names of two countries.

$\mathrm{IV}_{\mathrm{T}}$ - Time difference is measured in hours or minutes $(\mathrm{h} / \mathrm{m})$. We treat these as interval scale data as opposed to ratio scale since this satisfies the similar conditions as distance.

IV $\mathrm{V}_{\mathrm{C}}$ - Retrieved through Hofstede (2013) model. Values are from 0 - 100 but normalization processes applied for the data narrows down the scale. Treated as interval scale data as values can be predictable values between 0-100 range which will include possibility of some decimal values between 0 and 100 . 
$\mathrm{DV}_{\text {success }}$ - Dependent variable, success of agile methodology in a project was averaged in over a scale between $1-6$ (refer section 5.2) which is the original scale used in the instrument. Nature of data is hence interval scale.

Based on the description of the nature of this data and hypotheses presented earlier, following statistical methods were chosen as the best fit method for the purpose of extracting information and give meaning to raw data. There are in-fact multiple ways of treating the data hence multiple possibilities of statistical method to use (section 7.2). However to keep a realistic scope in check for this research, only methods a) and b) below, were used.

a) Simple Regression analysis or Pearson correlation

Investigate the scale of relationship/direction to confirm relationship between distance, culture and time to success of agile methodology in outsourced projects.

b) Multiple regression analysis -

Helpful in analysing which variable out of all 3 distance, time and culture has the strongest impact on the success of agile methodology in outsourced projects. 


\subsection{Pre-processing data for initial analysis}

Refined questionnaire was distributed through an email list. Data collection window was 3 weeks and 111 responses were returned as a result. However not all responses were valid data points for the purpose of the study and had to be pre-processed and cleansed. Section below describes the process in detail.

All cases with unfinished flag (status) were removed. Unfinished flag indicates whether the questionnaire was continued to completion or not and for the purpose of the research it's important the respondent has completed the questionnaire for the response to be marked as a valid response there by weighing in for the final analysis and results.

A question for the respondent to indicate whether he/she has worked with agile methodology before is included and only the responses that came from people who've had experience in agile are counted towards the set of final analysis. This step helps towards eliminating invalid responses that come from professionals with no Agile experience which is important in this research as the questionnaire is based on a previous project the respondent has practiced Agile methodology.

Some data points had spelling mistakes in country names and these were obvious enough to be corrected to the correct response e.g. Spone was corrected to Spain and Oreland corrected to Ireland. Qualtrics feature which allows responses to be compulsory was used throughout the questionnaire when needed, so number of responses with missing values was very low. Whenever they were present was due to technical errors in Qualtrics and was removed from data analysis.

Survey completion times varied from 5 minutes to 55 minutes in general. The longer times could be due to the respondent having browser tab open for the survey for a while, then move on to some other work, come back after a while to submit the survey. The test runs indicated general survey completion time to be under 15 minutes if completed in a single attempt. 


\section{Data Normalization}

Following section discusses the min-max statistics of each variable time difference, culture difference and physical distance. These values were then used to normalize values for each variable to a 0-1 scale.

Culture difference - Hofstede Culture Difference tool (Hofstede, 2015) gives a country specific score for each dimension ( 5 or 6 dimensions). Score for each dimension was added up to derive culture score for each country and this figure was used to calculate the culture gap between any given two countries. An example illustrated below (Figure 6-1).

E.g. Culture comparison between Belgium and Brazil

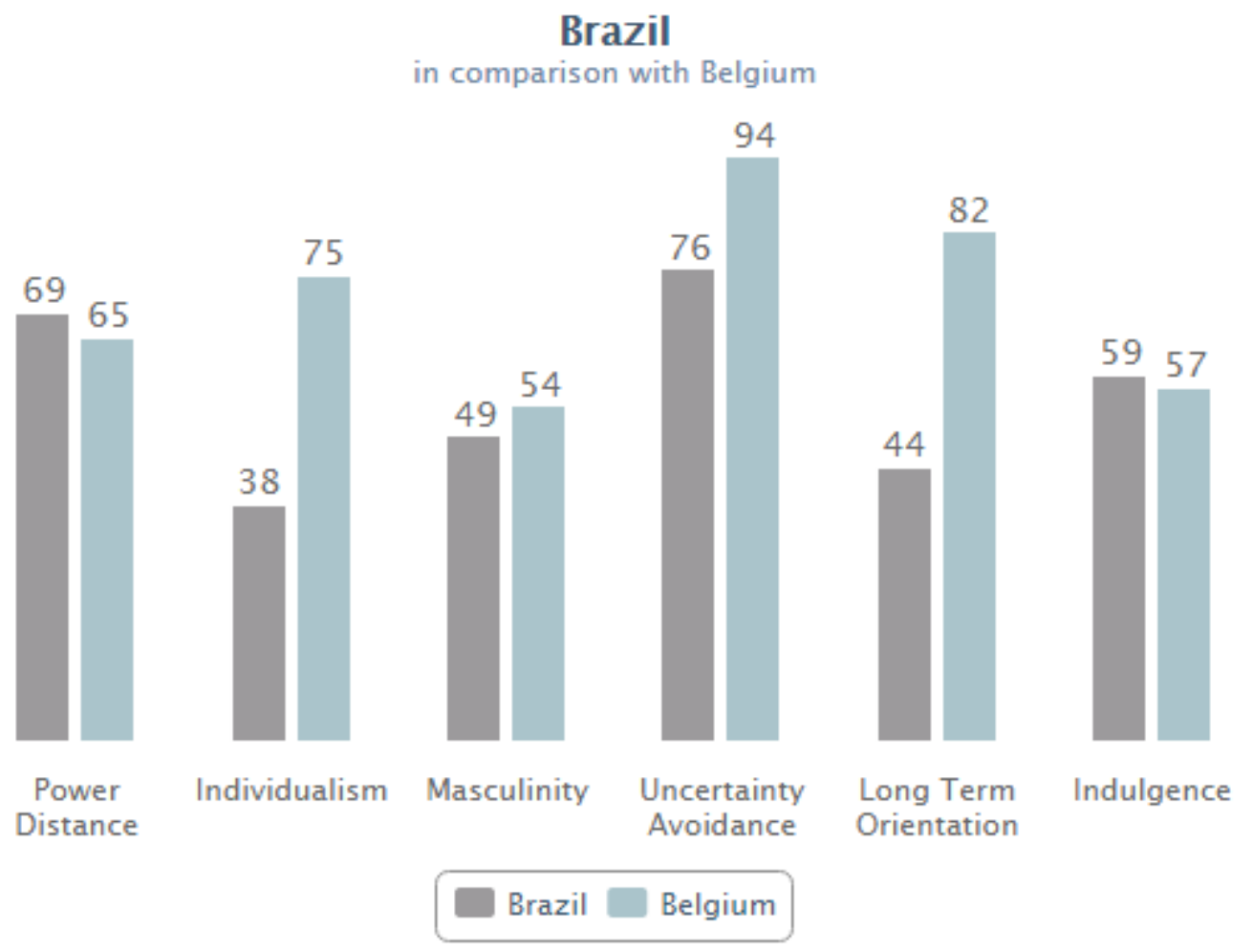

Figure 6-1 Country culture comparison example Source - (Geert-hofstede.com, 2013) 
According to the graph immediately above Brazil Scores $=>69+38+49+76+44+59=335$ where Belgium Scores $=>65+75+54+94+82+57=427$. Then the Culture gap between these countries would be 92 (427 - 335) which is a relative high value.

Culture gap values in the collected data ranged from 0 through to 127 as in Table 6-1 below.

\begin{tabular}{lr}
\multicolumn{2}{l}{ CultureDifference } \\
\hline $\mathrm{N} \quad$ Valid & 75 \\
& Missing \\
Mode & 0 \\
Range & .00 \\
Minimum & 127.00 \\
Maximum & .00 \\
\hline \hline
\end{tabular}

Table 6-1 Culture difference (descriptive statistics)

This information was then used to normalize Culture gap between a scale of $0-1$ using the common formulae,

$$
z_{i}=\frac{x_{i}-\min (x)}{\max (x)-\min (x)}
$$

$x_{i}$ is the raw data value where $z_{i}$ is the normalized data value

Physical Distance - Online services (Distance Calculator, 1995) were used to measure distance between two countries in kilometres. While pinpoint accuracy wasn't needed as the values were as large as $18000 \mathrm{~km}$, a good estimate was enough for the purpose of the research. The numbers retrieved through the online service were quite reliable. Table 6-2 below gives an idea of range of values, 


\begin{tabular}{|c|c|c|}
\hline \multicolumn{3}{|c|}{ PhysicalDistance } \\
\hline $\mathrm{N}$ & Valid & 75 \\
\hline \multicolumn{3}{|c|}{ Missing } \\
\hline Mc & & 12433.00 \\
\hline $\mathrm{Ra}$ & & 18567.00 \\
\hline Mi & mum & .00 \\
\hline $\mathrm{Ma}$ & imum & 18567.00 \\
\hline
\end{tabular}

Table 6-2 Physical distance (descriptive statistics)

Same normalization equation was applied to all data points to re-scale them between 0 and 1.

Time difference - Time difference between countries is available through multiple online sources and are extremely reliable and common these days. One such service (Time Zone Converter, 1995) was used to measure time zone difference in hours. Table 6-3 below gives an idea of what the value ranges were.

\begin{tabular}{|c|c|c|}
\hline \multicolumn{3}{|c|}{ TimeZoneDifference } \\
\hline \multirow[t]{2}{*}{$\mathrm{N}$} & Valic & 75 \\
\hline & Miss & 0 \\
\hline \multicolumn{2}{|c|}{ Mode } & .00 \\
\hline \multicolumn{2}{|c|}{ Range } & 20.00 \\
\hline \multicolumn{2}{|c|}{ Minimum } & .00 \\
\hline \multicolumn{2}{|c|}{ Maximum } & 20.00 \\
\hline
\end{tabular}

Table 6-3 Time zone difference (descriptive statistics) 


\subsection{Descriptive Statistics}

The first section of the questionnaire (Appendix B) aim to retrieve background information of participants to get an idea of the level of expertise, roles they act in, industries etc.

The pie chart below (Figure 6-1) gives a good visualization of distribution of respondents by Role. There seems to be an equal representation from all layers of organization hierarchy which is important for the research. Good equal spread through multiple roles means data points are less likely to skew towards a specific area due to biased opinion of each role. For example upper management might view the success of a project and how team worked from a high level management perspective biased towards impact of project on strategic goals whereas quality assurance professionals, developers and architects might view the project from a technical success viewpoint rather than from a management point of view. While there is no such hard and fast rule of representing project success it's important to include opinions from multiple perspectives, if the opinions are biased let them be biased from different perspective to negate the effect. 


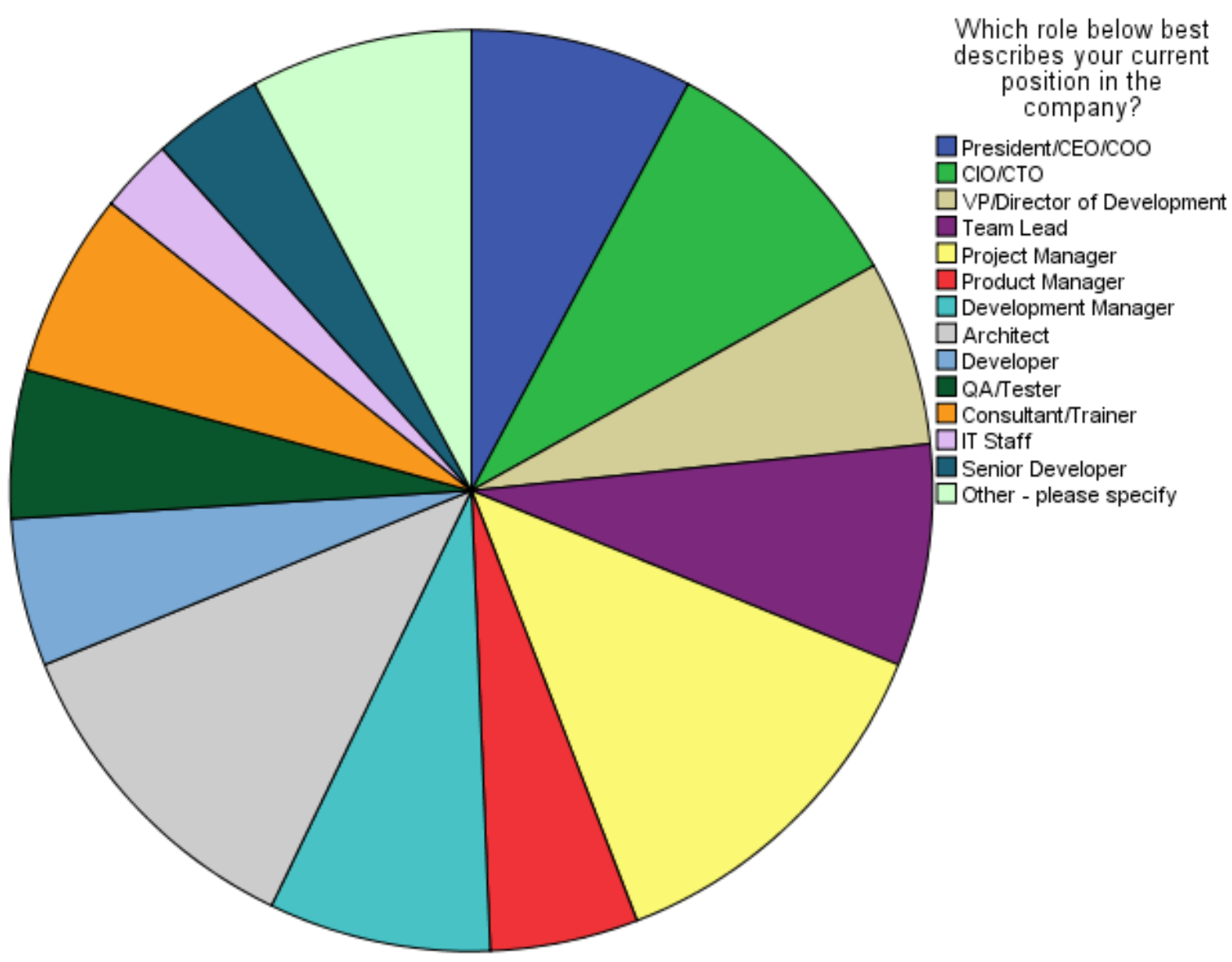

Figure 6-2 Respondents by role

According to numbers shown as per Table 6-4 below, project managers and Architects seem to occupy $12 \%$ each out of total responses. That is close to $25 \%$ total responses combined. Cumulative percentage of management representation accounts to $56 \%$ while cumulative representation of technical staff accounts for $44 \%$. This is ideal for reasons we speculated above around having roughly equal representation of opinions from both management and operational point of view. Other than the pre-defined categories there were also responses from scrum masters, agile coaches, developer consultants, enterprise transformation coach and a subject matter expert. 


\begin{tabular}{|c|c|c|c|c|c|}
\hline & & Frequency & Percent & $\begin{array}{l}\text { Valid } \\
\text { Percent }\end{array}$ & $\begin{array}{c}\text { Cumulative } \\
\text { Percent }\end{array}$ \\
\hline \multirow[t]{15}{*}{ Valid } & $\begin{array}{l}\text { President/CEO } \\
\text { /COO }\end{array}$ & 6 & 8.0 & 8.0 & 8.0 \\
\hline & $\mathrm{ClO} / \mathrm{CTO}$ & 6 & 8.0 & 8.0 & 16.0 \\
\hline & $\begin{array}{l}\text { VP/Director of } \\
\text { Development }\end{array}$ & 5 & 6.7 & 6.7 & 22.7 \\
\hline & Team Lead & 6 & 8.0 & 8.0 & 30.7 \\
\hline & $\begin{array}{l}\text { Project } \\
\text { Manager }\end{array}$ & 9 & 12.0 & 12.0 & 42.7 \\
\hline & $\begin{array}{l}\text { Product } \\
\text { Manager }\end{array}$ & 4 & 5.3 & 5.3 & 48.0 \\
\hline & $\begin{array}{l}\text { Development } \\
\text { Manager }\end{array}$ & 6 & 8.0 & 8.0 & 56.0 \\
\hline & Architect & 9 & 12.0 & 12.0 & 68.0 \\
\hline & Developer & 4 & 5.3 & 5.3 & 73.3 \\
\hline & $\mathrm{QA} / \mathrm{Tester}$ & 4 & 5.3 & 5.3 & 78.7 \\
\hline & $\begin{array}{l}\text { Consul tant/Tra } \\
\text { iner }\end{array}$ & 5 & 6.7 & 6.7 & 85.3 \\
\hline & IT Staff & 2 & 2.7 & 2.7 & 88.0 \\
\hline & $\begin{array}{l}\text { Senior } \\
\text { Developer }\end{array}$ & 3 & 4.0 & 4.0 & 92.0 \\
\hline & $\begin{array}{l}\text { Other - please } \\
\text { specify }\end{array}$ & 6 & 8.0 & 8.0 & 100.0 \\
\hline & Total & 75 & 100.0 & 100.0 & \\
\hline
\end{tabular}

Table 6-4 Respondent by role (descriptive statistics)

Responses on past, current and future usage of Agile were collected. Close to half of the accounted respondents (37) indicated that they are currently using Agile and plan to use in the future. $8 \%$ of respondents said they plan to stop using Agile in the future, as for why they are planning to do so could dependent on various reasons such as need for more structure and predictability for critical projects or/and regulations governing particular industries for example, nevertheless falls out of the scope of current research. Around $6 \%$ of the respondents indicated they are planning to take up Agile again, have used in the past but don't use in their current roles. 


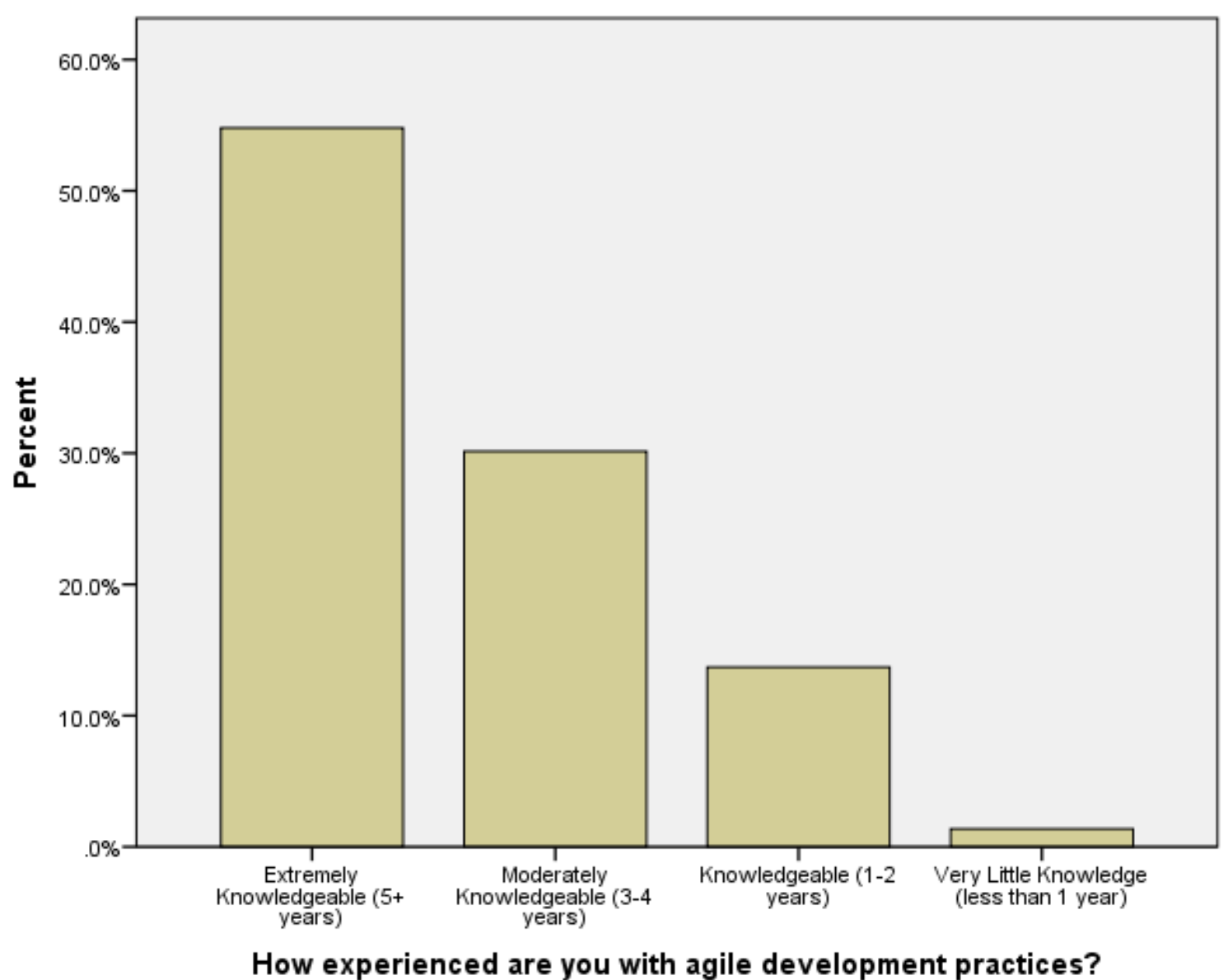

Figure 6-3 Experience with agile by number of years

Over $50 \%$ respondents has 5 or more years of experience with Agile according to Figure 6-2 above, while $30 \%$ had between 3 to 4 years of experience with Agile. $15 \%$ of the total respondents have 1-2 years of experience with Agile and only $2 \%$ of the respondents had very little knowledge. Collecting responses from respondents with as much agile experience is a key aim as doing so further strengthens the reliability of data. It's inevitable that respondents who can give most reliable information are the ones with more number of agile experiences under their belt. According to above chart $85 \%$ of our total response base comprised of highly reliable data points that came from people over 3 years of agile experience.

Information on whether the survey participant belonged to client's side or vendor's side was collected. It's important that our data set includes a fair representation from both client and vendor to be able to claim that data represents opinions from both perspectives which can be affected by various factors. E.g. from what I have seen in the industry client would expect 
the vendor to deliver the sprint/iteration deliverables on time and see it as a failure not to do so regularly whereas vendor wouldn't classify such small delays necessarily as an nonsuccess. Also our aim is to measure how well agile worked between client and vendor. It's healthy that we include equal representation from both vendor and client to refrain data from being biased towards one's perspective (hence unreliable). As per the graph below (Figure 6-3) it's clearly seen that $50.7 \%$ of the respondents belonged to a vendor role while $48 \%$ acted in Client role which is roughly a good $50 / 50$ spread between roles. One respondent didn't belong to either but acted as a mediator between the client and the vendor as he states "I have represented IBM but have also been at Client sites - participating in SCRUM of both client and vendor".

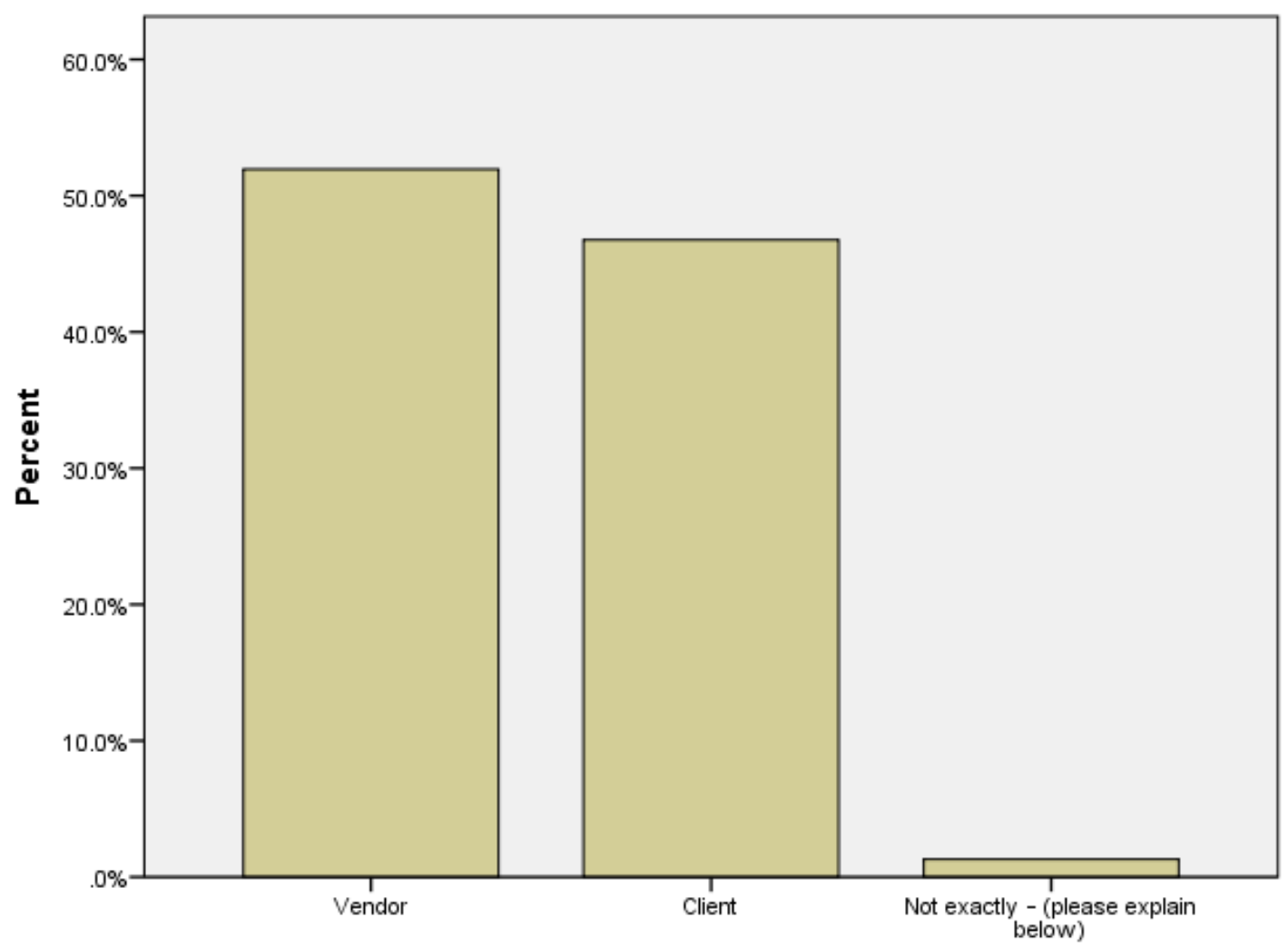

What was the role of the team which you belonged to in the outsourced project you referred above?

Figure 6-4 Percentage of vendors vs clients 
It was expected that respondents would come from teams of multiple sizes. To get an idea of the scale of projects we collected data pertaining to team sizes. Following is a brief summary of what teams look like. A wide variation can be seen around team sizes. Team sizes range from 700 through to 1 . The one could be a contractor who took up work for a client and worked with the client in an agile way. About $9 \%$ of the teams were bigger than 100 members and close to $15 \%$ were between $50-100$. Close to $75 \%$ of the teams are less than 50 members and around $49 \%$ would be teams with less than 15 heads. This is an important fact where smaller teams seem to be using more Agile methods over larger teams. One could relate this to other research in this area where arguments for and against have been made about scalability of agile for larger projects and teams. According to the agile manifesto (The Agile Alliance, 2001) and numerous Agile methods including Scrum, Kanban etc. involves having the whole team participate in minute details of implementation and low level decision making, often giving updates in the same room (co-location). With larger teams this becomes harder for obvious reasons. Pattern observed above is in-line with the arguments against scalability of agile where more smaller teams adopting the methodology over larger teams jumping in the agile bandwagon.

Above premise is also supported by the fact that client size which is a completely independent variable showing similar distribution to vendor. That is just $12 \%$ of client teams using agile were of sizes over 100 (in line with $9 \%$ in vendor teams) and $55.2 \%$ teams made up of 20 or lesser number of members which is identical to what's observed with the vendor teams (56.7\%). These independent convergences are strong evidence to state that smaller teams adopt agile more than larger teams.

However there were limitations around accessible populations in this research which hold back making conclusion around the matter above, this is not the scope of current research but there is room for further work. Mean vendor and client team sizes were about $36 \%$ and $38 \%$ respectively.

Next the types of industries related to agile projects chosen as subjects by respondents were looked at. As shown in Table 6-5 below both finance/Insurance and Software industries were dominant industry types with a total of $41.3 \%$ of projects in the dataset belonging to one of the two. Marketing/retail took away the next spot with $12 \%$ of projects coming from this 
domain. Among other industry types that didn't belong to a pre specified category were Telecom, CAD/CNC machinery, courthouse, book publishing, government/military, ERP, food, media and consumer electronics.

In what industry was the outsourced project you referred above conducted?

\begin{tabular}{lrrrr}
\hline & Frequency & Percent & $\begin{array}{c}\text { Valid } \\
\text { Percent }\end{array}$ & $\begin{array}{c}\text { Cumulative } \\
\text { Percent }\end{array}$ \\
\hline $\begin{array}{l}\text { Valid } \\
\text { Finance/Insuar } \\
\text { ance }\end{array}$ & 13 & 17.3 & 17.3 & 17.3 \\
Manufacturing & 1 & 1.3 & 1.3 & 18.7 \\
Marketing/ret & 9 & 12.0 & 12.0 & 30.7 \\
ail & & & & \\
Health & 6 & 8.0 & 8.0 & 38.7 \\
Consulting & 2 & 2.7 & 2.7 & 41.3 \\
Software & 18 & 24.0 & 24.0 & 65.3 \\
Transportation & 4 & 5.3 & 5.3 & 70.7 \\
Utility & 2 & 2.7 & 2.7 & 73.3 \\
Education & 6 & 8.0 & 8.0 & 81.3 \\
Other - please & 14 & 18.7 & 18.7 & 100.0 \\
specify & 75 & 100.0 & 100.0 & \\
Total & & & & \\
\hline \hline
\end{tabular}

Table 6-5 Respondents by industry

While respondents came from different regions of the world India, USA, Argentina, Brazil, Germany, Ireland topped the list. US, Ireland, India and Brazil are well known to be engagers in outsourcing and the statistics back the already known. USA is known to be a big player in software industry which uses agile as a preferred project management method that has also been an early adopter during Agile's rise to fame. Countries like India and Brazil on the other hand are known to be receiver of contractual work from outsourcers like US. Hence what's observed above can be explained using what is intuitively known about the nature of the industry. Rather than having an unfavourable skew to a specific region dataset is seen to be 
sourced from respondents in different parts of the world. This is important for generalization of the conclusions.

Standard deviation, mean, minimum and maximum values of three independent variables of interest before normalization are shown in Table 6-6 below.

\begin{tabular}{|l|l|l|l|l|}
\hline Variable & Mean & Std. Deviation & Minimum & Maximum \\
\hline $\begin{array}{l}\text { Culture } \\
\text { difference }\end{array}$ & 22.79 & 26.43 & 0 & 127 \\
\hline $\begin{array}{l}\text { Time difference } \\
\text { (hours) }\end{array}$ & 4.96 & 5.26 & 0 & 20 \\
\hline Distance $(\mathrm{km})$ & 6363.54 & 7772 & 18567 & 0 \\
\hline
\end{tabular}

Table 6-6 Descriptive statistics for all three independent variables

Mean value culture difference is around 23 which is at the lower end between 0 and 127 which indicates that most vendor-client connections involve moderate culture differences. Mean time difference is around 5 hours and distance around $6363 \mathrm{kms}$. These values combined with range gives an idea of spread of the data.

\subsection{Reliability Analysis}

Questions that measured success of agile were sourced from SAFe assessment (ScaledAgileFramework.com, 2015) which is an established questionnaire; nevertheless a reliability test was carried out to re-confirm that this was the case. Cronbach's alpha test was employed to derive the reliability value. Table 6-7 below summarizes the result. 


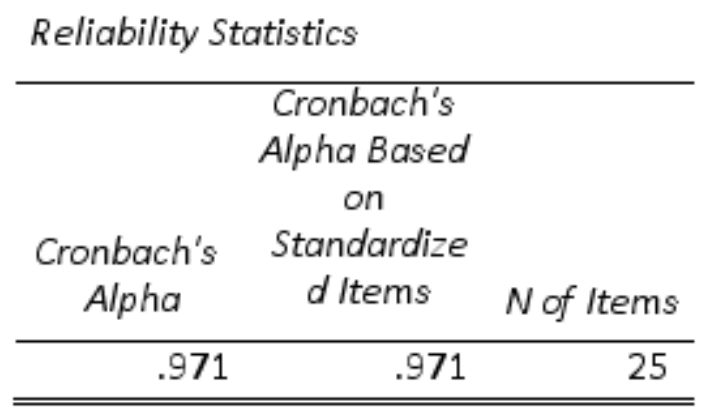

Table 6-7 Reliability Test for the Instrument

Cronbach's alpha is a high value (.971). This indicates that all 25 questions in fact measure the same variable consistently. Reliability can be viewed from two perspectives. On one hand it is impacted by the structural integrity and consistency of the questionnaire. On the other hand it will also depend on what source has been used this instrument with or whether the correct audience was targeted. Hence as explained in a previous section (6.2) dataset included responses by people who has worked with agile long enough or has enough exposure for the questionnaire to provide useful data.

Questions that measures independent variables measure the variables straight away with country names without going through intermediary scales, hence highly reliable to measure the variable correctly. Please refer questionnaire appended at the end (Appendix B). 


\subsection{Correlational analysis}

A correlational analysis between each independent variable and the dependent variable was carried out. Pearson correlation coefficient is a measure of direction and strength of a possible association that exists between two variables. Behind the scenes Pearson correlation tries to draw a line of best fit through data points and measure how far the data points are from all these lines. Correlation coefficient is the indication of how well the data points fit the line of best fit.

\subsubsection{Culture difference vs Success of agile in Outsourced Projects}

\begin{tabular}{|c|c|c|c|}
\hline & & $\begin{array}{c}\text { CultureDiffe } \\
\text { rence }\end{array}$ & $\begin{array}{c}\text { AgileSucces } \\
\text { sScore }\end{array}$ \\
\hline \multirow[t]{3}{*}{$\begin{array}{l}\text { Cul tureDiffere } \\
\text { nce }\end{array}$} & $\begin{array}{l}\text { Pearson } \\
\text { Correlation }\end{array}$ & 1 & $-.241^{7}$ \\
\hline & Sig. (2-tailed) & & .038 \\
\hline & $\mathrm{N}$ & 75 & 75 \\
\hline \multirow[t]{3}{*}{$\begin{array}{l}\text { AgileSuccessS } \\
\text { core }\end{array}$} & $\begin{array}{l}\text { Pearson } \\
\text { Correlation }\end{array}$ & $-.241^{*}$ & 1 \\
\hline & Sig. (2-tailed) & .038 & \\
\hline & $\mathrm{N}$ & 75 & 75 \\
\hline
\end{tabular}

*. Correlation is significant at the 0.05 level (2tailed).

Table 6-8 Pearson Correlation between Culture Difference and Success of Agile in Outsourced Projects

Table 6-8 indicates the results of the test. As indicated by number -0.241 , it is evident that there is a good correlation in the inverse direction between culture difference and success of agile in outsourced projects at .05 confidence level $(.05>0.038)$. Put in other words this means higher the culture gap the lesser success agile has in outsourced projects. 
Based on analysis above (section 6.5.1) the null hypothesis can be rejected as the alternative hypothesis $\rho_{\text {culture/DV }} \neq 0$ is supported and additionally gives a sense of magnitude of the relationship in numerical terms.

\subsubsection{Time difference vs Success of agile in Outsourced Projects}

\section{Correlations}

\begin{tabular}{llrr}
\hline & & $\begin{array}{c}\text { AgileSucces } \\
\text { sScore }\end{array}$ & $\begin{array}{c}\text { TimeZoneDi } \\
\text { fference }\end{array}$ \\
\hline AgileSuccessS & Pearson & 1 & -.222 \\
core & Correlation & & .056 \\
& Sig. (2-tailed) & & 75 \\
& $\mathrm{~N}$ & 75 & 1 \\
\hline TimeZoneDiffe & Pearson & -.222 & \\
rence & Correlation & & \\
& Sig. (2-tailed) & .056 & 75 \\
\hline \hline & $\mathrm{N}$ & 75 & \\
\hline
\end{tabular}

Table 6-9 Pearson Correlation between Time zone Difference and Success of Agile in Outsourced Projects (2-tailed)

As indicated in test results above (Table 6-9) there is no significant correlation between time and success of agile in outsourced project at the $95 \%$ confidence level since Sig. $=.056$ is slightly above .05 . However it can be argued that there is a good correlation between independent and dependent variable at the $90 \%$ confidence level (is sig<0.10).

In addition, since the above was a two tailed Pearson correlation test and its already known to us that the relationship between time zone difference and dependent variable in unidirectional one tailed Pearson correlation test was performed on the same pair of variables and the results are summarized below (Table 6-10). 


\section{Correlations}

\begin{tabular}{llrr}
\hline & & $\begin{array}{c}\text { AgileSucces } \\
\text { sScore }\end{array}$ & $\begin{array}{l}\text { TimeZoneDi } \\
\text { fference }\end{array}$ \\
\hline AgileSuccessS & Pearson & 1 & $-.222^{*}$ \\
core & Correlation & & .028 \\
& Sig. (1-tailed) & & 75 \\
& $\mathrm{~N}$ & 75 & 1 \\
\hline TimeZoneDiffe & Pearson & $-.222^{*}$ & \\
rence & Correlation & & \\
& Sig. (1-tailed) & .028 & 75 \\
& $\mathrm{~N}$ & 75 & \\
\hline \hline
\end{tabular}

*. Correlation is significant at the 0.05 level (1tailed).

Table 6-10 Pearson Correlation between Time zone Difference and Success of Agile in Outsourced Projects (1-tailed)

Results indicate there is a significant negative correlation between the two variables at the $95 \%$ confidence level when tested via a one-tailed test (Table 6-10). Since this is a negative correlation it indicates that larger the time zone difference between teams less likely of agile to be a success between the teams.

However since there is a need to keep measures consistent enough across all three variables, only a $95 \%$ confidence interval is accepted under 2 -tailed test, hence null hypothesis $\rho_{\text {time/DV }}$ $=0$ is accepted.

\subsubsection{Physical distance vs Success of agile}

Lastly a two tailed Pearson correlation test was applied to only remaining independent variable physical distance and the dependent variable. According to the results below there is a good negative correlation between physical distance and success of agile in outsourced projects at a $99 \%$ confidence interval (Table 6-11). 


\section{Correlations}

\begin{tabular}{llrr}
\hline & & $\begin{array}{c}\text { AgileSucces } \\
\text { sScore }\end{array}$ & $\begin{array}{c}\text { PhysicalDist } \\
\text { ance }\end{array}$ \\
\hline $\begin{array}{l}\text { AgileSuccessS } \\
\text { core }\end{array}$ & $\begin{array}{l}\text { Pearson } \\
\text { Correlation }\end{array}$ & 1 & $-.365^{* *}$ \\
& Sig. (2-tailed) & & .001 \\
& $\mathrm{~N}$ & 75 & 75 \\
\hline $\begin{array}{l}\text { PhysicalDistan } \\
\text { ce }\end{array}$ & Pearson & $-.365^{* *}$ & 1 \\
& Correlation & & \\
& Sig. (2-tailed) & .001 & \\
& $\mathrm{~N}$ & 75 & \\
\hline \hline & $* * *$ Correlation is significant at the 0.01 level (2- \\
tailed). & &
\end{tabular}

Table 6-11 Pearson Correlation between Physical Distance and Success of Agile in Outsourced Projects

The results are quite promising and provides us with good leads into further statistical analysis such as regression, as physical distance is more highly correlated with project success at the $99 \%$ confidence level compared to time and culture.

Based on the correlation analysis above we reject the null hypothesis $\rho_{\text {distance/DV }}=0$ since there is a significant negative (inverse) correlation between the independent and dependent variables and decide that alternative hypothesis stands true.

The tests so far has indicated and provided us quantitative support of the nature of relationships that exists between independent variables and dependent variables in the dataset. It has also provided information on the direction of the relationship.

The next step, regression analysis was carried out for all combinations between independent and dependent variables. Regression analysis is equipped with a mechanism which could indicate a proper strength between an independent variable and its dependent variable (Cavana, Delahaye, \& Sekaran, 2001). All regression coefficients found can then be compared to devise conclusions as to which independent variable has the strongest impacts on the 
dependent variable and which independent variable impacts the least over dependent variable. Following sections elaborate details of results of this set of statistical tests.

\subsection{Linear regression analysis}

A core aim behind this research work was to find out which variable/variables out of culture difference, time difference and physical distance predominantly affect the success of agile in outsourcing project. So it's particularly important all 3 independent variables show some correlation towards the dependent variable. Independent variables physical distance and culture difference has shown strong correlation to the dependent variables with time zone difference showing a slightly weaker correlation. However correlation tests so far has been promising and been in line with what's already known and provided formal groundings to informal knowledge floating in Agile project management literature. Since all three variable show some correlation towards the dependent variable, linear regression analysis was done between each bi-variate combination. Linear regression is typically used after correlation and used to predict one variable using another.

\subsubsection{Culture difference as the predictor}

Both normality tests Kolmogorov-Smirnoc and Shapiro-Wilk tests reveal that agile success score (the dependent variable) is approximately normally distributed against the independent variable culture difference. This is an important enabling point for most of statistical tests. The $p$-values revealed by the tests are all above .05 which confirms the positivity of normality test.

Analysis of three main variables with results from regression analysis are summarized below. 


\begin{tabular}{lrrrr}
\hline Model & $R$ & $R$ Square & $\begin{array}{c}\text { Adjusted } R \\
\text { Square }\end{array}$ & $\begin{array}{c}\text { Std. Error of } \\
\text { the } \\
\text { Estimate }\end{array}$ \\
\hline 1 & $.241^{\mathrm{a}}$ & .058 & .045 & .27228 \\
\hline \hline
\end{tabular}

a. Predictors: (Constant), Norm_Cul ture_Diff

Table 6-12 Model Summary - Culture

$R$ value of .241 (Table 6-12) indicates a moderate degree of correlation between predictor and dependent variable. Looking further through the ANOVA results below (Table 6-13), it can be said that regression model for culture difference predicts the dependent variable significantly well. This is backed by $p(=0.038)<0.05$ or being significantly lower value than .05 .

\begin{tabular}{|c|c|c|c|c|c|c|}
\hline \multicolumn{2}{|c|}{ Model } & \multirow{2}{*}{$\begin{array}{r}\begin{array}{l}\text { Sum of } \\
\text { Squares }\end{array} \\
.333\end{array}$} & \multirow{2}{*}{$\frac{d f}{1}$} & \multirow{2}{*}{$\begin{array}{r}\begin{array}{l}\text { Mean } \\
\text { Square }\end{array} \\
.333\end{array}$} & \multirow{2}{*}{$\frac{F}{4.489}$} & \multirow{2}{*}{$\begin{array}{c}\text { Sig. } \\
.038^{\mathrm{b}}\end{array}$} \\
\hline 1 & Regression & & & & & \\
\hline & Residual & 5.412 & 73 & .074 & & \\
\hline & Total & 5.745 & 74 & & & \\
\hline
\end{tabular}
a. Dependent Variable: AgileSuccessScore
b. Predictors: (Constant), Norm_Cul ture_Diff

Table 6-13 ANOVA - Culture

Finally building on top of what's observed so far, coefficients shown below (Table 6-14) aid in forming a mathematical relationship between culture difference and success of agile in outsourced projects which can be established at a 95\% confidence interval, Success of Agile in Outsourced Projects $=0.636-(0.322)$ Culture Difference 


\begin{tabular}{|c|c|c|c|c|c|c|}
\hline \multirow{2}{*}{\multicolumn{2}{|c|}{ Model }} & \multicolumn{2}{|c|}{$\begin{array}{c}\text { Unstandardized } \\
\text { Coefficients }\end{array}$} & \multirow{2}{*}{$\begin{array}{c}\text { Standardize } \\
d \\
\text { Coefficients } \\
\text { Beta }\end{array}$} & \multirow[b]{2}{*}{$t$} & \multirow[b]{2}{*}{ Sig. } \\
\hline & & $B$ & Std. Error & & & \\
\hline \multirow[t]{2}{*}{1} & (Constant) & .636 & .042 & & 15.281 & .000 \\
\hline & $\begin{array}{l}\text { Norm_Cul ture } \\
\text { _Diff }\end{array}$ & -.322 & .152 & -.241 & -2.119 & .038 \\
\hline
\end{tabular}

a. Dependent Variable: AgileSuccessScore

Table 6-14 Culture difference - Regression Results

\subsubsection{Time difference as the predictor}

Both normality tests Kolmogorov-Smirnoc and Shapiro-Wilk tests reveal that agile success score (the dependent variable) is approximately normally distributed against the independent variable time difference as most sig. values lie above .05 level.

Next, regression analysis between time difference and dependent variable was employed which resulted in following model summary values.

\begin{tabular}{lcrrr}
\hline Model & $R$ & $R$ Square & $\begin{array}{c}\text { Adjusted } R \\
\text { Square }\end{array}$ & $\begin{array}{c}\text { Std. Error of } \\
\text { the } \\
\text { Estimate }\end{array}$ \\
\hline 1 & $.222^{\mathrm{a}}$ & .049 & .036 & .27355 \\
\hline \hline
\end{tabular}

a. Predictors: (Constant), Norm_Time_Diff

Table 6-15 Model Summary - Time zone difference

$\mathrm{R}$ value of .22 (Table 6-15) above indicates a moderate degree of correlation between predictor and dependent variable. Looking further through the ANOVA results below, it can be said that regression model for time difference does not predicts the dependent variable well within the $95 \%$ confidence interval as $p(=.056)>.05$. P value is slightly higher than the .05 however it doesn't stop stating that time difference will moderately predict independent variable within a $90 \%$ confidence interval. However to keep the measures consistent across 
all three independent variables, one could argue that Time does not have such a significant correlation with the dependent variable. This matter can be argued in both ways but a passive approach of simply presenting what's found in the data analysis is with all possible options is followed here.

Looking further through the ANOVA results below (Table 6-17), it can be said that regression model for time difference does not predict the dependent variable well within the $95 \%$ confidence interval as $p(=.056)>.05$. $P$ value is slightly higher than the .05 however it doesn't stop stating that time difference will moderately predict independent variable within a $90 \%$ confidence interval. Again what's found and present in data is passively presented here.

ANOVA

\begin{tabular}{|c|c|c|c|c|c|c|}
\hline \multicolumn{2}{|c|}{ Model } & \multicolumn{2}{|l|}{ Sum of } & \multicolumn{3}{|l|}{ Mean } \\
\hline \multirow[t]{3}{*}{1} & Regression & .144 & 1 & .144 & 3.771 & $.056^{b}$ \\
\hline & Residual & 2.780 & 73 & .038 & & \\
\hline & Total & 2.923 & 74 & & & \\
\hline
\end{tabular}
a. Dependent Variable: AgileSuccessScore
b. Predictors: (Constant), Norm_Time_Diff

Table 6-16 ANOVA - Time zone difference

For completeness the mathematical representation of a possible relationship between time difference and success of agile in outsourced project is formed using information captured in coefficients table below (Table 6-18), 


\section{Coefficients $^{a}$}

\begin{tabular}{|c|c|c|c|c|c|c|}
\hline \multirow{2}{*}{\multicolumn{2}{|c|}{ Model }} & \multicolumn{2}{|c|}{$\begin{array}{c}\text { Unstandardized } \\
\text { Coefficients }\end{array}$} & \multirow{2}{*}{$\begin{array}{c}\text { Standardize } \\
d \\
\text { Coefficients } \\
\text { Beta }\end{array}$} & \multirow[b]{2}{*}{$t$} & \multirow[b]{2}{*}{ Sig. } \\
\hline & & $B$ & Std. Error & & & \\
\hline 1 & (Constant) & .637 & .044 & & 14.615 & .000 \\
\hline & $\begin{array}{l}\text { Norm_Time_Di } \\
\mathrm{ff}\end{array}$ & -.235 & .121 & -.222 & -1.942 & .056 \\
\hline
\end{tabular}

a. Dependent Variable: AgileSuccessScore

Table 6-17 Time zone Difference - Regression Results

Success of Agile in Outsourced Projects $=0.637+(-0.235)$ Time difference

\subsubsection{Physical distance as the predictor}

Lastly physical distance was considered for lining up against the dependent variable for statistical tests. For physical distance, both normality tests Kolmogorov-Smirnoc and ShapiroWilk tests reveal that agile success score (the dependent variable) is approximately normally distributed against the independent variable time difference as most sig. values lie above .05 level.

Regression analysis between the physical distance and dependent variable was then employed, which resulted in following model summary values (Table 6-19).

Model Summary

\begin{tabular}{lcrrr}
\hline & & & & Adjusted $R$ \\
Model & $R$ & $R$ Square & $\begin{array}{c}\text { Std. Error of } \\
\text { Square }\end{array}$ & Estimate \\
\hline 1 & $.365^{\mathrm{a}}$ & .133 & .122 & .26114 \\
\hline \hline
\end{tabular}

a. Predictors: (Constant), Norm_Phy_Dist

Table 6-18 Model Summary - Physical Distance

$R$ value of 0.365 indicates a good correlation between predictor and dependent variable. $R$ value in this instance with physical distance as the independent variable is higher than both $R$ 
values resulted in for culture and time as the predictor variable which were respectively .241 and .222 respectively. $R$ squared in the current instance is also higher than both culture and time combined which in other words means variation of independent variable, agile success in outsourced projects can be explained stronger than both independent variables culture distance and time difference combined. Arguments for physical distance is further supported by the revelations of ANOVA results below.

\begin{tabular}{lrrrrrr}
\multicolumn{1}{l}{ ANOVA $^{a}$} \\
\hline \multicolumn{2}{l}{ Model } & $\begin{array}{l}\text { Sum of } \\
\text { Squares }\end{array}$ & \multicolumn{1}{c}{ df } & $\begin{array}{l}\text { Mean } \\
\text { Square }\end{array}$ & $F$ & Sig. \\
\hline 1 & Regression & .767 & 1 & .767 & 11.241 & $.001^{\mathrm{b}}$ \\
& Residual & 4.978 & 73 & .068 & & \\
& Total & 5.745 & 74 & & & \\
\hline \hline
\end{tabular}

a. Dependent Variable: AgileSuccessScore

b. Predictors: (Constant), Norm_Phy_Dist

Table 6-19 ANOVA - Physical Distance

ANOVA (Table 6-20) indicates that physical distance as the independent variable is capable of explaining variations of agile success in outsourced projects with a $99 \%$ confidenceinterval as the $p$ values is a low 0.001 which is a really lower value than 0.05 .

For further clarity the histogram (Figure 6-4) of residuals is also included as further proof of stronger ground of applicability of physical distance and towards its relationship with dependent variable as the residuals are normally distributed. 


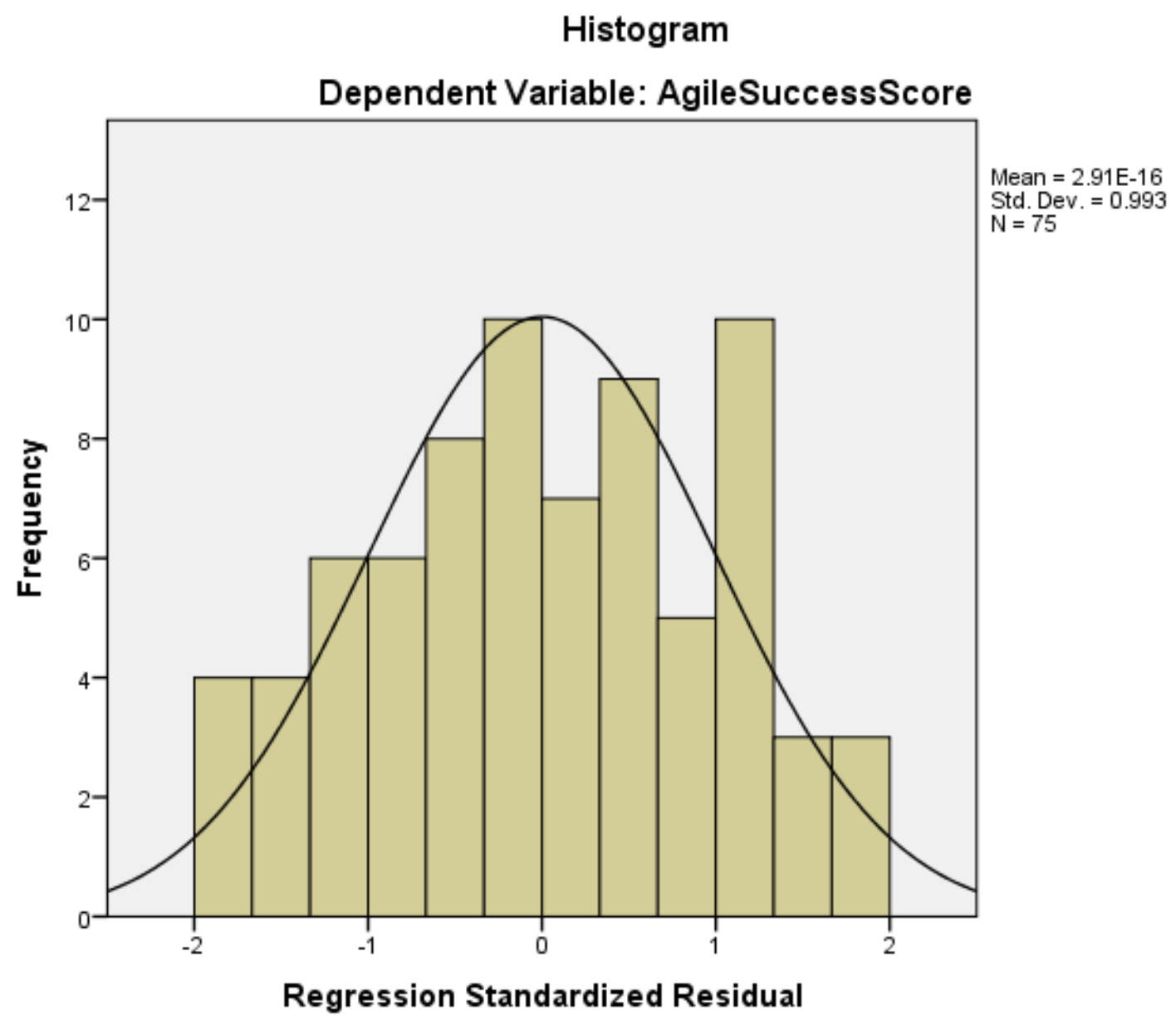

Figure 6-5 Error Residuals of Regression Analysis with Physical Distance as the Predictor

With all above analysis backing up a strong case for physical distance the relationship can be mathematically using coefficients presented below (Table 6-21).

\section{Coefficients $^{a}$}

\begin{tabular}{|c|c|c|c|c|c|c|}
\hline \multirow{2}{*}{\multicolumn{2}{|c|}{ Model }} & \multicolumn{2}{|c|}{$\begin{array}{c}\text { Unstandardized } \\
\text { Coefficients }\end{array}$} & \multirow{2}{*}{$\begin{array}{c}\text { Standardize } \\
d \\
\text { Coefficients } \\
\text { Beta }\end{array}$} & \multirow[b]{2}{*}{$t$} & \multirow[b]{2}{*}{ Sig. } \\
\hline & & $B$ & Std. Error & & & \\
\hline \multirow[t]{2}{*}{1} & (Constant) & .693 & .046 & & 15.198 & .000 \\
\hline & $\begin{array}{l}\text { Norm_Phy_Dis } \\
\mathrm{t}\end{array}$ & -.335 & .100 & -.365 & -3.353 & .001 \\
\hline
\end{tabular}

a. Dependent Variable: AgileSuccessScore

Table 6-20 Regression Analysis - Physical Distance 
Success of Agile in Outsourced Projects $=(-.335)$ Physical distance +0.693

\subsubsection{Multiple Regression Analysis}

While regression analysis with individual independent variables provide important insights relevant to this research, multiple regression analysis combining all three independent variables were employed next to test the last hypotheses and the results are summarized below (Table 6-22).

Model Summary

\begin{tabular}{lcrrr}
\hline Model & $R$ & $R$ Square & $\begin{array}{c}\text { Adjusted } R \\
\text { Square }\end{array}$ & $\begin{array}{c}\text { Std. Error of } \\
\text { the } \\
\text { Estimate }\end{array}$ \\
\hline 1 & $.416^{\mathrm{a}}$ & .173 & .138 & .25872 \\
\hline \hline
\end{tabular}

a. Predictors: (Constant), Norm_Time_Diff, Norm_Culture_Diff, Norm_Phy_Dist

Table 6-21 Model Summary - Multiple Regression

Model summary signals an $\mathrm{R}$ value of .416 which is a good indication of effectiveness of all three independent variables in predicting the dependent variable. Further looking into $R$ square value (.17) is higher than any of the individual $R$ square values of independent variables. Highest square value comes to a .13 for physical distance predictor and clearly .17 $>$.13. Hence a good indication that all three variables combined do a better job at predicting the dependent variables than by individually themselves alone.

Expanding on the results of ANOVA table (Table 6-23) it can be clearly seen that the above stated relationship of all 3 IVs and the DV is statistically significant at a 95\% confidence interval as the $p=.004$. 
ANOVA ${ }^{a}$

\begin{tabular}{|c|c|c|c|c|c|c|}
\hline \multicolumn{2}{|c|}{ Model } & $\begin{array}{l}\text { Sum of } \\
\text { Squares }\end{array}$ & $d f$ & $\begin{array}{l}\text { Mean } \\
\text { Square }\end{array}$ & $F$ & Sig. \\
\hline 1 & Regression & .992 & 3 & .331 & 4.941 & $.004^{b}$ \\
\hline & Residual & 4.752 & 71 & .067 & & \\
\hline & Total & 5.745 & 74 & & & \\
\hline
\end{tabular}

a. Dependent Variable: AgileSuccessScore

b. Predictors: (Constant), Norm_Time_Diff, Norm_Culture_Diff, Norm_Phy_Dist

Table 6-22 ANOVA - All three variables

Table 6-25 below summarizes the coefficients for all 3 independent variables towards the dependent variable and the relationship can be mathematically stated as below.

Coefficients $^{a}$

\begin{tabular}{|c|c|c|c|c|c|c|c|c|}
\hline \multirow{2}{*}{\multicolumn{2}{|c|}{ Model }} & \multirow{2}{*}{\multicolumn{3}{|c|}{$\begin{array}{c}\text { Standardize } \\
d \\
\text { Coefficients } \\
\text { Beta }\end{array}$}} & \multirow[b]{2}{*}{$t$} & \multirow[b]{2}{*}{ Sig. } & \multicolumn{2}{|c|}{$\begin{array}{c}95.0 \% \text { Confidence Interval } \\
\text { for B }\end{array}$} \\
\hline & & & & & & & $\begin{array}{l}\text { Lower } \\
\text { Bound }\end{array}$ & $\begin{array}{l}\text { Upper } \\
\text { Bound }\end{array}$ \\
\hline \multirow[t]{4}{*}{1} & (Constant) & .713 & .048 & & 14.843 & .000 & .617 & .809 \\
\hline & $\begin{array}{l}\text { Norm_Phy_Dis } \\
\mathrm{t}\end{array}$ & -.485 & .176 & -.530 & -2.753 & .007 & -.837 & -.134 \\
\hline & $\begin{array}{l}\text { Norm_Culture } \\
\text { _Diff }\end{array}$ & -.198 & .152 & -.148 & -1.304 & .196 & -.501 & .105 \\
\hline & $\begin{array}{l}\text { Norm_Time_Di } \\
\mathrm{ff}\end{array}$ & .269 & .202 & .254 & 1.336 & .186 & -.133 & .671 \\
\hline
\end{tabular}

a. Dependent Variable: AgileSuccessScore

Table 6-23 Multiple Regression - All Three Variables

Success of Agile in Outsourced Projects $=(-.485)$ Physical distance $+(-.198)$ Culture difference $+(.269)$ Time difference +0.713 
From results above it can now established that regression coefficients, $\beta_{\text {distance }}(=-0.485) \neq$ $\beta_{\text {culture }}(=-0.198) \neq \beta_{\text {time }}(=0.269)$. Hence null hypothesis can be rejected and alternative hypothesis below accepted.

$H_{1:} \beta_{\text {distance }} \neq \beta_{\text {culture }} \neq \beta_{\text {time }}$

To accomplish one of the main goals of this study, that is to learn whether there is any one dominant independent variables which impacts on the dependent, a hypothesis as shown above was devised earlier. Looking at the magnitudes of the regression coefficients above it can now be established that physical distance $(0.485)$ has a dominant impact on deciding how successful agile methodology will be in outsourced projects.

There are a few interesting facts to be noted from above analysis. It was seen earlier with individual correlation tests that time difference had the weakest correlation with the dependent variable and time difference is expected to have a negative correlation with dependent variable. Results above where time variable ended up with a positive coefficient and a weak significance further supports what was seen with individual correlation tests.

Since it can be argued that culture difference would take precedence on level of impact on success of agile in outsourced projects as culture difference could predict the dependent variable within a $95 \%$ confidence interval as opposed to $90 \%$ confidence interval for time, an extra test that omitted time from the multiple regression analysis was also carried out. As per the results of this (Table 6-25) test it can be seen $R$ squared value only had a slight change from around $17 \%$ to $15 \%$ which indicates that Culture and Physical distance can be used to model the change in success of agile in outsourced project relatively well. 
Model Summary

\begin{tabular}{|c|c|c|c|c|}
\hline Model & $R$ & $R$ Square & $\begin{array}{c}\text { Adjusted } R \\
\text { Square }\end{array}$ & $\begin{array}{c}\text { Std. Error of } \\
\text { the } \\
\text { Estimate }\end{array}$ \\
\hline 1 & $.390^{\mathrm{a}}$ & .152 & .128 & .26013 \\
\hline
\end{tabular}

a. Predictors: (Constant), Norm_Culture_Diff, Norm_Phy_Dist

Table 6-24 Multiple Regression Physical Distance and Time

Nevertheless it can be concluded that physical distance between teams strongly predicts and become the dominant factor in deciding how successful adopting agile in outsourced projects.

\subsection{So how well has agile done so far with outsourced software projects?}

To answer that question, summary statistics of the data collected through that part of the instrument are looked at.

\begin{tabular}{lr}
\multicolumn{2}{l}{l Statistics } \\
\multicolumn{2}{l}{ Agile_Success } \\
\hline $\mathrm{N} \quad$ Valid & 75 \\
\multicolumn{1}{l}{ Missing } & 0 \\
Mean & .5783 \\
Median & .6636 \\
Std. Deviation & .27862 \\
Range & 1.00 \\
Minimum & .00 \\
Maximum & 1.00 \\
\hline \hline
\end{tabular}

Table 6-25 Mean of Agile Success Score 
As discussed in the research methodology (chapter 5) we used an instrument based on five health factors (team, technical, release, sprint, product ownership) to measure the dependent variable. Each factor had a total score of 30 and the entire section of the instrument (section 5.2) that measured the dependent variable which had 25 questions (5 questions for each factor) which added up to a total points of 150 which was used in calculating the final AgileSuccessScore. In the pre-processing stage further normalization was applied on this data to project every data point onto a 0 -1 scale which above (Table 6-26) summary statistics relate to.

To easily interpret what a mean value of 0.578 describes, this mean value was decoded back into its original form (Scale of 1 to 6 ) as below.

Original scale of $1-6=0.58 \times 6=3.48$

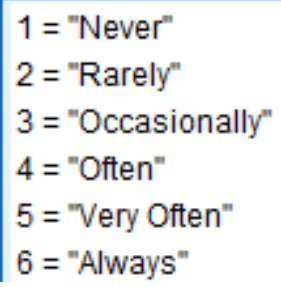

It can be seen that value 3.48 is between 3 and 4 with a slight lean towards 3 . In the domain language of the context this observation interprets as below. The average response for questions in all of 25 question measuring the dependent variable was between occasionally and often with a lean towards 'occasionally' if we round 3.48 to the nearest integer. In other words teams didn't always do well in all departments that were needed for successful execution and application of agile methodology in projects. They didn't completely fail either, rather occasionally complied with the practices that results in better application of agile. So what stopped them from sticking to best practices $100 \%$ of the time? They are the factors physical distance, culture difference and time difference with physical distance playing the main role.

Translate the above score in to $1-10$ scale with 1 being 'agile doesn't work at all' and 10 being 'agile works very well all the time' as shown below,

$0.58 * 10=5.8$ 
This results in a rating for how well does agile works with outsourcing which is 5.8 out of 10 . Hence based on what is observed above we accept the null hypotheses (refer section operationalization of variables) for Hypotheses \#1.

$$
\begin{aligned}
& H_{0}: \mu D V_{\text {success }}<=0.6 \\
& H_{1}: \mu_{D V_{\text {success }}}>0.6
\end{aligned}
$$

\subsection{Validity of conclusions}

There were two ways to measure the dependent variable with different reliabilities. They are,

1. Use a tested instrument to measure the variable

2. Ask respondents to indicate the success of agile on a scale such as a 5 point Likert scale.

The former would be the most reliable way accounted for individual questions as an instrument goes through reliability tests before being put into use and often is tried and tested. Hence data collected through such instruments are quite reliable. In the case of this research, an existing instrument (ScaledAgileFramework.com, 2015) based on 25 questions was used to measure how successful agile methodology in outsourced projects has been.

The latter approach takes the form of getting respondents to indicate a value for the same dependent variable on a scale. The reliability of this form obviously is quite subjective over the former approach as values represented are pure perception of success of individual respondent as there are no multiple questions which try to minimize the subjective bias of perception of a concept like success of a project or a project management methodology or any other variable.

Does that mean latter shouldn't be used? Yes and no it shouldn't be used for the sole purpose of measuring a variable but acts as a fine complementary measure of reliability of the values recorded by the former method, the instrument. Hence we included a question that asks each respondent to indicate their perception of success of agile in outsourced projects. The idea was to compare the results of the instruments side by side with the results of the one off question mentioned above and the results are summarized below. 
Values were measured on a six point interval scale below,

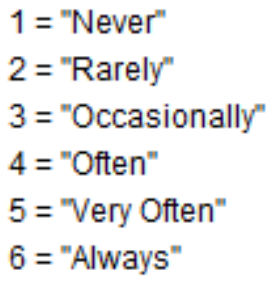

The mean value of data points for how much physical distance affected success of agile in projects according to gut feeling of respondents is 3.45 with a standard deviation of 1.6.

\begin{tabular}{|c|c|c|}
\hline \multirow[t]{2}{*}{$N$} & Valid & 75 \\
\hline & Missing & 0 \\
\hline \multicolumn{2}{|c|}{ Mean } & 3.45 \\
\hline \multicolumn{2}{|c|}{ Median } & 3.00 \\
\hline \multicolumn{2}{|c|}{ Std. Deviation } & 1.646 \\
\hline \multicolumn{2}{|c|}{ Range } & 5 \\
\hline \multicolumn{2}{|c|}{ Minimum } & 1 \\
\hline \multicolumn{2}{|c|}{ Maximum } & 6 \\
\hline
\end{tabular}

Table 6-26 Opinion on physical distance

This indicates that respondents in general thought that physical distance affected success of project more than occasionally. As $4>3.45>3$ indicates. Similarly mean value of how much respondents though time zone difference affected success of agile in outsourced projects was 2.92 a value less than 3 and greater than 2 but more skewed towards value 3 . This translates into that respondents in general thought that time zone difference occasionally affected the success of agile methodology in outsourced projects. 


\begin{tabular}{lr}
\hline $\mathrm{N}$ & \multicolumn{1}{c}{ Valid } \\
Missing & 0 \\
Mean & 2.92 \\
Median & 3.00 \\
Std. Deviation & 1.531 \\
Range & 5 \\
Minimum & 1 \\
Maximum & 6 \\
\hline \hline
\end{tabular}

Table 6-27 Opinion on time difference

Finally analysis of descriptive statistics for what respondents felt about culture differences between teams impacting projects highlights a mean value of 2.93. In the current research context this translates into that respondents in general felt that culture difference occasionally affected the success of the project.

\begin{tabular}{|c|c|c|}
\hline \multirow[t]{2}{*}{$N$} & Valid & 75 \\
\hline & Missing & 0 \\
\hline \multicolumn{2}{|c|}{ Mean } & 2.93 \\
\hline \multicolumn{2}{|c|}{ Median } & 3.00 \\
\hline \multicolumn{2}{|c|}{ Std. Deviation } & 1.528 \\
\hline \multicolumn{2}{|c|}{ Range } & 5 \\
\hline \multicolumn{2}{|c|}{ Minimum } & 1 \\
\hline \multicolumn{2}{|c|}{ Maximum } & 6 \\
\hline
\end{tabular}

Table 6-28 Opinion on culture difference

Notice the mean of culture related variable and time zone related variable subjected above. It can be observed that $\mu_{\text {culture }}>\mu_{\text {time }}$. To be accurate the mean values are slightly different from each other where $\mu_{\text {culture (2.93) }}$ is slightly larger than $\mu_{\text {time (2.92) }}$.

The observations so far with these one off questions around time, culture and distance which extracted the overall perception from respondents are in line with what instrument has revealed. To break it down, instrument data revealed earlier that physical distance as the dominant factor having the biggest impact on success of agile in outsourced projects which is

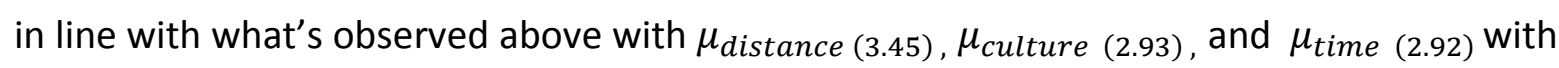
the current validation analysis. 
Hence it can confidently be concluded that physical distance in fact is the dominant factor in deciding how successful agile as a project management method is going to be in an outsourcing scenario.

\subsection{Additional Data analysis}

This section subjects the collected data to a few other statistical tests to see if there are better relationships (other than linear) between independent and dependent variables.

When subjected to curve estimation culture difference yields results below (Figure 6-6).

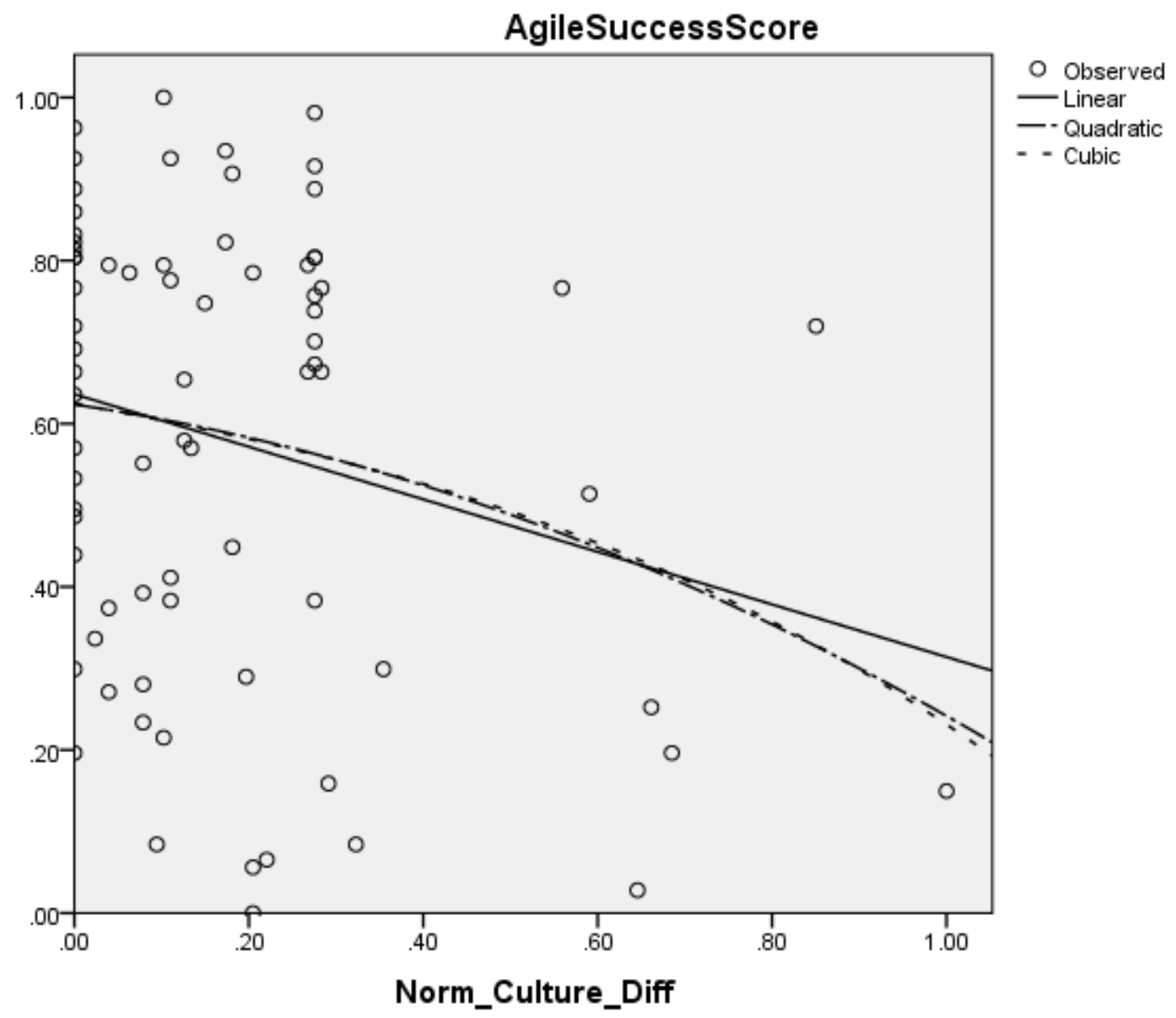

Figure 6-6 Curve estimation with Culture difference 
Both quadratic and cubic curves have a slight improvement on $\mathrm{R}$ squared with high sig values hence no statistical significance (See Appendix D).

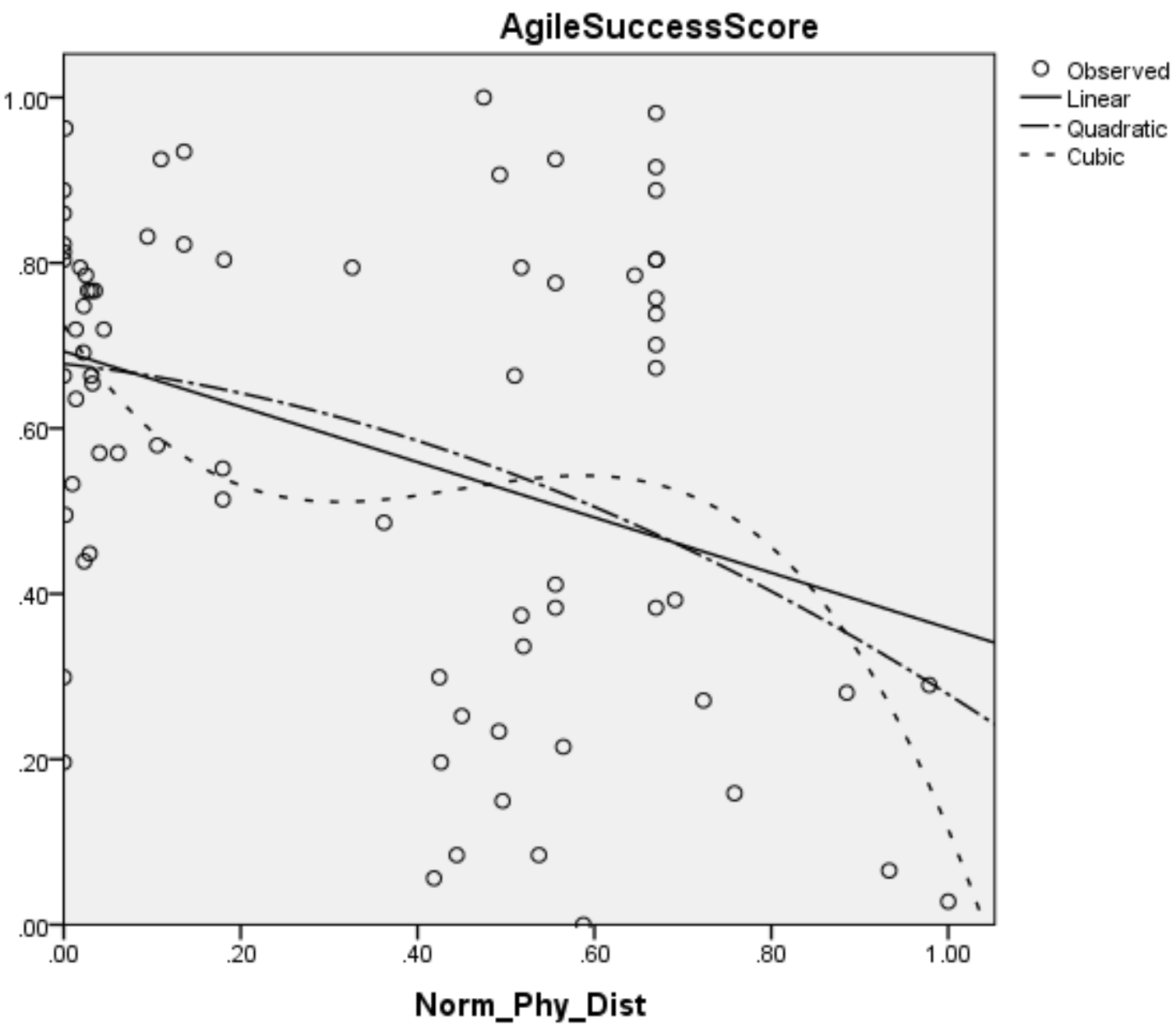

Figure 6-7 Curve estimation for physical distance

Curve estimation for physical distance (Figure 6-7) yields a better significance value (.001) for linear model which is slightly better than significance value of cubic model (.003) but cubic curve seems to yield a better $\mathrm{R}$ squared value over linear model. More work will be needed to see which one out of cubic and linear models better explain physical distance. Nevertheless physical distance has a significant statistical correlation to success in both models as shown by 'sig' values (See Appendix D). 


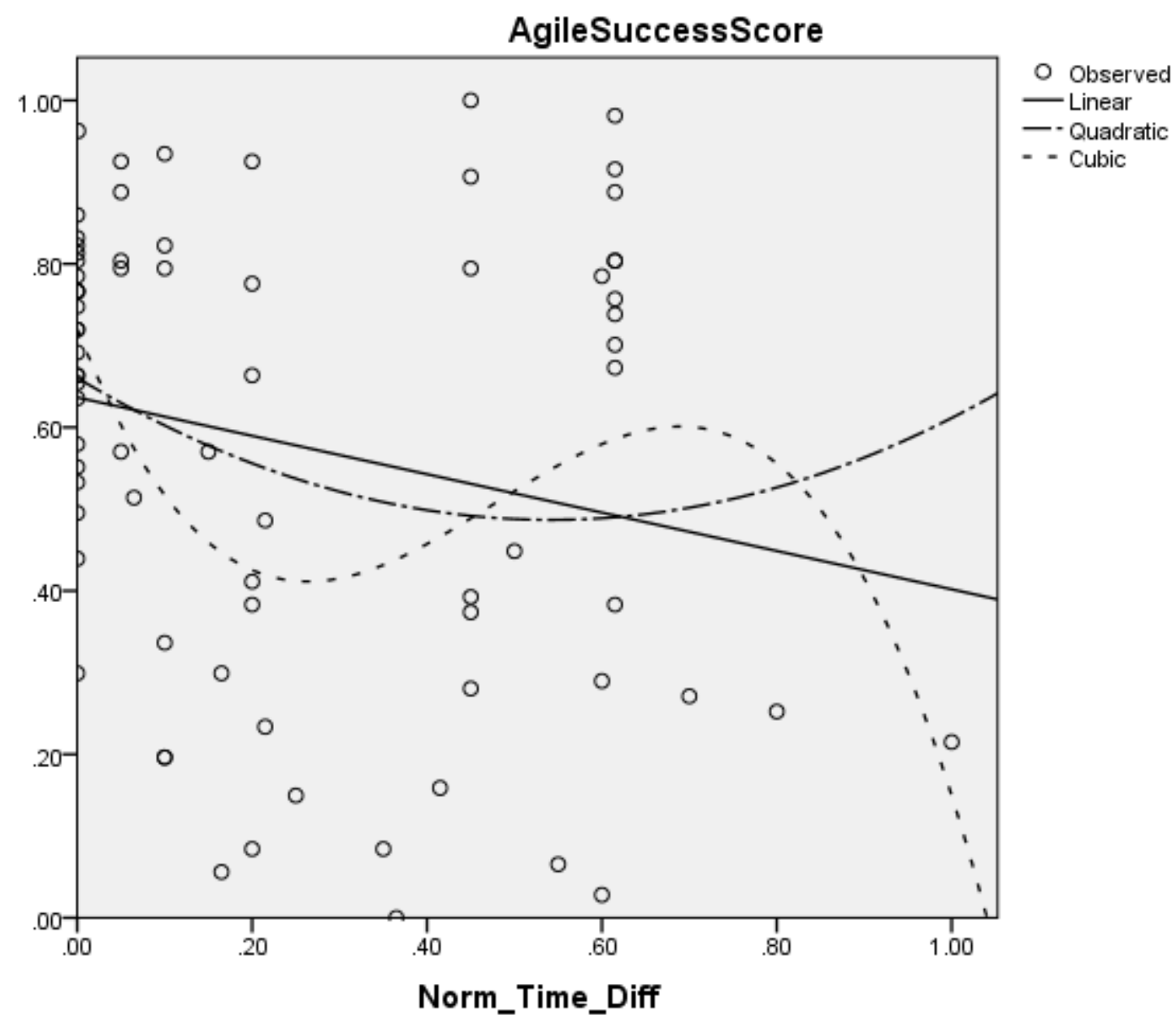

Figure 6-8 Curve estimation with time difference

Curve estimation with time difference reveals a better $\mathrm{R}$ squared (.18) and better significance for cubic model over linear model. But as shown above (Figure 6-8) a Sin wave doesn't explain what is commonly known about time difference and dependent variable. This could be due to high correlation between time and distance and distance dominantly controlling the success even when teams come from same time zone, essentially making it harder for time zone to act as a good predictor for dependent variable. 


\section{Correlations}

\section{Correlations}

\begin{tabular}{llrrrr}
\hline & & $\begin{array}{c}\text { Norm_Cultu } \\
\text { re_Diff }\end{array}$ & $\begin{array}{r}\text { Norm_Time } \\
\text { _Diff }\end{array}$ & $\begin{array}{r}\text { Norm_Phy_ } \\
\text { Dist }\end{array}$ & $\begin{array}{r}\text { AgileSucces } \\
\text { sScore }\end{array}$ \\
\hline $\begin{array}{l}\text { Norm_Cul ture } \\
\text { _Diff }\end{array}$ & Pearson & 1 & $.270^{*}$ & $.305^{* *}$ & $-.241^{*}$ \\
& Correlation & & & & \\
& Sig. (2-tailed) & & .019 & .008 & .038 \\
& $\mathrm{~N}$ & 75 & 75 & 75 & 75 \\
\hline $\begin{array}{l}\text { Norm_Time_D } \\
\text { iff }\end{array}$ & Pearson & $.270^{*}$ & 1 & $.823^{* *}$ & -.222 \\
& Correlation & & & & \\
& Sig. (2-tailed) & .019 & & .000 & .056 \\
& N & 75 & 75 & 75 & 75 \\
\hline Norm_Phy_Dis & Pearson & $.305^{* *}$ & $.823^{* *}$ & 1 & $-.365^{* *}$ \\
t & Correlation & & & & \\
& Sig. (2-tailed) & .008 & .000 & & .001 \\
& N & 75 & 75 & 75 & 75 \\
\hline AgileSuccessS & Pearson & $-.241^{* *}$ & -.222 & $-.365^{* *}$ & 1 \\
core & Correlation & & & & \\
& Sig. (2-tailed) & .038 & .056 & .001 & \\
& N & 75 & 75 & 75 & 75 \\
\hline \hline
\end{tabular}

*. Correlation is significant at the 0.05 level (2-tailed).

**. Correlation is significant at the 0.01 level (2-tailed).

Table 6-29 Correlation matrix between variables

Correlation matrix between all independent and dependent variables (Table 6-30) involved in the study shows a very high correlation between time and physical distance $(0.823)$ with sig $.000<.01$ in line with what's stated above. This will be mentioned as potential future work related to this study.

As a means for searching the breadth for evidence on a better model, log (base 10) transformations were applied to each independent variable and regression analysis carried out between dependent variable. 


\section{AgileSuccessScore}

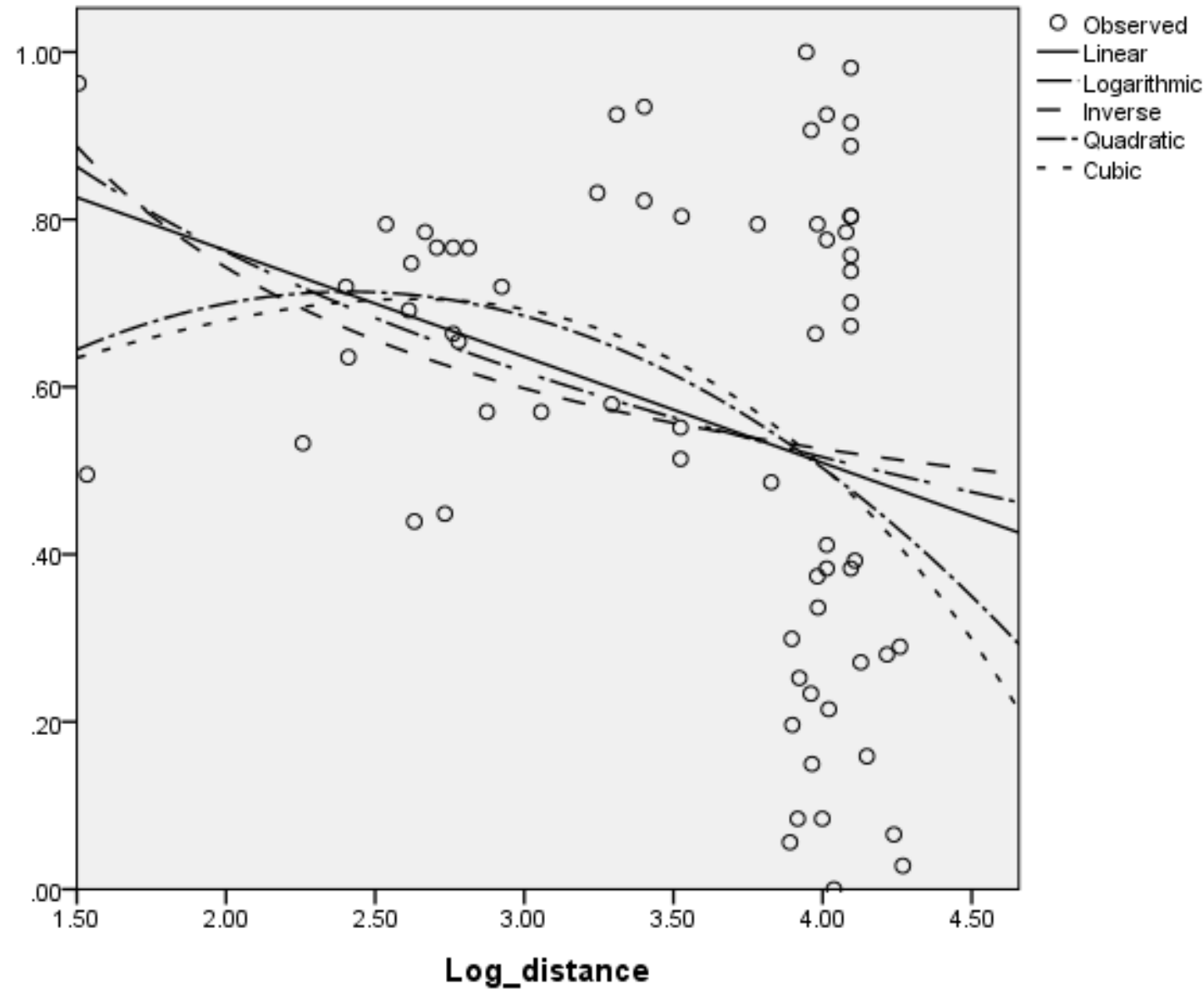

Figure 6-9 Regression curves between physical distance and agile success score

Logarithmic physical distance seem to improve results for physical distance so far on some models but only inverse and linear would be valid as they seem to fit what is already known about physical distance and other curves has variations that can't be explained as shown above (Figure 6-9). Log Linear model still has a better R squared $(.09>.07)$ and sig value $(.009$ $>$.03) over inverse model (see Table 6-31 and Table 6-32 below). 


\section{Linear}

Model Summary

\begin{tabular}{|c|c|c|c|}
\hline$R$ & $R$ Square & $\begin{array}{c}\text { Adjusted } R \\
\text { Square }\end{array}$ & $\begin{array}{c}\text { Std. Error of } \\
\text { the } \\
\text { Estimate }\end{array}$ \\
\hline .315 & .099 & .085 & .268 \\
\hline
\end{tabular}

The independent variable is Log_distance.

ANOVA

\begin{tabular}{lrrrrr}
\hline & $\begin{array}{l}\text { Sum of } \\
\text { Squares }\end{array}$ & \multicolumn{1}{c}{ df } & \multicolumn{1}{c}{$\begin{array}{l}\text { Mean } \\
\text { Square }\end{array}$} & \multicolumn{1}{c}{$F$} & Sig. \\
\hline Regression & .513 & 1 & .513 & 7.168 & .009 \\
Residual & 4.652 & 65 & .072 & & \\
Total & 5.165 & 66 & & & \\
\hline \hline
\end{tabular}

The independent variable is Log_distance.

Table 6-30 Linear model summary for log transformed physical distance and dependent variable 


\section{Inverse}

\section{Model Summary}

\begin{tabular}{|c|c|c|c|}
\hline$R$ & $R$ Square & $\begin{array}{c}\text { Adjusted } R \\
\text { Square }\end{array}$ & $\begin{array}{c}\text { Std. Error of } \\
\text { the } \\
\text { Estimate }\end{array}$ \\
\hline .264 & .070 & .055 & .272 \\
\hline
\end{tabular}

The independent variable is Log_distance.

ANOVA

\begin{tabular}{lrrrrr}
\hline & \multicolumn{1}{c}{$\begin{array}{l}\text { Sum of } \\
\text { Squares }\end{array}$} & \multicolumn{1}{c}{ df } & \multicolumn{1}{l}{$\begin{array}{l}\text { Sean } \\
\text { Square }\end{array}$} & \multicolumn{1}{c}{ F } & Sig. \\
\hline Regression & .359 & 1 & .359 & 4.855 & .031 \\
Residual & 4.806 & 65 & .074 & & \\
Total & 5.165 & 66 & & & \\
\hline \hline
\end{tabular}

The independent variable is Log_distance.

Coefficients

\begin{tabular}{lccccc}
\hline & \multicolumn{2}{c}{$\begin{array}{c}\text { Unstandardized } \\
\text { Coefficients }\end{array}$} & \multicolumn{2}{c}{$\begin{array}{c}\text { Standardize } \\
\text { Coefficients }\end{array}$} \\
& B & Std. Error & Beta & $t$ & Sig. \\
\hline $1 /$ & .867 & .394 & .264 & 2.203 & .031 \\
Log_distance & & & & & \\
(Constant) & .309 & .122 & & 2.534 & .014 \\
\hline \hline
\end{tabular}

Table 6-31 Inverse model summary for log transformed physical distance and dependent variable

Both log transformed time difference and culture difference don't achieve any improvements over its counterpart as shown in tables 6-33 and Table 6-34 below. 


\section{Linear}

Model Summary

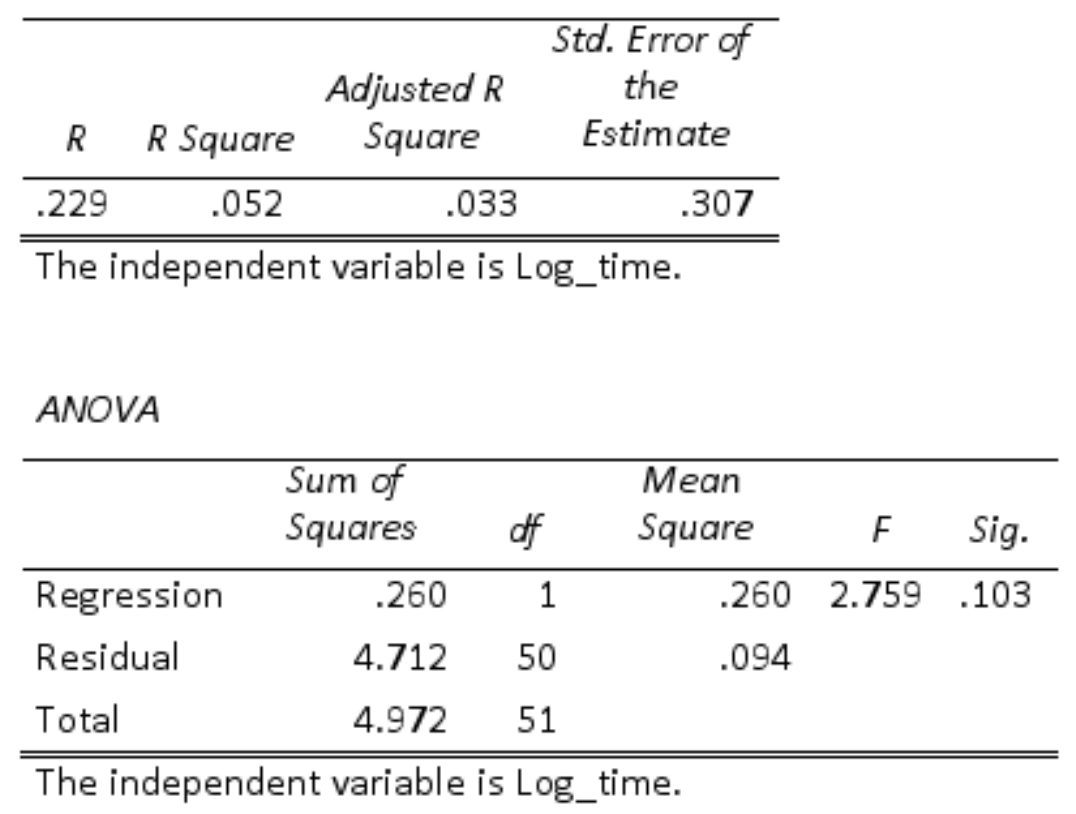

Table 6-32 Linear model summary for log transformed time difference and dependent variable 


\section{Linear}

Model Summary

\begin{tabular}{cccc}
\hline & Adjusted $R$ & $\begin{array}{c}\text { Std. Error of } \\
\text { the } \\
\text { Estimate }\end{array}$ \\
\hline .034 & $R$ Square & Square & .001 \\
\hline \hline
\end{tabular}

ANOVA

\begin{tabular}{lrrrrr}
\hline & $\begin{array}{l}\text { Sum of } \\
\text { Squares }\end{array}$ & \multicolumn{1}{c}{ df } & \multicolumn{1}{l}{$\begin{array}{l}\text { Mean } \\
\text { Square }\end{array}$} & F & Sig. \\
\hline Regression & .005 & 1 & .005 & .059 & .808 \\
Residual & 4.597 & 52 & .088 & & \\
Total & 4.603 & 53 & & & \\
\hline \hline
\end{tabular}

The independent variable is Log_cul ture.

Table 6-33 Linear model summary for log transformed culture difference and dependent variable 


\section{Chapter Seven: Discussion and Conclusion}

This chapter provides an extended discussion of the results of the data analysis while elaborating on each agile principle and effects of research findings on each principle. It also provides a summary of findings through data analysis while discussing limitation of the research. Last but not least this chapter also provides directions for future research in the area and a summary of contributions of this study.

It's quite clear that agile doesn't work perfectly in outsourced projects where teams are dispersed in multiple time, cultural and countries. A quantitative analysis involving all three variables revealed that physical distance and culture has a strong influence in deciding how successful agile methodology is going to be in outsourced project.

Trying to fit traditional agile principles as set out in the Agile Manifesto (The Agile Alliance, 2001) with offshore outsourcing teams doesn't seem to work. There is a basic error if one tries to apply methods based on Agile Manifesto (The Agile Alliance, 2001) to an outsourcing context.

Based on the findings of the data analysis, principles can be divided into two groups based on whether the principle is more affected by physical distance or culture. It might be worth attending to problems with principles affected by physical distance first and then culture difference in order to better leverage what agile has to offer in outsourced projects. Table 71 presents a summary of these ideas. 


\subsection{Agile principles vs Dominant Independent Variables}

\begin{tabular}{|c|c|c|c|c|}
\hline No & Principle & $\begin{array}{l}\text { Works } \\
\text { really well } \\
\text { with } \\
\text { Outsourcing }\end{array}$ & Dist. & Cult. \\
\hline 1 & $\begin{array}{l}\text { Our highest priority is to satisfy the customer } \\
\text { through early and continuous delivery } \\
\text { of valuable software }\end{array}$ & Yes & - & - \\
\hline 2 & $\begin{array}{l}\text { Welcome changing requirements, even late in } \\
\text { development. Agile processes harness change } \\
\text { for } \\
\text { the customer's competitive advantage. }\end{array}$ & No & - & $x$ \\
\hline 3 & $\begin{array}{l}\text { Deliver working software frequently, from a } \\
\text { couple of weeks to a couple of months, with a } \\
\text { preference to the shorter timescale. }\end{array}$ & Yes & - & - \\
\hline 4 & $\begin{array}{l}\text { Business people and developers must work } \\
\text { together daily throughout the project. }\end{array}$ & No & $x$ & \\
\hline 5 & $\begin{array}{l}\text { Build projects around motivated individuals. } \\
\text { Give them the environment and support they } \\
\text { need, and trust them to get the job done. }\end{array}$ & No & - & $x$ \\
\hline 6 & $\begin{array}{l}\text { The most efficient and effective method of } \\
\text { conveying information to and within a } \\
\text { development team is face-to-face conversation. }\end{array}$ & No & $x$ & - \\
\hline 7 & $\begin{array}{l}\text { Working software is the primary measure of } \\
\text { progress. }\end{array}$ & Yes & - & - \\
\hline 8 & $\begin{array}{l}\text { Agile processes promote sustainable } \\
\text { development. }\end{array}$ & Yes & - & - \\
\hline
\end{tabular}




\begin{tabular}{|l|l|l|l|l|}
\hline & $\begin{array}{l}\text { The sponsors, developers, and users should be } \\
\text { able to maintain a constant pace indefinitely. }\end{array}$ & & & \\
\hline 9 & $\begin{array}{l}\text { Continuous attention to technical excellence } \\
\text { and good design enhances agility. }\end{array}$ & No & - & $\mathrm{X}$ \\
\hline 10 & $\begin{array}{l}\text { Simplicity--the art of maximizing the amount } \\
\text { of work not done--is essential. }\end{array}$ & Yes & - & - \\
\hline 11 & $\begin{array}{l}\text { The best architectures, requirements, and } \\
\text { designs emerge from self-organizing teams. }\end{array}$ & No & - & $\mathrm{X}$ \\
\hline 12 & $\begin{array}{l}\text { At regular intervals, the team reflects on how } \\
\text { to become more effective, then tunes and } \\
\text { adjusts its behaviour accordingly. }\end{array}$ & No & $\mathrm{X}$ & - \\
\hline
\end{tabular}

Table 7-1 Agile Principles and Controlling Factors Summary

\subsection{Discussion of Each Principle Against Affecting Independent Variables}

Agile needs to think in terms of people. As the second principle in the table mention that agile teams should welcome changing requirements even late in the development and harness constant change for customer's competitive advantage, this again depends on how proficient and how much buy in the team has in terms of agile (Perica, 2014). Acceptance of late changes is highly subjective where some people have strong opposing feelings about last minute changes and others would be neutral and relaxed about it. But agile team acts as a unit and to be successful complete buy in by all team members are important (Perical, 2014). As one can already figure out, this is a hard task. Team members can be forced to buy in the way of agile and forced to deal with last minute changes but then again this would have adverse effects on individual's motivation. What's more interesting is that motivation again links up with the fifth principle above which states that "projects should be built around motivated individuals and trust them to get the job done". The adverse chain effect should be obvious at this point. Now with multicultural teams engaging in working towards the mission of moulding the final product, this can be a curse on the project as it can be hard to 
get people from multiple cultures to converge to one acceptance as seen with existing complications with multicultural teams (McDonough, Kahnb \& Barczaka, 2001).

As seen in the data analysis culture difference, even though not as much as physical distance does affect the coherence of teams. This can partly be explained by the argument built above. When teams come from different cultures they will have traits accepted as the norm for the culture they belong (McDonough, Kahnb \& Barczaka, 2001) so it's important that time and money is invested in training all team members in agile way of working its principles and values. That way, team members irrespective of the culture at least become aware of what's expected and why, which will help them control emotions (Von, Shapiro \& Bret, 2004) and help minimize the effects of demotivation Culture after all is partially when a group of beings behave in a similar manner sharing similar values and beliefs which can't be neglected.

Fourth principle states that "Business people and developers must work together daily throughout the project". It's hard to keep up with this principle in outsourcing scenarios especially with offshore outsourcing. As revealed by data analysis there is a significant negative correlation between success of agile in outsourced projects and distance. In fact the analysis revealed that distance is more significant than culture and time differences. It'll be hard for business people and developers to work together closely daily when physical distance get in the way (Noll, Beecham \& Richardson, 2010). Not to mention this is even worsened by cultural gaps. For example India acts as a massive source of vendors in outsourcing market and there are many projects that are outsourced to India where client comes from a different part of the world. Inherently Indian culture is quite hierarchical (Gupta \& Ferguson, 1992). This is not local and specific to India but in the all of South/Southeast Asian region at least (Goh, 2008). It doesn't of course apply only to South Asia but could draw examples out from other regions too but for the purpose of explanation I'd go as far as that. The hierarchical culture in these countries further spread this unfavourable cultural attribute into the local organization cultures and team cultures too (Nicholson \& Sahay, 2001). This essentially means that subordinates agreeing to whatever the superior powers/ managers decide without giving any feedback or thoughts (Nicholson \& Sahay, 2001). Managers on the other hand seem to enforce these common flows for some reason from my experience. This is not favourable in agile where team members are required 
to communicate with other teams and participate in a constructive feedback process working closely throughout other distant teams.

As it can be seen solution for these problems should initiate inside the organizations themselves. Especially in the management and executive levels where they promote and encourage subordinates to engage in constructive feedback process. For agile to be successful I believe that strategic, middle, operational - that is all managers should buy in the agile way of thinking before they can ask teams to adopt them.

Once the human culture elements and disparities between teams are fixed the impact on working closely everyday with distant team members can be achieved in many ways. Using digital task boards status update boards could help in this situation. Forms of these tools are already in use according to Rubart(2014), where each member of all distant teams note down what they have done yesterday- what they plan to do today and what roadblocks he has come across according to agile scrum method. This status update board is available 24/7 for any other team member regardless of their location (this is a shared digital board). This is a good way to gap the inability to participate at daily stand-ups like other co-located agile teams. Offshore outsourcing teams should also leverage other digital communication methods (e.g. Slack, Yammer) which are significantly different from traditional email approach.

Sixth principle mentions that the most efficient and effective method of conveying information to and within a development team is face-to-face conversation. Face-to-face communication is not easily achieved in outsourced projects due to reasons unwound in paragraph above. When the time zone difference allows, that is if the time zone difference in usually less than 8 hours as most countries have an 8 hour workday there is a chance both teams get together for a video conference to carry out a daily stand up/ status update meeting. This way of leveraging overlap of time has proven to be favoured according to Vax \& Michaud (2008). Problems around face-to-face meetings and distance teams can somewhat be mitigated by leveraging latest communication mediums that gives the illusion of up close discussions. Arguments against the sixth principle and outsourcing are further backed by comments received from the participant. One participant mentioned that outsourced projects should aim at "working with teams that can partially overlap their time 
zones or no deal. Daily meetings without face to face overlap makes no sense to me. If you can't, then consider them separate teams".

In the latter part of the questionnaire opinion from industry professionals were sought for on solutions that best worked for them or what they think would work. One idea was to see how successful digital task boards would be. There are similar solutions in use already so could have possible links to the occasions where agile has been successful in outsourced projects. As illustrated below (Figure 7-1) participants were polled for their opinion on digital task boards and a vast majority of them thought it was a good solution and they were strongly in favour of such a tool in place. Only a quarter of the respondents who chose to answer the section was indecisive or thought it wasn't a good solution. The poll however didn't go as far as asking respondent why they though it was a good solution or why it isn't this would be potential feature for an extension of this study.

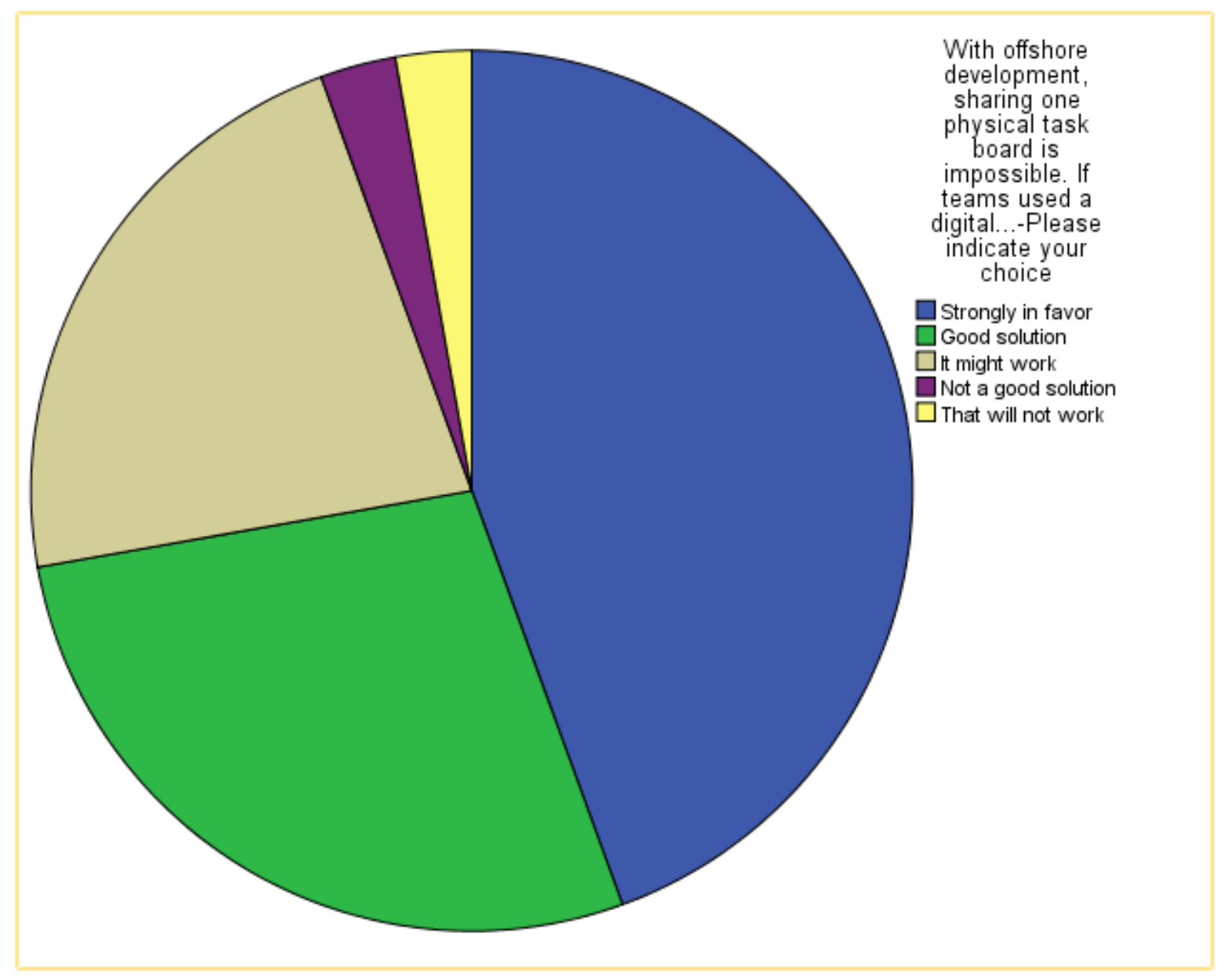

Figure 7-1 Respondent Data on Digital Task Board 
Principle number 9 states that "Continuous attention to technical excellence and good design enhances agility". Continuous attention to technical excellence is easier said than done. Even with co-located teams this could be a struggle in real life projects from my experience. When sprint deadline loom in things might get ugly with all kinds of code hacks and oversights sneaking (Lussier, 2004) in to the code base to meet the sprint goals. Agile is supposed to be significantly different from its counterpart with a tightly controlled predictive deadline. However this doesn't mean agile is a deadline free world. There may be a slight change to jargon used in the form of sprint goals but deadlines in agile do exist albeit as a softer form. Desire to meet the sprint goals aren't the only party spoiler. The cultural norm of a team defined by country specific culture will have a say in what team defines as excellent. After all what excellent means in one country doesn't mean it is universal and consistent across cross cultural teams and criteria for success is even proven to be different from different organizations in the same country let alone a different country (Thomas \& Fernández, 2008).

For example from my experience having worked at both New Zealand companies and Sri Lankan companies, I notice a clear difference of quality control and audit work in companies in two cultures. In Sri Lanka things seem to be more relaxed in terms of quality unless explicitly enforced among teams, whereas in New Zealand individuals and teams (at least in the software industry) more often take initiatives to provide quality work to the end customer. I have noticed proactive involvement in quality as opposed to reactive quality control in a country like Sri Lanka. So it's important to have consistent definitions for jargon when multiple teams involve off-shore outsourcing. Technical excellence has to be defined and processes to control quality such multiple channels of testing etc. has to be in place to make what teams from different cultures perceive as technical excellence more consistent across cultures (Furrer, Liu \& Sudharshan, 2000).

Principle 11 states that "The best architectures, requirements, and designs emerge from selforganizing teams". This principle is about building projects around autonomous teams. In outsourced projects which factors would govern the autonomy of the team? Will teams be 
self-motivated to engage across cultural barriers? Without clear understanding of controls that regulates cross cultural team autonomy, built in assumptions will paralyze the project management methodology when applied to outsourcing. Work by Man \& Lam (2003) supports the ideas pitched here with their study that looked at cross cultural collectivistic and individualistic dynamics.

A recent study (Cramton \& Hinds, 2004) in distributed teams mentions the presence of a fault line concept. The study uses an example to elaborate the idea further. If key attributes of the groups correlate there will be a stronger fault line as opposed to if the key attributes were cross cut across the group. E.g. If two teams were made up of Engineers and Designers separately and all Engineers in one group were male and all designers in other group were female the common attributes of the group such as gender and profession co-relate with each other. These fault lines are compared to earth's fault lines which when activated in this scenario results in consequences such as formation, polarization and conflict. There are further arguments that supports the groundwork of this research such as evidence of increase in distributed team activity.

Team members who work from different locales are likely to experience multiple exogenous events, physical settings, constraints and practices. These could be events such as public transport strike, local economic condition changes, differences in the environment and facilities, equipment and technology tools team members have access to. Demographic differences can also result in individuals defining situations differently, political, ideologies or beliefs can result in assumptions when one remote team start to notice patterns of behaviours they consider odd. They notice but might not know the actual reason behind it because of cultural differences present.

Drawing from the gender based professions example above, a more relevant example for outsourcing follows. It's quite common products get designed at client offices (ex: US, Germany) and gets implemented in another country like India. Now if all product designers were in US and all programmers were in India this creates a fault line between teams. These arguments are further supported by Kramer \& Brewer (1984) who reported interference of subgroup behaviour with corporate group behaviour and Armstrong \& Cole (1995) who explain how polarization of subgroups lead to teams withholding information from each 
other. Not only that, Early (2002) highlighted that international teams with strong fault lines or strong cultural differences exhibit many communication problems, relational conflict and low levels of team identity and attributes lack of cross cultural empathy and understanding contribute to the dysfunctional activities.

Current work in this area point in the direction of equal status. For a group that sits at a higher status (Client party for example), engaging across cultural differences may seem as a loss of valuable status, hence they drive towards preserving existing social arrangement rather than initiating or participating in change (Jost \& Burgess, 2000). On the other end lower status group (Vendor) might stick to their in-group membership and closed boundary (Brewer \& Campbell, 1976). Feelings of threatened by another group are likely to emerge where unequal power and status levels exist. Even if these ideas weren't part of the agile outsourcing related research, they can be related to agile and outsourcing quite intuitively where multicultural teams are expected to engage beyond their comfortable zones for mutual interest.

Reducing the gap between the remote teams is hence proved essential. There a multitude ways of going about it. Most ideas are centric around getting members from both teams to engage in members from the remote team. Minor changes in the processes can accommodate this requirement and can help stimulate healthy engagement between remote teams when such connections aren't proactively nourished. One such way is to get developers, business analysts to work in pairs (quite similar to XP - extreme programming where two programmers are paired and seated together to build the same piece of work only in this case members will not sit together rather communicate through telecommunication channels available) in initials sprints. First sprints form the direction and pace of the project hence is a good opportunity to harness healthy relationships between remote team members using a one to one methodology. In the subsequent sprints members will still work in pairs to build some functionality but member pair should be shuffled this time around. Whether this would make an impact on effective throughput while allowing a new relationship to be built, doesn't belong in this research. 
Principle 12 states at regular intervals, the team reflects on how to become more effective, then tunes and adjusts its behaviour accordingly. Following similar arguments to sections above, it's fair to say that ability to carry out what principle 12 states is clearly challenged by prevalence of distance factor. Adding to this is time and culture gap. Dorairaj, Noble \& Alan, (2013) points out the importance of space, culture and trust among many other factors that needs to be carefully risk mitigated by means of inception workshops, cross site visits, rotation, cultural awareness, language support, open communication, shared values and collaboration initiatives.

There are a plethora of recommendations around how to fix agile for distributed teams. But in real life from my experience not all these practices are implemented at each company. The real value of this research is the identification of the most significant challenge in distributed agile projects. Now that the distance is identified as the clear challenger over cultural and time factors more focus could be set on mitigating the risks associated with physical distance and eventually move on to culture which is the next candidate inline.

Dorairaj et al. (2013) points out that the face to face is the most efficient and effective method of communication when circulating information within agile teams as it encourages and facilitates sharing of knowledge and supports cohesion between members of distributed teams.

There are many suggestions to help overcome spatial challenges distributed teams come across. One of them are Inceptions workshops where projects are kicked off with a series of workshops where business context, time, quality and budget constraints are discussed at the presence of subject matter experts. This could help set the direction of the project with management.

\subsection{Summary of findings through Data Analysis}

The discussion above focuses on identifying and explaining which of the 12 principles of agile are least likely to work with outsourced projects. This was one of the research questions of interest to us. We were also interested to know understand how each variable distance, time difference and culture difference between teams impact on success of agile methodology in outsourced projects. Time difference and physical distance were calculated based on the countries and cities client and vendor came from. Culture difference was based on Hofstede 
model (Hofstede, 2013) of cultural differences between cultures. Correlations and regression analysis for each individual variable and all three variables as a whole was then carried out.

It was noticed that physical distance had a clear impact on success of agile methodology in outsourced projects where variation of the dependent variable was explained significantly by physical distance at a $99 \%$ confidence interval. Cultural difference then came second and was able to explain the variation of dependent variable at a $95 \%$ confidence interval. Relationship between time difference and the dependent variable was rather weak. Hence we can confidently say that physical distance and cultural difference manage to explain the variations well at a $95 \%$ confidence interval and hence had a high impact on success of agile methodology in outsourced projects.

\subsection{Limitations of the Research}

The approach taken in this research was using a questionnaire which seeks opinion of industry experts. It's inevitable that the data collected have a subjective bias and depend massively on individual perception. Methods were employed to confirm that experience based data were sourced from a sample where most respondent came from a working background with agile. Further measures were taken to make sure that group of respondents not only had just enough but significant number of years of working with agile. Subjective bias and inconsistency is inherent and there is room for further empirical validation of the findings.

Data collected were based on the experience of respondents with the immediately previous project that involved agile project management. Immediately previous can vary from several weeks to several months and relied on respondents remembering how certain factors affect the project and how processes were implemented and carried out. Average humans tend to have a volatile memory and hence are a limitation of the research.

Independent variables time and distance had strong correlations with each other (as opposed to correlations between other variables). There is room for an improved study which will 
build on this study that will explore an improved model with inter independent variable correlations taken into account.

Statistical analysis for this research had around 75 data points to work with. There is room for an improved research that will work with a higher number of data points.

\subsection{Future Research}

There is room for more work which involves further validating the findings by gathering data using a live project which would implement measures that focus on the findings of this research. For example since distance has been identified as the dominant factor which affects the success of agile in outsourced project, a comparison study which involves control groups who will and will not remedy the distance factor and will and will not implement recommendations of this research to mitigate risks posed by non co-located teams working together can complement this work. This can be paired up with a live project which only implements time/culture related remedies and leave distance related remedies alone.

Confirmation of results through such live ongoing project will be interesting to see and would give more confidence in further studies in this area.

There is also room for analysis of best model fit between physical distance and success of agile methodology in outsourced projects by collecting more data points along the directions provided in this study.

Further work can also be carried in terms of organizational culture. When teams come from the same country the country wise culture difference is thought to be zero. While this is true anatomy of culture can be further divided in to a channel is controlled by organizational culture. Now even when teams come from the same country there could be differences in organizational culture between team that could impact on successful application of agile methodology in on-shore outsourced projects. Hence there is room for further work that improves the current model of culture and physical distance as drivers behind success of 
agile methodology in outsourced projects, to expand the model to include factors like organizational culture too.

There are also potential factors Hofstede model doesn't necessarily capture. For example national holidays in one country are often different to another country and are usually in line with important cultural events. Schedule of national holidays may then have some effect on business processes as a remote team may shut down operations for the holiday period while the other team continues to operate normally. The best example for this can be drawn out referring to Christmas holiday period where businesses usually shut down for almost 2 weeks. Communications during this period could be limited and information around parts of the system built by one team can be of limited accessibility. If no workarounds for such situations were thought in advance, this may drive to inefficiencies in the other team and might have impact on their agile prints during the holiday period.

It's also possible to transform the variables/ data into nominal scale based on explanations that follow. For example -far/close, significant time difference/ insignificant time difference e.g. are they within 4 hours of a difference where teams have overlapping 4 hours of daytime work hours rather than one team finish their work day before other team from another side of the world even wakes up with no overlapping work hours? Closely related cultures and significantly different cultures e.g. South Asian countries, European countries. Once independent variables are categorized, data can then be tested for relationships as below,

- Do 'far' away teams have 'less' success using agile methodologies?

- Do teams from 'similar cultures' do better with agile etc.?

- Do teams that are in different time zones but are within overlapping working hours do better than teams with no overlapping times zones in outsourced projects using agile methodology?

\subsection{Summary of Research Contributions}

There are a number of ways to develop this research further as discussed above. Nevertheless, this research has provided a useful contribution in identifying that physical 
distance is the single most dominant factor that affect success of agile in outsourced projects as oppose to the popular belief involving all three factors culture, time and physical distance. Teams/Managers/Stakeholders can now focus on fixing distance related issues in outsourced agile project management. Furthermore this research have identified correlation between distance, time and culture difference that explains finding mentioned above. This work has further contributions in identifying which set of principles needs fixing first based on findings around physical distance thereby pointing teams towards effective use of agile in outsourced projects. 


\section{References}

Agile Alliance and Institute Agile (2013). Map of Agile Practices. Retrieved September 28, 2014, from http://guide.agilealliance.org/subway.html

Scaledagileframework.com (2015). Agile Release train Metrics Abstract. Retrieved April 30, 2015 from http://www.scaledagileframework.com/art-metrics/

Alecu, F. (2011). Managing software development projects, the project management process. Oeconomics of Knowledge, 3(3), 26-33.

Ambler, S. W. (2005). Agile outsourcing. Software Development, 13(6), 69-70,72. Retrieved from http://search.proquest.com/docview/222141992?accountid=14782

Ahimbisibwe, A. (2015). Critical success factors for outsourced software development projects from a vendor's perspective: A structural equation modelling analysis of traditional plan-based and agile methodologies. Unpublished PhD thesis, Victoria University of Wellington, New Zealand.

Ahimbisibwe, A., Cavana, R. Y., \& Daellenbach, U. (2015). A contingency fit model of critical success factors for software development projects: A comparison of agile and traditional plan-based methodologies. Journal of Enterprise Information Management, 28(1), 7-33. Ahmed, A., Ahmad, S., Ehsan, N., Mirza, E., \& Sarwar, S. Z. (2010, June). Agile software development: Impact on productivity and quality. In Management of Innovation and Technology (ICMIT), 2010 IEEE International Conference on (pp. 287-291). IEEE Armstrong, D. J., \& Cole, P. (1995). Managing distances and differences in geographically distributed work groups. In: S. E. Jackson \& M. N. Ruderman (Eds), Diversity in Work Teams: Research Paradigms for a Changing Workplace (pp. 187-216). Washington, DC: American Psychological Association.

Boris, R., \& Ram, A. (2006). Agile outsourcing projects: Structure and management. International Journal of e-Collaboration (IJeC), 2(4), 37-52. doi:10.4018/jec.2006100103 
Boden, A., G. Avram, L. Bannon, und V. Wulf. „Knowledge Management in Distributed Software Development Teams - Does Culture Matter? “In Fourth IEEE International Conference on Global Software Engineering, 2009. ICGSE 2009, 18-27, 2009. doi:10.1109/ICGSE.2009.10

Boehm, B., \& Turner, R. (2005). Management challenges to implementing agile processes in traditional development organizations. IEEE Software, 22(5), 30-39. doi:10.1109/MS.2005.129

Bos, N., Shami, N. S., Olson, J. S., Cheshin, A., \& Nan, N. (2004, November). In-group/outgroup effects in distributed teams: an experimental simulation. In Proceedings of the 2004 ACM conference on Computer supported cooperative work (pp. 429-436). ACM.

Brewer, M. B., \& Campbell, D. T. (1976). Ethnocentrism and intergroup attitudes: East African evidence.

Bond, M. H., \& Hofstede, G. (1989). The cash value of Confucian values. Human systems management, 8(3), 195-199.

Cavana, R. Y., \& Delahaye, B. I., and Sekaran. U. 2001. Applied business research: qualitative and quantitative methods.

Conforto, E. C., Salum, F., Amaral, D. C., da Silva, S. L., \& de Almeida, L. F. M. (2014). Can Agile Project Management Be Adopted by Industries Other than Software Development?. Project Management Journal, 45(3), 21-34.

Cramton, C. D., \& Hinds, P. J. (2004). Subgroup dynamics in internationally distributed teams: Ethnocentrism or cross-national learning?. Research in organizational behaviour, 26, 231263.

Demir, K. A. (2008). Measurement of software project management effectiveness. NAVAL POSTGRADUATE SCHOOL MONTEREY CA.

Distance Calculator. (1995). Retrieved October 15, 2015, from http://www.timeanddate.com/worldclock/distance.html 
Dorairaj, S., \& Noble, J. (2013). Understanding How Agile Teams Manage Knowledge in Global Software Development. Agile Conference (pp.5-9). NashVille, TN: IEEE

Dorairaj, S., Noble, J., \& Allan, G. (2013, August). Agile software development with distributed teams: Senior management support. In Global Software Engineering (ICGSE), 2013 IEEE 8th International Conference on (pp. 197-205). IEEE.

Downey, J. (2005, July/August). The Future of Off shore Out Sourcing. Financial Management, p.20.

dummies.com (2015). Ten Key Metrics for Agile Project Management. Retrieved May 18, 2015 from http://www.dummies.com/how-to/content/ten-key-metrics-for-agile-projectmanagement.html

Espinosa, J. A., Slaughter, S. A., Kraut, R. E., \& Herbsleb, J. D. (2007). Team knowledge and coordination in geographically distributed software development. Journal of Management Information Systems, 24(1), 135-169. doi:10.2753/MIS0742-1222240104

Earley, P. C. (2002). Redefining interactions across cultures and organizations: Moving forward with cultural intelligence. In: B. M. Staw \& R. M. Kramer (Eds), Research in Organizational Behaviour (Vol. 24, pp. 271-299). Greenwich, CT: JAI Press.

Fulgham, C., Johnson, J., Crandall, M., Jackson, L., \& Burrows, N. (2011). The FBI gets agile. IT Professional, 13(5), 57-59. doi:10.1109/MITP.2011.88

Furrer, O., Liu, B. S. C., \& Sudharshan, D. (2000). The relationships between culture and service quality perceptions basis for cross-cultural market segmentation and resource allocation. Journal of service research, 2(4), 355-371.

Fossey, E., Harvey, C., McDermott, F., \& Davidson, L. (2002). Understanding and evaluating qualitative research. Australian and New Zealand journal of psychiatry, 36(6), 717-732.

Flood, M. (2014, June 16). Humanism and Culture. Retrieved May 17, 2015, from http://humanistlife.org.uk/2014/06/16/humanism-and-culture/ 
Gorton, I., \& Motwani, S. (1996). Issues in co-operative software engineering using globally distributed teams. Information and Software Technology, 38(10), 647-655. doi:10.1016/0950-5849(96)01099-3

Griffith, D. A., \& Harmancioglu, N. (2009). Governance decisions for the offshore outsourcing of new product development in technology intensive markets. Journal of World Business, 44(3), 217-224. doi:10.1016/j.jwb.2008.08.007

Gregg, D. G., Kulkarni, U. R., \& Vinzé, A. S. (2001). Understanding the philosophical underpinnings of software engineering research in information systems. Information Systems Frontiers, 3(2), 169-183.Gupta, S., \& Pal, C. (2012). ISDLCM: An Improved Software Development Life Cycle Model. International Journal of Management, IT and Engineering, 2(2), 234-245.

Geert-hofstede.com (2013). National Culture. Retrieved June 10, 2015, from http://geerthofstede.com/national-culture.html

Gupta, A., \& Ferguson, J. (1992). Beyond "culture": Space, identity, and the politics of difference. Cultural anthropology, 7(1), 6-23.

Goh, E. (2008). Great powers and hierarchical order in Southeast Asia: analysing regional security strategies.

Guba, E. G., \& Lincoln, Y. S. (1994). Competing paradigms in qualitative research. Handbook of qualitative research, 2(163-194).

Hoda, R., Noble, J., \& Marshall, S. (2013). Self-organizing roles on agile software development teams. IEEE Transactions on Software Engineering, 39(3), 422-444. doi:10.1109/TSE.2012.30

Hong, Y., Morris, M. W., Chiu, C., \& Benet-Martínez, V. (2000). Multicultural minds: A dynamic constructivist approach to culture and cognition. American Psychologist, 55(7), 709720. doi:10.1037/0003-066X.55.7.709

Hofstede, G (2013) Value Survey Module 2013. Retrieved from http://www.geerthofstede.nl/vsm2013 
Hofstede, G. (2015). Country Comparison. Retrieved October 15, 2015, from http://geerthofstede.com/countries.html

Hofstede, G. (1984). Culture's consequences: International differences in work-related values (Vol. 5). Sage.

Hoftede, G., Hofstede, G. J., \& Minkov, M. (2010). Cultures and organizations: software of the mind: intercultural cooperation and its importance for survival. McGraw-Hill.

Hughes, B. (2013, November 11). The rise of Scrum. Retrieved September 27, 2014, from http://www.computerworld.co.nz/article/531454/opinion_rise_scrum/

Hightower, R., \& Sayeed, L. (1996). Effects of communication mode and pre discussion information distribution characteristics on information exchange in groups. Information Systems Research, 7(4), 451-465.

Jaanu, T., Paasivaara, M., \& Lassenius, C. (2012). Effects of four distances on communication processes in global software projects. Proceedings of the ACM-IEEE international symposium on empirical software engineering and measurement (pp.231-234). ACM. doi:10.1145/2372251.2372293

Jost, J. T., \& Burgess, D. (2000). Attitudinal ambivalence and the conflict between group and system justification motives in low status groups. Personality and Social Psychology Bulletin, 26(3), 293-305.

Joentakanen, T. (2014, January 15). Agile metrics by Spotify. Retrieved March 8, 2015, from https://medium.com/@joentakanen/agile-metrics-by-spotify-4c8653f6984\#.Ivsnli6yo

Khan, S. U., \& Azeem, M. I. (2014). Intercultural challenges in offshore software development outsourcing relationships: An exploratory study using a systematic literature review. IET Software, 8(4), 161-173. doi:10.1049/iet-sen.2013.0012

Kramer, R. M., \& Brewer, M. B. (1984). Effects of group identity on resource use in a simulated commons dilemma. Journal of personality and social psychology, 46(5), 1044

Kroeber, A. L. 1., \& Kluckhohn, C., 1905-1960. (1952). Culture: A critical review of concepts and definitions. Cambridge, Mass: The Museum. 
Kwak, Y. H. (2005). A brief history of Project Management. The story of managing projects.

Kramer, R., \& Brewer, M. (1984). Effects of group identity on resource use in a simulated commons dilemma. Journal of Personality and Social Psychology, 46, 944-1057.

Kuhn, T. S. (2012). The structure of scientific revolutions. University of Chicago press. (Original work published in 1962)

Largent, D. (2010). Getting and staying agile. XRDS: Crossroads, the ACM Magazine for Students, 17(1), 38-41. doi:10.1145/1836543.1836555

Lacity, M. C., Khan, S., Yan, A., \& Willcocks, L. P. (2010). A review of the IT outsourcing empirical literature and future research directions. Journal of Information Technology, 25(4), 395-433. doi:10.1057/jit.2010.21

Laplante, P. A., \& Neill, C. J. (2004). The demise of the waterfall model is imminent. Queue, 1(10), 10.

Lewis, D. E. (2004). Offshore Outsourcing Gaining Popularity: Retrieved September 26, 2014, from http://www.highbeam.com/doc/1P2-7843080.html

Lussier, S. (2004). New tricks: How open source changed the way my team works. Software, IEEE, 21(1), 68-72.

Man, D. C., \& Lam, S. S. (2003). The effects of job complexity and autonomy on cohesiveness in collectivistic and individualistic work groups: a cross-cultural analysis. Journal of Organizational Behaviour, 24(8), 979-1001.

Maznevski, M. L., \& Chudoba, K. M. (2000). Bridging space over time: Global virtual team dynamics and effectiveness. Organization science, 11(5), 473-492.

Medinilla, Á. (2012). Agile management: Leadership in an agile environment. Berlin [u.a.]: Springer Berlin Heidelberg. doi:10.1007/978-3-642-28909-5

Medium.com (2015). Agile Metrics by Spotify. Retrieved May 15, 2015, from https://medium.com/@joentakanen/agile-metrics-by-spotify-4c8653f6984 
Mishra, A., \& Mishra, D. (2013). Software project management tools: A brief comparative view. ACM SIGSOFT Software Engineering Notes, 38(3), 1-4. doi:10.1145/2464526.2464537

Maurer, F., \& Melnik, G. (2006). Agile methods: Moving towards the mainstream of the software industry. Proceedings of the 28th international conference on software engineering (pp.1057-1058). ACM. doi:10.1145/1134285.1134503

McDonough, E. F., Kahnb, K. B., \& Barczaka, G. (2001). An investigation of the use of global, virtual, and collocated new product development teams. Journal of product innovation management, 18(2), 110-120.

Nicholson, B., \& Sahay, S. (2001). Some political and cultural issues in the globalisation of software development: Case experience from Britain and India. Information and Organization, 11(1), 25-43. doi:10.1016/S0959-8022(00)00008-4

Noll, J., Beecham, S., \& Richardson, I. (2010). Global software development and collaboration: barriers and solutions. ACM Inroads, 1(3), 66-78.

Ocker, R. J., Huang, H., Benbunan-Fich, R., \& Hiltz, S. R. (2011). Leadership dynamics in partially distributed teams: An exploratory study of the effects of configuration and distance. Group Decision and Negotiation, 20(3), 273-292.

Orlikowski, W. J., \& Baroudi, J. J. (1991). Studying information technology in organizations: Research approaches and assumptions. Information systems research, 2(1), 1-28.

Pauleen, D. J., \& Yoong, P. (2001). Relationship building and the use of ICT in boundarycrossing virtual teams: a facilitator's perspective. Journal of Information Technology, 16(4), 205-220.

Perica Jankoviæ. (2014). Project team motivation in project realisation. St. Louis: Federal Reserve Bank of St Louis. Retrieved from http://search.proquest.com.helicon.vuw.ac.nz/docview/1698363755?accountid=14782

Pinto, J. K., \& Slevin, D. P. (1998). Critical success factors. The Project Management Institute: Project management handbook, 379-395.

Quinn, J. B., \& Hillmer, F. G. (1995). Strategic outsourcing. The McKinsey Quarterly, (1), 48. 
Racheva, Z., Daneva, M., \& Herrmann, A. (2010, September). A conceptual model of clientdriven agile requirements prioritization: Results of a case study. In Proceedings of the 2010 acm-ieee international symposium on empirical software engineering and measurement ( $p$. 39). ACM.

Richardson, I., Casey, V., McCaffery, F., Burton, J., \& Beecham, S. (2012). A process framework for global software engineering teams. Information and Software Technology, 54(11), 1175-1191. doi:10.1016/j.infsof.2012.05.002

Rivard, S., \& Dupré, R. (2009). Information systems project management in PMJ: A brief history. Project Management Journal, 40(4), 20-30. doi:10.1002/pmj.20143

Robinson, A. (2011). Behind India's technological boom: The rise of outsourcing by western companies stifles local innovation. Nature, 472(7341), 34.

Rosland, J., \& Cowger, M. (2015, March 13). Agile Methodology. Retrieved June 5, 2015, from https://github.com/emccode/training/blob/master/accreditation/agile-methodology.md

Rubart, J. (2014, November). A Cooperative Multi touch Scrum Task Board for Synchronous Face-to-Face Collaboration. In Proceedings of the Ninth ACM International Conference on Interactive Table tops and Surfaces (pp. 387-392). ACM.

Sheffield, J., \& Lemétayer, J. (2013). Factors associated with the software development agility of successful projects. International Journal of Project Management, 31(3), 459-472. doi:10.1016/j.ijproman.2012.09.011

Sharma, A., Sengupta, S., \& Gupta, A. (2011). Exploring risk dimensions in the Indian software industry. Project Management Journal, 42(5), 78-91.

Stafford, J. (2011). Agile software development: What's behind the rise in hybrid agile?. Retrieved September 26, 2014 from http://itagenda.blogs.techtarget.com/2011/09/14/agilesoftware-development-what\%E2\%80\%99s-behind-the-rise-in-hybrid-agile/

Stoica, M., Mircea, M., \& Ghilic-Micu, B. (2013). Software development: Agile vs. traditional. Informatica Economica, 17(4), 64-64. doi: 10.12948/issn14531305/17.4.2013.06 
Spalek, S. (2014). Finding a New Way to Increase Project Management Efficiency in Terms of Time Reduction. Inzinerine Ekonomika-Engineering Economics, 25(5), 538-548.

Software Development Life Cycle. (2007, December 31). Retrieved April 10, 2015, from http://www.stylusinc.com/Bl/it-outsourcing/the-software-development-life-cycle-sdlc/ Tajfel, H., \& Turner, J. C. (2004). The Social Identity Theory of Intergroup Behaviour. Time Zone Converter. (1995). Retrieved October 15, 2015, from http://www.timeanddate.com/worldclock/converter.html

The Agile Alliance (2001). Principles behind the Agile Manifesto. Retrieved August 24, 2014, from http://agilemanifesto.org/principles.html

Thenusan, S. (2014). Software Development Life Cycle Models, Retrieved May 02, 2015, from http://thenuzan.blogspot.co.nz/2014/09/sdlc.html

Thomas, G., \& Fernández, W. (2008). Success in IT projects: A matter of definition?. International Journal of Project Management, 26(7), 733-742.

Turner, J. R. (2014). The handbook of project-based management (Vol. 92). McGraw-hill. Vax, M., \& Michaud, S. (2008, August). Distributed Agile: Growing a practice together. In Agile, 2008. AGILE'08. Conference (pp. 310-314). IEEE.

VersionOne (2015). The 9th Annual State of AgileTM Survey. Retrieved Feb 05, 2015 from http://info.versionone.com/state-of-agile-development-survey-ninth.html

Von Glinow, M. A., Shapiro, D. L., \& Brett, J. M. (2004). Can we talk, and should we? Managing emotional conflict in multicultural teams. Academy of Management review, 29(4), 578-592.

Wells, H. (2012). How effective are project management methodologies? An explorative evaluation of their benefits in practice. Project Management Journal, 43(6), 43-58.

Wikipedia (2014). Agile software development. Retrieved September 23, 2014, from http://en.wikipedia.org/wiki/Agile_software_development 
Wikipedia (2015). Total quality management. Retrieved May 08, 2015 from http://en.wikipedia.org/wiki/Total_quality_management

Wikipedia (2013). Project Management. Retrieved June 20, 2015 from https://en.wikipedia.org/?title=Project_management. 


\section{Appendices}

\section{Appendix A : Value Survey Module}

\section{VALUES SURVEY MODULE 2013}

\section{QUESTIONNAIRE}

English langage version

MAY BE FREELY USED FOR RESEARCH PURPOSES

FOR REPRODUCTION IN COMMERCIAL PUBLICATIONS,

PERMISSION IS NEEDED

Release May 2013

Copyright @ Geert Hofstede BV

www.geerthofstede.eu 


\section{INTERNATIONAL QUESTIONNAIRE (VSM 2013)}

Please think of an ideal job, disregarding your present job, if you have one. In choosing an ideal job, how important would it be to you to ... (please circle one answer in each line across):

$$
\begin{aligned}
& 1=\text { of utmost importance } \\
& 2=\text { very important } \\
& 3=\text { of moderate importance } \\
& 4=\text { of little importance } \\
& 5=\text { of very little or no importance }
\end{aligned}
$$

01. have sufficient time for your

personal or home life

02. have a boss (direct superior) you can respect

03. get recognition for good performance

04. have security of employment

05. have pleasant people to work with

06. do work that is interesting

07 . be consulted by your boss in decisions involving your work

08. live in a desirable area

09. have a job respected by your family and friends

10. have chances for promotion

$\begin{array}{lllll}1 & 2 & 3 & 4 & 5\end{array}$

$\begin{array}{lllll}1 & 2 & 3 & 4 & 5\end{array}$

$\begin{array}{lllll}1 & 2 & 3 & 4 & 5\end{array}$

$\begin{array}{lllll}1 & 2 & 3 & 4 & 5\end{array}$

$\begin{array}{lllll}1 & 2 & 3 & 4 & 5\end{array}$

$\begin{array}{lllll}1 & 2 & 3 & 4 & 5\end{array}$

$\begin{array}{lllll}1 & 2 & 3 & 4 & 5\end{array}$

$\begin{array}{lllll}1 & 2 & 3 & 4 & 5\end{array}$

$\begin{array}{lllll}1 & 2 & 3 & 4 & 5\end{array}$

$\begin{array}{lllll}1 & 2 & 3 & 4 & 5\end{array}$ 
In your private life, how important is each of the following to you: (please circle one answer in each line across):

$\begin{array}{lllllll}\text { 11. keeping time free for fun } & 1 & 2 & 3 & 4 & 5 \\ \text { 12. moderation: having few desires } & 1 & 2 & 3 & 4 & 5 \\ \text { 13. doing a service to a friend } & 1 & 2 & 3 & 4 & 5 \\ \text { 14. thrift (not spending more than needed) } & 1 & 2 & 3 & 4 & 5\end{array}$

15. How often do you feel nervous or tense?
1. always
2. usually
3. sometimes
4. seldom
5. never

16. Are you a happy person?
1. always
2. usually
3. sometimes
4. seldom
5. never

17. Do other people or circumstances ever prevent you from doing what you really want to?
1. yes, always
2. yes, usually
3. sometimes
4. no, seldom
5. no, never 
18. All in all, how would you describe your state of health these days?

1. very good

2. good

3. fair

4. poor

5. very poor

19. How proud are you to be a citizen of your country?

1. very proud

2. fairly proud

3. somewhat proud

4. not very proud

5. not proud at all

20. How often, in your experience, are subordinates afraid to contradict their boss (or students their teacher?)

1. never

2. seldom

3. sometimes

4. usually

5. always

To what extent do you agree or disagree with each of the following statements? (please circle one answer in each line across):

1 = strongly agree

2 = agree

$3=$ undecided

4 = disagree

5 = strongly disagree 
21. One can be a good manager

without having a precise answer to

every question that a subordinate

may raise about his or her work

$\begin{array}{lllll}1 & 2 & 3 & 4 & 5\end{array}$

22. Persistent efforts are the

surest way to results

$\begin{array}{lllll}1 & 2 & 3 & 4 & 5\end{array}$

23. An organization structure in

which certain subordinates have two

bosses should be avoided at all cost

$\begin{array}{lllll}1 & 2 & 3 & 4 & 5\end{array}$

24. A company's or organization's

rules should not be broken -

not even when the employee

thinks breaking the rule would be

in the organization's best interest

$\begin{array}{lllll}1 & 2 & 3 & 4 & 5\end{array}$ 
Some information about yourself (for statistical purposes):

25. Are you:
1. male
2. female

26. How old are you?

1. Under 20

2. $20-24$

3. $25-29$

4. $30-34$

5. $35-39$

6. $40-49$

7. $50-59$

8. 60 or over

27. How many years of formal school education (or their equivalent) did you complete (starting with primary school)?

1. 10 years or less

2. 11 years

3. 12 years

4. 13 years

5. 14 years

6. 15 years

7. 16 years

8. 17 years

9. 18 years or over 
28. If you have or have had a paid job, what kind of job is it / was it?

1. No paid job (includes full-time students)

2. Unskilled or semi-skilled manual worker

3. Generally trained office worker or secretary

4. Vocationally trained craftsperson, technician, IT-specialist, nurse, artist or equivalent

5. Academically trained professional or equivalent (but not a manager of people

6. Manager of one or more subordinates (non-managers)

7. Manager of one or more managers

29. What is your nationality?

30. What was your nationality at birth (if different)?

Thank you very much for your cooperation! 


\title{
APPENDIX B : Research Questionnaire
}

\author{
VICTORIA UNIVESITY OF WELINGTON

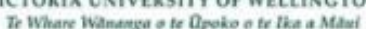

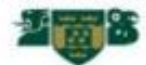 \\ VICTORIA \\ MANAGEMENT SCHOOL \\ Te Kura Whatahaen
}

International Survey on Adopting Agile Methodologies in Outsourced Software Projects

Thank you for accessing this questionnaire. Please kindly read the following information before you proceed.

My name is Nivarthana Warnakulasooriya. I am a Masters student at Victoria University of Wellington, New Zealand and am conducting research on adopting agile software methodologies in outsourced software projects. You have been selected as a knowledgeable person in the area of software development and therefore kindly invited to participate in this study.

This research is being conducted as part of the requirements for the completion of my Masters degree. Agile methodology wasn't designed with outsourcing in mind where teams working on the same project could be based far apart from each other. The purpose of this research is to investigate how well agile currently works with such outsourced software projects.

Ethics approval has been obtained for this research from the Victoria University Human Ethics Committee. Your participation is completely voluntary. The questionnaire is anonymous and thus does not collect identifying information such as name of participants. The completion of the web based questionnaire should take no longer than 15 minutes. All the material related to this survey will be kept confidential and only accessible to me and my supervisor A/Prof. Bob Cavana. During this project electronic data will be kept under password protection and any printed material will be kept locked. All the data will be destroyed two years after the completion of the thesis. Results of this questionnaire will contribute to my thesis and may appear in publications in academic journals or may be presented at academic conferences. All results from the survey will be reported in an aggregated and non-attributable form.

If you would like further information or a summary of key findings, please contact me or my supervisor through contact details given below.

Researcher: Nivarthana Warnakulasooriya

warnakniva@myvuw.az.nz

Supervisor: A/Prof Bob Cavana

bob.cavana@vuw.ac.nz

Thank you in advance for your participation and time.

Niv Warnakulasooriya 
Section A: Background information (please click on your choice).

Q1 Which role below best describes your current position in your company?

- President/CEO/COO

- $\mathrm{CIO} / \mathrm{CTO}$

- VP/Director of Development

- Team Lead

- Project Manager

- Product Manager

- Development Manager

- Architect

- Developer

- $\mathrm{QA} /$ Tester

- Consultant/Trainer

- IT Staff

- Senior Developer

- Other-Please specify

Q2 Do you currently use or plan to use agile development methods on outsourced development projects?

- Do not currently use, do not plan to in future

- Do not currently use, but are planning to in future

- Do use, and are planning to

- Do use, but are not planning to in future

- Do not outsource

- Other - please specify

Q3 How experienced are you with agile development practices? 
- Extremely Knowledgeable

- Moderately Knowledgeable (3-4 years)

- Knowledgeable (1-2 years)

- Very Little Knowledge (less than 1 year)

- No Knowledge

Q4 Have you ever worked on a software project which had,

1. An outsourced component as part of it OR was fully outsourced

AND

2. Also used agile methodology as the project management methodology?

- Yes

- No

Section B: Please note that you should indicate your response for all questions in this section based on the software project which you referred in the previous question.

Q5 What was the role of the team which you belonged to in the outsourced project you referred above?

Vendor

Client

Not exactly - (please explain below)

Q6 Which countries were client and vendor from (please enter country names for both client and vendor)?

Vendor 
Client

Q7 If both Client and Vendor were from same country, please enter below which cities they were from. If not please skip to the next question.

Vendor

Client

Q8 Did any software developers/ programmers/ engineers/ business analysts from the client team actually work closely along with the vendor team on a day to day basis on detailed technical implementation details?

- Yes

- No

Q9 Did the remote team (If you belonged to Vendor team, then 'remote team' would be the Client team and vice versa) use Agile methodology at their end?

- Yes

- No

Q10 How large were the client and vendor teams? (including employees related to all aspects of software development and delivery, please enter a whole number, rough estimate would be sufficient)

Vendor

Client

Q11 In what industry was the outsourced project you referred above conducted?

- Finance/Insurance

- Manufacturing

- Marketing/Retail

- Health 
- Consulting

- Software

- Transportation

- Utility

- Aerospace

- Education

- Other - please specify

Please indicate your response for the following questions based on the same outsourced software project that you referred to in the previous section. Please answer all five questions below as they are quite important for the accuracy of the research.

Term 'teams', below refers to teams from both client and vendor.

Q12 Please rate each statement below with regard to the outsourced project you referred to in the previous section. Your answers will help us measure aspects related to product ownership of the outsourced software project. 
Appendices

Product ownership health

\begin{tabular}{|c|c|c|c|c|c|c|}
\hline & Never & Rarely & Occasionally & Often & $\begin{array}{l}\text { Very } \\
\text { Often }\end{array}$ & Always \\
\hline $\begin{array}{l}\text { Product owner } \\
\text { facilitated user story } \\
\text { development, } \\
\text { prioritization and } \\
\text { negotiation }\end{array}$ & 0 & $\mathrm{O}$ & $\mathrm{O}$ & $\mathrm{O}$ & $\mathrm{O}$ & $\mathrm{O}$ \\
\hline $\begin{array}{l}\text { Product Owner } \\
\text { collaborated } \\
\text { proactively with } \\
\text { Product Management } \\
\text { and other } \\
\text { stakeholders }\end{array}$ & 0 & 0 & 0 & $\mathrm{O}$ & $\mathrm{O}$ & $\mathrm{O}$ \\
\hline $\begin{array}{l}\text { User Stories were } \\
\text { small, estimated, } \\
\text { functional and vertical }\end{array}$ & 0 & 0 & 0 & $\mathrm{O}$ & $\mathrm{O}$ & $\mathrm{O}$ \\
\hline $\begin{array}{l}\text { Product owner } \\
\text { facilitated } \\
\text { development of } \\
\text { acceptance criteria } \\
\text { which were used in } \\
\text { planning, review and } \\
\text { story acceptance }\end{array}$ & 0 & 0 & 0 & $\mathrm{O}$ & $\mathrm{O}$ & $\mathrm{O}$ \\
\hline $\begin{array}{l}\text { BOTH teams } \\
\text { together(Client and } \\
\text { Vendor) refined the } \\
\text { backlog after every } \\
\text { sprint }\end{array}$ & 0 & 0 & 0 & $\mathrm{O}$ & $\mathrm{O}$ & $\mathrm{O}$ \\
\hline
\end{tabular}

Q13 Please rate each statement below with regard to the outsourced project you referred to in the previous section. Your answers will help us measure aspects related to release health of the outsourced software project. 
Release health - PSI below stands for Potentially Shippable Increment

$\begin{array}{lllll} & \text { Very } & \\ \text { Never Rarely Occasionally Often } & \text { Often } & \text { Always }\end{array}$

BOTH Teams

together (Client and

Vendor) participated

fully in Release

Planning, Inspect and

Adapt

Product backlog for the PSI was itemized and prioritized

BOTH Teams (Client and Vendor)

proactively interacted with other teams as

necessary to resolve

impediments

BOTH Teams

together (Client and

Vendor) participated

in System Demo

every two weeks (or

similar interval)

illustrating real

progress towards

objectives

BOTH Teams (Client and Vendor) reliably met $80-100 \%$ of nonstretch PSI

Objectives

O

O

O

$\mathrm{O}$

O

O

(n)

$\bigcirc$

$\mathrm{O}$

$\bigcirc$

$\mathrm{O}$

O

$\mathrm{O}$

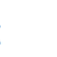

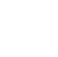

$\mathrm{O}$

O

O

O 0

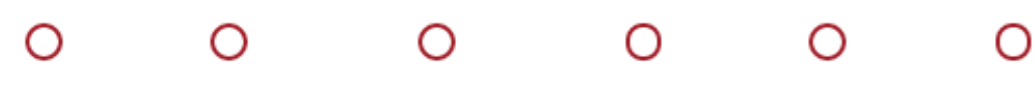

O 
Appendices

Sprint health

$\begin{array}{lllll} & \text { Very } & \\ \text { Never Rarely Occasionally Often } & \text { Often Always }\end{array}$

BOTH Teams

together (Client and

Vendor) planned the

sprint collaboratively,

$\mathrm{O}$

O

O

O

O

effectively and

efficiently

BOTH Teams (Client and Vendor) always had clear sprint

goals, in support of

PSI objectives, and

committed to meeting

them

BOTH Teams (Client and Vendor) applied acceptance criteria and Definition of

Done to story

acceptance

BOTH Teams (Client and Vendor) had a predictable,

normalized velocity

which was used for

estimating and

planning

BOTH Teams (Client and Vendor) regularly delivered on their

$\mathrm{O}$

$\mathrm{O}$

O

$\mathrm{O}$

$\mathrm{O}$

sprint goals

$\begin{array}{ll}0 & 0 \\ 0 & 0\end{array}$

O $\mathrm{O}$

O

O

O 0

O 
Q15 Please rate each statement below with regard to the outsourced project you referred above. Your answers will help us measure aspects related to team health of the outsourced software project. The term 'RTE' below refers to 'Release Train Engineer'. If you didn't have one in the outsourced project you can select 'Never' as the answer.

Term 'teams', below refers to teams from both client and vendor. 
Appendices

Team health

Never Rarely Occasionally Often Often Always

Members from BOTH

Teams (Client and

Vendor) were self-

organized, respect

each other, helped

each other complete

sprint goals, managed

interdependencies

and stay in-sync with

each other

Scrum Master

attended Scrum of

Scrums and

interacted with RTE

as appropriate

Stories were iterated

through the sprint with

multiple define-build-

test cycles (e.g. the

sprint is not a

waterfall)

BOTH Teams (Client and Vendor) were

collaborative, effective and efficient in

planning and present

TOGETHER in daily

meetings where all

members participate,

status was given

clearly, issues were

raised, obstacles were

removed and

information

exchanged

BOTH Teams

together (Client and

Vendor) held a

retrospective after

each sprint and made

incremental changes

to continually improve

its performance 
Q16 Please rate each statement below with regard to the outsourced project you referred above. Your answers will help us measure aspects related to technical health of the outsourced software project. Term 'DoD' below refers to 'Definition of Done'. 'Cl' stands for 'Continuous Integration'.

Technical health

BOTH Teams actively
reduced technical
debt in each sprint

Q17 How often did cultural, physical distance and time zone difference impact success of agile methodology on the outsourced project you referred earlier (please indicate your choice for each row)? 
$\begin{array}{llll} & \text { Very } & \\ \text { Never Rarely Occasionally Often } & \text { Often } & \text { Always }\end{array}$

$\begin{array}{lcccccc}\begin{array}{l}\text { Physical Distance of } \\ \text { teams }\end{array} & \bigcirc & \bigcirc & \bigcirc & \bigcirc & \bigcirc & \bigcirc \\ \begin{array}{l}\text { Time Zone difference } \\ \text { of team locations }\end{array} & \bigcirc & \bigcirc & \bigcirc & \bigcirc & \bigcirc & \bigcirc \\ \begin{array}{l}\text { Cultural difference } \\ \text { between teams }\end{array} & \bigcirc & \bigcirc & \bigcirc & \bigcirc & \bigcirc & \bigcirc\end{array}$

Q18 How successful overall was the outsourced software project you referred to in above sections?

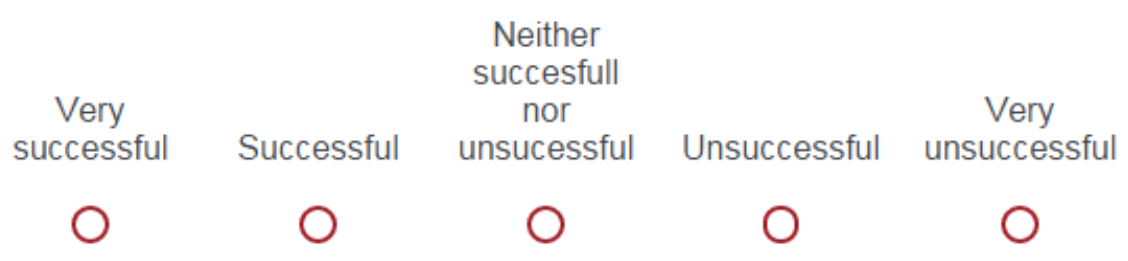

Please write down if you have any suggestions on how to minimize the impact on successful application of agile from barriers - physical distance between teams/ time zone difference between team locations/ culture gap between teams

Q19 With offshore development, sharing one physical task board is impossible. If teams used a digital task board which is projected to a larger screen (eg: projected to a large white board) at both locations where both teams onshore and offshore can make changes to and make changes readily visible to both teams then that would be a good workaround for not having one physical board. How much in favour are you for such a digital task board?

\begin{tabular}{|c|c|c|}
\hline $\begin{array}{l}\text { Strongly in } \\
\text { favor }\end{array}$ & $\begin{array}{l}\text { Good } \\
\text { solution }\end{array}$ & $\begin{array}{l}\text { It might } \\
\text { work }\end{array}$ \\
\hline
\end{tabular}

Please indicate your choice

$\mathrm{O}$


Q20 With geographically separated teams, time zone difference may have a significant impact on doing daily stand-ups. If teams used a shared digital status update solution where each member from both teams write down their daily status update so other team can access it at a separate time whenever they want, time zone differences in daily stand up meetings can be overcome. How much in favour are you for such a system?

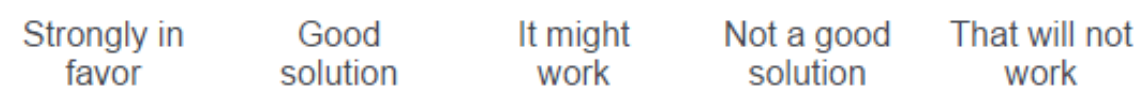

Please indicate your choice
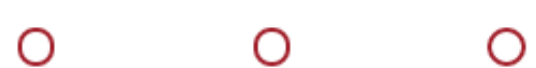

O

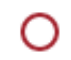

Q21 Sprint planning (selecting the prioritized stories from the product backlog, dividing them to sub tasks if needed and distributing tasks among team members) is once per sprint so should be done at the presence of all members of both teams by using a digital method like video conferencing rather than only one team been involved in the sprint planning. How far do you agree?

\begin{tabular}{|c|c|c|c|}
\hline $\begin{array}{l}\text { Strongly in } \\
\text { favor }\end{array}$ & $\begin{array}{l}\text { Good } \\
\text { solution }\end{array}$ & It might & $\begin{array}{l}\text { Not a good } \\
\text { solution }\end{array}$ \\
\hline
\end{tabular}

Please indicate your choice

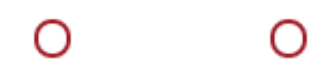

Q22 Having two scrum masters (per team) in each location (country) rather than having just one scrum master for both teams works better. Each scrum master can then update each other daily as representatives of team members in each location and work on any impediments/barriers they were made aware of. How much in favour are you for such a mechanism?

\begin{tabular}{|c|c|c|c|}
\hline $\begin{array}{l}\text { Strongly in } \\
\text { favor }\end{array}$ & $\begin{array}{l}\text { Good } \\
\text { solution }\end{array}$ & $\begin{array}{l}\text { It might } \\
\text { work }\end{array}$ & $\begin{array}{l}\text { Not a good } \\
\text { solution }\end{array}$ \\
\hline
\end{tabular}

Please indicate your choice 
Q23 Building trust amongst distributed teams is important. We suggest using closely related tasks in the initial sprint (ex: two closely related tasks in a sprint) assigned to members from both locations so it will act as a catalyst for improving close communication/ collaboration between members from both teams. How much in favour are you for such a mechanism?

\begin{tabular}{|c|c|c|c|}
\hline $\begin{array}{l}\text { trongly in } \\
\text { favor }\end{array}$ & $\begin{array}{l}\text { Good } \\
\text { solution }\end{array}$ & $\begin{array}{l}\text { It might } \\
\text { work }\end{array}$ & $\begin{array}{l}\text { Not a good } \\
\text { solution }\end{array}$ \\
\hline
\end{tabular}

Please indicate your choice

Your time and corporation to make this study a success is much appreciated. Please leave any general comments that you may have about this questionnaire or the whole study in general. 


\title{
APPENDIX C - SAFe Instrument
}

\section{SCALED AGILE}

\author{
SAFe ScrumXP Team Self-Assessment \\ Team Name: $x x x x x x x x x x x x x x x x x$ Date: $x x / x / 20 x x$
}

Scoring: 0 - Never, 1 - Rarely 2 - Occasionally, 3 - Often, 4 - Very Often, 5 - Always

\begin{tabular}{|c|c|c|}
\hline Area / Question & Score & \\
\hline \multicolumn{3}{|l|}{ Product Ownership Health } \\
\hline Product Owner facilitates user story development, prioritization and negotiation & 3.0 & \\
\hline Product Owner collaborates proactively with Product Management and other stakeholders & 3.0 & \\
\hline User Stories are small, estimated, functional and vertical & 3.0 & \\
\hline $\begin{array}{l}\text { Product owner facilitates development of acceptance criteria which are used in planning, } \\
\text { review and story acceptance }\end{array}$ & 3.0 & \\
\hline Teams refine the backlog every sprint & 3.0 & \\
\hline Total Product Health Score & 15.0 & $60 \%$ \\
\hline \multicolumn{3}{|l|}{ PSI/Release Health } \\
\hline Team participates fully in Release Planning and Inspect and Adapt & 3.0 & \\
\hline Product backlog for the PSI is itemized and prioritized & 3.0 & \\
\hline Teams proactively interact with other teams on the train as necessary to resolve impediments & 3.0 & \\
\hline $\begin{array}{l}\text { Team participates in System Demo every two weeks, illustrating real progress towards } \\
\text { objectives }\end{array}$ & 3.0 & \\
\hline Team reliably meet $80-100 \%$ of non-stretch PSI Objecives & 3.0 & \\
\hline Total PSI/Release Health Score & 15.0 & $60 \%$ \\
\hline \multicolumn{3}{|l|}{ Sprint Health } \\
\hline Team plans the sprint collaboratively, effectively and efficiently & 3.0 & \\
\hline $\begin{array}{l}\text { Team always has clear sprint goals, in support of PSI objectives, and commits to meeting } \\
\text { them }\end{array}$ & 3.0 & \\
\hline Teams apply acceptance criteria and Definition of Done to story acceptance & 3.0 & \\
\hline Team has a predictable, normalized velocity which is used for estimating and planning & 3.0 & \\
\hline Team regularly delivers on their sprint goals & 3.0 & \\
\hline Total Sprint Health Score & 15.0 & $60 \%$ \\
\hline \multicolumn{3}{|l|}{ Team Health } \\
\hline $\begin{array}{l}\text { Team members are self-organized, respect each other, help each other complete sprint goals, } \\
\text { manage interdependencies and stay in-sync with each other }\end{array}$ & 3.0 & \\
\hline Scrum Master attends Scrum of Scrums and interacts with RTE as appropriate & 3.0 & \\
\hline $\begin{array}{l}\text { Stories are iterated through the sprint with multiple define-build-test cycles (e.g. the sprint is } \\
\text { not a waterfalled) }\end{array}$ & 3.0 & \\
\hline $\begin{array}{l}\text { Team holds collaborative, effective and efficient planning and daily meetings where all } \\
\text { members participate, status is given clearly, issues are raised, obstacles are removed and } \\
\text { information exchanged }\end{array}$ & 3.0 & \\
\hline $\begin{array}{l}\text { Team holds a retrospective after each sprint and makes incremental changes to continually } \\
\text { improve its performance }\end{array}$ & 3.0 & \\
\hline Total Team Health Score & 15.0 & $60 \%$ \\
\hline \multicolumn{3}{|l|}{ Technical Health } \\
\hline Teams actively reduce technical debt in each sprint & 3.0 & \\
\hline $\begin{array}{l}\text { Team has clear guidance and understanding of intentional architecture guidance, but is free } \\
\text { and flexible enough to allow emergent design to support optimal implementation }\end{array}$ & 3.0 & \\
\hline Automated acceptance tests and unit tests are part of story DoD & 3.0 & \\
\hline Refactoring is always underway & 3.0 & \\
\hline $\mathrm{Cl}$, build and test automation infrastructure is improving & 3.0 & \\
\hline Total Technical Health Score & 15.0 & $60 \%$ \\
\hline Total Team Score & 75.0 & $60 \%$ \\
\hline
\end{tabular}




\section{APPENDIX D - Additional Data Analysis Tests}

ANOVA and Model Summary Tables for Curve Estimation with Culture Difference.

\section{Linear}

Model Summary

\begin{tabular}{crrr}
\hline & Adjusted $R$ & $\begin{array}{c}\text { Std. Error of } \\
\text { the } \\
\text { Estimate }\end{array}$ \\
\hline .241 & $R$ Square & Square & \multicolumn{1}{c}{.058 } \\
\hline \hline
\end{tabular}

The independent variable is

Norm_Culture_Diff.

ANOVA

\begin{tabular}{lrrrrr}
\hline & $\begin{array}{l}\text { Sum of } \\
\text { Squares }\end{array}$ & \multicolumn{1}{c}{ df } & $\begin{array}{l}\text { Mean } \\
\text { Square }\end{array}$ & F & Sig. \\
\hline Regression & .333 & 1 & .333 & 4.489 & .038 \\
Residual & 5.412 & 73 & .074 & & \\
Total & 5.745 & 74 & & & \\
\hline \hline
\end{tabular}

The independent variable is Norm_Cul ture_Diff. 


\section{Quadratic}

Model Summary

\begin{tabular}{|c|c|c|c|}
\hline$R$ & $R$ Square & $\begin{array}{c}\text { Adjusted } R \\
\text { Square }\end{array}$ & $\begin{array}{c}\text { Std. Error of } \\
\text { the } \\
\text { Estimate }\end{array}$ \\
\hline .246 & .061 & .035 & .274 \\
\hline
\end{tabular}

The independent variable is

Norm_Cul ture_Diff.

ANOVA

\begin{tabular}{lrrrrr}
\hline & $\begin{array}{l}\text { Sum of } \\
\text { Squares }\end{array}$ & \multicolumn{1}{c}{ df } & \multicolumn{1}{l}{$\begin{array}{l}\text { Mean } \\
\text { Square }\end{array}$} & \multicolumn{1}{c}{ F } & Sig. \\
\hline Regression & .348 & 2 & .174 & 2.324 & .105 \\
Residual & 5.396 & 72 & .075 & & \\
Total & 5.745 & 74 & & & \\
\hline \hline
\end{tabular}

The independent variable is Norm_Cul ture_Diff.

\section{Cubic}

Model Summary

\begin{tabular}{|c|c|c|c|}
\hline$R$ & R Square & $\begin{array}{c}\text { Adjusted } R \\
\text { Square }\end{array}$ & $\begin{array}{c}\text { Std. Error of } \\
\text { the } \\
\text { Estimate }\end{array}$ \\
\hline .246 & .061 & .021 & .276 \\
\hline
\end{tabular}

The independent variable is

Norm_Cul ture_Diff.

ANOVA

\begin{tabular}{lrrrrr}
\hline & \multicolumn{1}{c}{$\begin{array}{l}\text { Sum of } \\
\text { Squares }\end{array}$} & \multicolumn{1}{c}{ df } & \multicolumn{1}{l}{$\begin{array}{l}\text { Sean } \\
\text { Square }\end{array}$} & \multicolumn{1}{c}{$F$} & Sig. \\
\hline Regression & .349 & 3 & .116 & 1.530 & .214 \\
Residual & 5.396 & 71 & .076 & & \\
Total & 5.745 & 74 & & & \\
\hline \hline
\end{tabular}

The independent variable is Norm_Cul ture_Diff. 
ANOVA and Model Summary Tables for Curve Estimation with Physical Distance.

\section{Linear}

Model Summary

\begin{tabular}{|c|c|c|c|}
\hline$R$ & $R$ Square & $\begin{array}{c}\text { Adjusted } R \\
\text { Square }\end{array}$ & $\begin{array}{c}\text { Std. Error of } \\
\text { the } \\
\text { Estimate }\end{array}$ \\
\hline .365 & .133 & .122 & .261 \\
\hline
\end{tabular}

The independent variable is

Norm_Phy_Dist.

ANOVA

\begin{tabular}{lrrrrr}
\hline & $\begin{array}{l}\text { Sum of } \\
\text { Squares }\end{array}$ & \multicolumn{1}{c}{ df } & \multicolumn{1}{l}{$\begin{array}{l}\text { Sean } \\
\text { Square }\end{array}$} & F & Sig. \\
\hline Regression & .767 & 1 & .767 & 11.241 & .001 \\
Residual & 4.978 & 73 & .068 & & \\
Total & 5.745 & 74 & & & \\
\hline \hline
\end{tabular}

The independent variable is Norm_Phy_Dist. 


\section{Quadratic}

Model Summary

\begin{tabular}{crrr}
\hline & & Adjusted $R$ & $\begin{array}{c}\text { Std. Error of } \\
\text { the } \\
\text { Estimate }\end{array}$ \\
\hline .373 & $R$ Square & Square & \multicolumn{1}{c}{ Estim } \\
\hline
\end{tabular}

The independent variable is

Norm_Phy_Dist.

ANOVA

\begin{tabular}{lrrrrr}
\hline & \multicolumn{1}{l}{$\begin{array}{l}\text { Sum of } \\
\text { Squares }\end{array}$} & \multicolumn{1}{c}{ df } & \multicolumn{1}{l}{$\begin{array}{l}\text { Sean } \\
\text { Square }\end{array}$} & \multicolumn{1}{c}{$F$} & Sig. \\
\hline Regression & .799 & 2 & .399 & 5.816 & .005 \\
Residual & 4.946 & 72 & .069 & & \\
Total & 5.745 & 74 & & & \\
\hline \hline
\end{tabular}

The independent variable is Norm_Phy_Dist.

\section{Cubic}

Model Summary

\begin{tabular}{|c|c|c|c|}
\hline$R$ & $R$ Square & $\begin{array}{c}\text { Adjusted } R \\
\text { Square }\end{array}$ & $\begin{array}{c}\text { Std. Error of } \\
\text { the } \\
\text { Estimate }\end{array}$ \\
\hline .422 & .178 & .143 & .258 \\
\hline
\end{tabular}

ANOVA

\begin{tabular}{lrrrrr}
\hline & $\begin{array}{l}\text { Sum of } \\
\text { Squares }\end{array}$ & \multicolumn{1}{c}{ df } & $\begin{array}{l}\text { Mean } \\
\text { Square }\end{array}$ & \multicolumn{1}{c}{ F } & Sig. \\
\hline Regression & 1.022 & 3 & .341 & 5.119 & .003 \\
Residual & 4.723 & 71 & .067 & & \\
Total & 5.745 & 74 & & & \\
\hline \hline
\end{tabular}

The independent variable is Norm_Phy_Dist. 
ANOVA and Model Summary Tables for Curve Estimation with Time Zone Difference.

\section{Linear}

Model Summary

\begin{tabular}{|c|c|c|c|}
\hline$R$ & $R$ Square & $\begin{array}{c}\text { Adjusted } R \\
\text { Square }\end{array}$ & $\begin{array}{c}\text { Std. Error of } \\
\text { the } \\
\text { Estimate }\end{array}$ \\
\hline .222 & .049 & .036 & .274 \\
\hline
\end{tabular}

The independent variable is

Norm_Time_Diff.

ANOVA

\begin{tabular}{lrrrrr}
\hline & \multicolumn{1}{c}{$\begin{array}{l}\text { Sum of } \\
\text { Squares }\end{array}$} & \multicolumn{1}{c}{ df } & \multicolumn{1}{c}{$\begin{array}{l}\text { Sean } \\
\text { Square }\end{array}$} & \multicolumn{1}{c}{$F$} & Sig. \\
\hline Regression & .282 & 1 & .282 & 3.771 & .056 \\
Residual & 5.462 & 73 & .075 & & \\
Total & 5.745 & 74 & & & \\
\hline \hline
\end{tabular}

The independent variable is Norm_Time_Diff. 


\section{Quadratic}

Model Summary

\begin{tabular}{|c|c|c|c|}
\hline$R$ & $R$ Square & $\begin{array}{c}\text { Adjusted } R \\
\text { Square }\end{array}$ & $\begin{array}{c}\text { Std. Error of } \\
\text { the } \\
\text { Estimate }\end{array}$ \\
\hline .256 & .066 & .040 & .273 \\
\hline
\end{tabular}

The independent variable is

Norm_Time_Diff.

ANOVA

\begin{tabular}{lrrrrr}
\hline & $\begin{array}{l}\text { Sum of } \\
\text { Squares }\end{array}$ & \multicolumn{1}{c}{ df } & \multicolumn{1}{l}{$\begin{array}{l}\text { Mean } \\
\text { Square }\end{array}$} & F & Sig. \\
\hline Regression & .378 & 2 & .189 & 2.533 & .086 \\
Residual & 5.367 & 72 & .075 & & \\
Total & 5.745 & 74 & & & \\
\hline \hline
\end{tabular}

The independent variable is Norm_Time_Diff.

\section{Cubic}

Model Summary

\begin{tabular}{|c|c|c|c|c|c|c|}
\hline$R$ & $R$ Square & \multicolumn{2}{|c|}{$\begin{array}{c}\text { Adjusted R } \\
\text { Square }\end{array}$} & $\begin{array}{c}\text { Std. Error of } \\
\text { the } \\
\text { Estimate }\end{array}$ & & \\
\hline .431 & .186 & & & .257 & & \\
\hline \multicolumn{7}{|c|}{$\begin{array}{l}\text { The independent variable is } \\
\text { Norm_Time_Diff. }\end{array}$} \\
\hline \multicolumn{7}{|c|}{ ANOVA } \\
\hline & & $\begin{array}{l}\text { sum of } \\
\text { quares }\end{array}$ & $d f$ & $\begin{array}{l}\text { Mean } \\
\text { Square }\end{array}$ & $F$ & Sig. \\
\hline Regr & ession & 1.066 & 3 & .355 & 5.393 & .002 \\
\hline Resic & lual & 4.678 & 71 & .066 & & \\
\hline Total & & 5.745 & 74 & & & \\
\hline
\end{tabular}

The independent variable is Norm_Time_Diff. 
Appendices 